
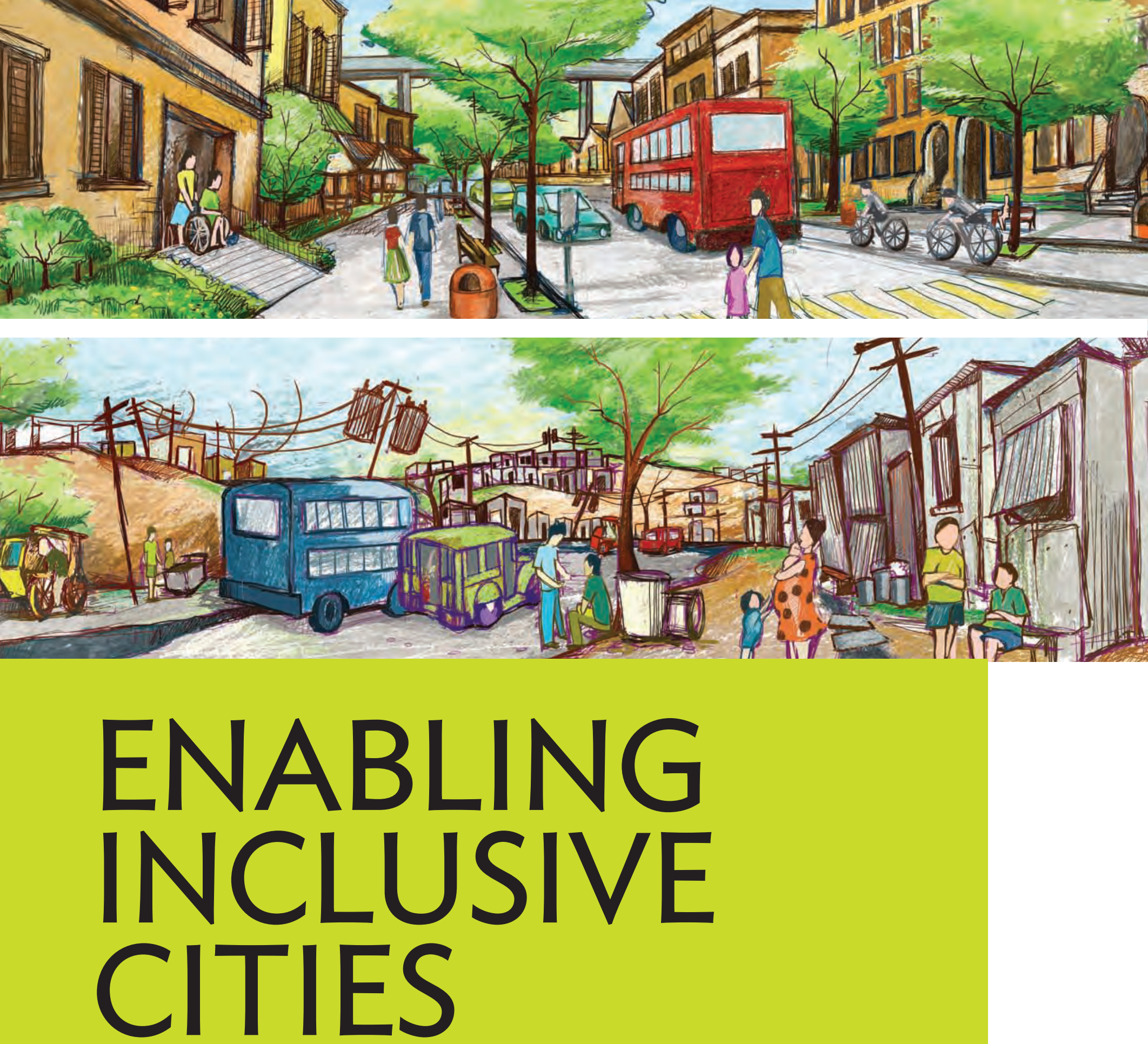

Tool Kit for Inclusive Urban Development 


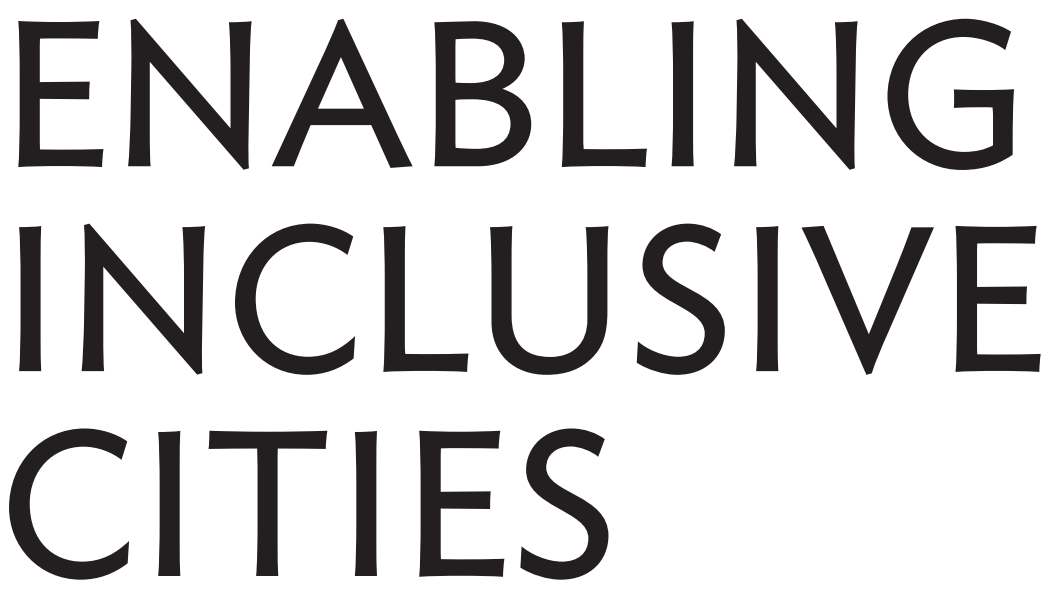

Tool Kit for Inclusive Urban Development 
(C) 2017 Asian Development Bank

6 ADB Avenue, Mandaluyong City, 1550 Metro Manila, Philippines

Tel +632632 4444; Fax +6326362444

www.adb.org

Some rights reserved. Published in 2017

Printed in the Philippines.

ISBN 978-92-9257-719-3 (Print), 978-92-9257-720-9 (e-ISBN)

Publication Stock No. TIM157428

DOI: http://dx.doi.org/10.22617/TIM157428

Cataloging-In-Publication Data

Asian Development Bank

Enabling inclusive cities: tool kit for inclusive urban development

Mandaluyong City, Philippines: Asian Development Bank, 2017.

1. Inclusive cities

2. Urban development.

I. Asian Development Bank.

The views expressed in this publication are those of the authors and do not necessarily reflect the views and policies of the Asian Development Bank (ADB) or its Board of Governors or the governments they represent.

ADB does not guarantee the accuracy of the data included in this publication and accepts no responsibility for any consequence of their use. The mention of specific companies or products of manufacturers does not imply that they are endorsed or recommended by ADB in preference to others of a similar nature that are not mentioned.

By making any designation of or reference to a particular territory or geographic area, or by using the term "country" in this document, $A D B$ does not intend to make any judgments as to the legal or other status of any territory or area.

This work is available under the Creative Commons Attribution 3.0 IGO license (CC BY 3.0 IGO)

https://creativecommons.org/licenses/by/3.0/igo/. By using the content of this publication, you agree to be bound by the terms of this license.

This CC license does not apply to non-ADB copyright materials in this publication. If the material is attributed to another source, please contact the copyright owner or publisher of that source for permission to reproduce it. ADB cannot be held liable for any claims that arise as a result of your use of the material.

Attribution-You should always acknowledge ADB as the source using the following format:

[Author]. [Year of publication]. [Title of the work in italics]. [City of publication]: [Publisher]. @ ADB. [URL or DOI] [license].

Translations-Any translations you create should carry the following disclaimer:

Originally published by ADB in English under the title [title in italics]. (c) ADB. [URL or DOI] [license]. The quality of the translation and its coherence with the original text is the sole responsibility of the translator. The English original of this work is the only official version.

Adaptations-Any adaptations you create should carry the following disclaimer:

This is an adaptation of an original work titled [title in italics]. () ADB. [URL or DOI][license]. The views expressed here are those of the authors and do not necessarily reflect the views and policies of ADB or its Board of Governors or the governments they represent. ADB does not endorse this work or guarantee the accuracy of the data included in this publication and accepts no responsibility for any consequence of their use.

Please contact pubsmarketing@adb.org if you have questions or comments with respect to content, or if you wish to obtain copyright permission for your intended use that does not fall within these terms, or for permission to use the ADB logo.

Notes:

In this publication, “\$” refers to US dollars.

Corrigenda to ADB publications may be found at http://www.adb.org/publications/corrigenda

ADB recognizes "China” as the People's Republic of China. 


\section{ABOUT THE REPORT}

\footnotetext{
- he Asian Development Bank (ADB) supports inclusive urban development under its Urban Operational Plan. This Inclusive Cities Tool Kit approved last January 2014 is prepared to provide guidelines for ADB staff and their development partners to engage in development and implementation of projects and programs, using the inclusive urban development approach, as an integral component of ADB lending programs in its developing member countries .
} 



\section{CONTENTS}

Foreword vii

Acknowledgments viii

About the Authors $x$

Abbreviations $\quad x i$

Executive Summary xii

Purpose of This Tool Kit xiii

Who Is This Tool Kit For? xiii

What Does This Tool Kit Contain? xiii

How to Use This Tool Kit $\quad$ xv

1 Inclusive Urban Development Framework $\quad 1$

1.1 Enabling Inclusive Development 2

1.2 Creating Resilient Environments 2

1.3 Developing an Integrated Approach for Inclusive Urban Development 2

1.3.1 What Does "Inclusive" Mean? 4

1.3.2 Inclusive Urban Redevelopment 6

1.3.3 Framework for Inclusive Cities $\quad 6$

1.4 Inclusive Urban Assessment Process 9

1.4.1 Phase 1: Urban Context 9

1.4.2 Phase 2: Sector Assessments and Options 16

1.4.3 Phase 3: Cross-Sectoral Prioritization and Project Programming 20

1.4.4 Undertaking Inclusive Urban Development Projects 22

2 Toolbox 25

2.1 Inventory of Tools 26

$\begin{array}{ll}\text { Bibliography } & 91\end{array}$

Annexes

1 Urban Indicators and Data 94

2 Information on Other Tool Kits for Inclusive Urban Assessments 97

3 Process Flowchart: Policy and Planning and Sectoral Components 100 
Figures

1 Dimensions of Urban Poverty $\quad 1$

2 Critical Aspects of Inclusive Urban Development 3

3 Inclusive Urban Development Approach 8

4 Framework for Understanding the Urban Context 10

5 Sector Assessments and Options 17

6 Approach to Cross-Sectoral Prioritization and Project Programming 22

Boxes

1 What Is an Inclusive City?

2 Amar Jyoti-An Inclusive School 5

3 Urban Renewal in India $\quad 71$ 


\section{FOREWORD}

n Asia, urbanization is expected to reach $55 \%$ by 2030 and $64 \%$ by 2050 , constituting

$53 \%$ of the world's urban population and contributing half the world's gross domestic

product. Cities generate up to $80 \%$ of gross domestic product in many countries of Asia and the Pacific and are the engines of economic growth that have lifted millions out of poverty. But as cities swell in size and number, they struggle with environmental degradation, traffic congestion, inadequate urban infrastructure, and a lack of basic civic services, affecting the quality of life of their populace, particularly the poor. Unless alternative approaches are put in place, the urban poor will continue to be the most vulnerable. Maintaining vital economic growth, while creating sustainable, livable cities for all, is one of the biggest urban challenges facing the Asia and Pacific region.

Since the 1960s, the Asian Development Bank (ADB) has been assisting its developing member countries with about $\$ 15$ billion in funding for over 200 urban development projects, which have improved urban transport, waste management, and access to clean water and sanitation. Currently, ADB's support for sustainable urban development is guided by the Urban Operational Plan 2012-2020 under ADB's Strategy 2020. It focuses on urban development that is inclusive, competitive, and environmentally sustainable. This requires urban investment decisions based on a comprehensive assessment of urban issues with their fiscal and institutional structures. Under the Urban Operational Plan 2012-2020, ADB has prepared the Manual for Undertaking National Urban Assessments, which presents an overarching framework for undertaking integrated urban development and for directing key investments to strategic spatial areas with a thematic focus.

ADB's Urban Sector Group has prepared tool kits for guiding the preparation of integrated urban plans or city development plans with inclusive cities, competitive cities, and green cities as the primary focus, depending on the relative importance of the $3 \mathrm{E}$ agenda: economy, environment, and equity. This publication provides guidelines for $A D B$ staff and their partners to engage in programming and implementation of inclusive urban development projects as an integral component of ADB's lending programs in its developing member countries.

I join the authors of this publication in the conviction that as urbanization grows rapidly in Asia and the Pacific, inclusiveness, competitiveness, and green growth will converge toward a sustainable urban future with the vision of leaders and urban managers.

\section{Anand Chiplunkar}

Chair, Urban Sector Group

Director, Urban Development and Water Division

Central and West Asia Department

Asian Development Bank 


\section{ACKNOWLEDGMENTS}

T

his tool kit was written by Michael Lindfield, lead urban development specialist and chair of the Urban Community of Practice (COP) (retired), and Ramola Naik Singru, urban development specialist, Urban Development and Water Division, Central and West Asia Department (CWUW-CWRD), who are grateful for discussions with and inputs from colleagues. The authors thank Gil-Hong Kim, senior director, Sector Advisory Services Division, Sustainable Development and Climate Change Department (SDCC); Ramesh Subramaniam, deputy director general, Southeast Asia Department (SERD); Amy Leung, deputy director general, East Asia Department (EARD); Anand Chiplunkar, director, CWUW-CWRD; Fei Yue, director (retired), Urban Development and Water Division, South Asia Department (SAUW-SARD); and Bart Edes, director, Poverty Reduction, Social Development, Governance and Gender Division, SDCC (SDGG-SDCC), for their valuable guidance.

This tool kit was prepared in consultation with the Inclusive Cities Working Group of the Urban Sector Group led by Florian Steinberg, senior urban development specialist (retired), Urban Development and Water Division SERD (SEUW-SERD), until 2013 and later by Arnaud Heckmann, senior urban development specialist, East Asia Urban and Social Sectors Division EARD (EASS-EARD). The authors thank Florian Steinberg; Arnaud Heckmann; Wendy Walker, principal social development specialist (EASS-EARD); Linda Adams, senior social development specialist (SEUW-SERD); Sonia Chand Sandhu, senior environment specialist (SEUW-SERD); the Inclusive Cities Working Group for the peer review; Arghya Roy Sinha, disaster risk management specialist (climate change adaptation), Climate Change and Disaster Risk Management Division SDCC (SDCD-SDCC), for his inputs on integrated disaster risk management; and Armin Bauer, principal economist (SDGG-SDCC), for his insightful comments.

The authors thank the participants of the Enabling Inclusive Cities Workshop held at ADB headquarters on 29 and 30 October 2013 for peer reviewing the tool kit. The authors also thank colleagues from the urban divisions for reviewing the tool kit and presenting inclusive project design elements from their ongoing projects. Gratitude goes to Linda Adams; Armin Bauer; Arnaud Heckmann; David Margornsztern, senior urban development specialist (transport) (CWUW-CWRD); Sonia Chand Sandhu; Ron Slangen, urban development specialist (SAUW-SARD); Elaine Thomas, social development specialist (civil society and participation), Human and Social Development Division SERD; and Alison Woodruff, urban development specialist, Urban, Social Development and Public Management 
Division, Pacific Department. The authors also thank Earl Kessler for providing initial inputs; the Publishing Team of the Department of External Relations for editing support; Virginia Herrera for assistance in administrative matters; Vince Docta for assistance with the Inclusive Cities Workshop; and Jay Presaldo, Aldrin Plaza, and Vergel Latay for overall coordination of production and publication.

Urban Sector Group

Sustainable Development and Climate Change Department Asian Development Bank 


\section{ABOUT THE AUTHORS}

\section{Ramola Naik Singru}

Urban Development Specialist, Urban Development and Water Division, Central and West Asia Department, Asian Development Bank (ADB)

Ramola Naik Singru is an urban development specialist with over 16 years of international multidisciplinary expertise spanning project management, technical advisory, research, knowledge management, and capacity building. She jointly led ADB's GrEEEn Cities Initiative and has developed GrEEEn City Action Plans for cities in Southeast Asia. She has authored or co-authored several conference papers, working papers, book chapters, and publications, including GrEEEn Solutions for Livable Cities (ADB, 2016), Manual for Undertaking National Urban Assessments (ADB, 2016), and Mumbai: Spatial Segregation in a Globalising City in Globalizing Cities: Inequality and Segregation in Developing Countries (Rawat Publications, 2007). She was an Adjunct Faculty of the Asian Institute of Management (AIM) and the Program Director for the joint urban management program of AIM, Cities Development Initiative for Asia (CDIA), and UN-Habitat. She has a master's degree in city design and social science from the London School of Economics and Political Science (United Kingdom) and a bachelor's degree in architecture from the University of Mumbai (India).

\section{Michael R. Lindfield}

Senior Advisor to the SMART Infrastructure Facility

Sydney, Australia

Michael Lindfield is an economist and financial analyst with over 30 years' experience in international sustainable urban development policy formulation and in designing the institutional and financial mechanisms to implement urban development and infrastructure policy. He is a senior advisor to the SMART Infrastructure Facility. Previously, he was lead urban development specialist and chair of the Urban Community of Practice at ADB, as well as program manager for the Cities Development Initiative for Asia. He has also served as department head of the Institute for Housing and Urban Development Studies in the Netherlands and as deputy director and senior research fellow in the Australian Housing and Urban Research Institute of Queensland University of Technology. He has worked as a consultant for the World Bank, ADB, and the United Nations, as well as for private sector and government agencies. He has a bachelor's degree in architecture from Sydney University, a master's degree in commerce from the University of New South Wales (Australia), and a doctorate in economics from Erasmus University (Netherlands). 


\section{ABBREVIATIONS}

$3 \mathrm{E}$

$A \& M$

$A D B$

CBO

CDIA

CIIPP

CPVP

CRC

DMC

DRM

GAM

IUD

JnNURM

NGO

ODA

UNDP economy, environment, and equity

adaptation and mitigation

Asian Development Bank

community-based organization

Cities Development Initiative for Asia

City Infrastructure Investment Prioritization and Programming

city poverty and vulnerability profile

Citizen Report Card

developing member country

disaster risk management

goals achievement matrix

inclusive urban development

Jawaharlal Nehru National Urban Renewal Mission

nongovernment organization

official development assistance

United Nations Development Programme 


\section{EXECUTIVE SUMMARY}

$\mathrm{T}$

he Asian Development Bank (ADB) through its Urban Operational Plan 2012-2020 will support developing member countries (DMCs) in developing their urban economies, in improving environmental sustainability, and in making pro-poor investments. This presents a critical opportunity for the urban sector to potentially play an integrative role, providing a way to focus ADB operations, beyond traditional urban investment sectors, to maximize their impact (ADB 2012).

Knowledge is a crucial component in addressing these challenges. Under Strategy 2020, ADB's urban sector will meet these challenges through the various knowledge products designed to share as well as contribute to available knowledge on technical assistance databases, country data profile, important issues and interventions, and information on urban infrastructure and developments in the Asia and Pacific region. Under its Urban Operational Plan 2012-2020, ADB has prepared tool kits for the assessment of cities and urban regions covering these themes-competitive cities, green cities, and inclusive cities. The Manual for Undertaking National Urban Assessments presents an overarching framework for undertaking integrated urban development and for directing key investments to strategic spatial areas or with a thematic focus. To enable an integrative process to maximize the impact of urban sector investments, ADB's Urban Operational Plan promotes the $3 \mathrm{E}$ approach comprising the three dimensions of sustainability-economy, environment, and equity.

Given the scale of urbanization in Asia, urban development is increasingly difficult to manage in ADB's DMCs. Poverty, disparities in well-being, environmental pressures, and climate change remain the key issues confronting the Asia and Pacific region. Urbanization is causing strain on the environment, affecting the quality of life of everyone, particularly the poor. Unless alternative approaches are put in place, the urban poor will continue to be the most vulnerable. This Inclusive Cities Tool Kit presents an integrated approach to inclusive urban development (IUD).

"Inclusive" urban infrastructure development is defined as an integrated approach encompassing sustainable, resilient, accessible, and affordable solutions to the challenges faced by the urban poor and vulnerable groups by enhancing their access to urban services and infrastructure through targeted investments. This integrated approach encourages an institutional delivery mechanism that brings together all institutions and stakeholdersgovernment, the private sector, and civil society-who have the capacity to deliver systems for inclusive urban service delivery. The approach proposes that the capacity of the urban poor communities, slum networks, and nongovernment organizations should be effectively used in conjunction with the city government and the private sector. 


\section{Purpose of This Tool Kit}

This tool kit has been prepared to provide support for the inclusive cities theme. It presents methods to gather the required information on a particular context and location for IUD; to decide priorities; and to plan, design, and implement inclusive urban projects. The tool kit presents an opportunity to create a record of the project design process that may be of use for others as well to scale up activities; to consolidate information that may be dispersed across different institutions; and to support ADB staff and other development partners to focus on the importance of IUD. The operational focus is provided by practical guidelines and criteria for IUD projects and is designed to stimulate innovation in the solutions and approaches that define IUD projects.

\section{Who Is This Tool Kit For?}

This tool kit has been prepared for ADB staff and other stakeholders to engage in IUD programming and implementation as an integral component of the ADB lending programs in DMCs. It is a guide to assist staff in supporting city governments in DMCs to prepare and implement IUD plans. The tool kit is intended as a practical guide for mayors, local government officials, sector specialists, planners, and other decision makers involved in project programming and design of urban infrastructure projects in cities. Its primary function is to guide city government officials in collecting and analyzing socioeconomic and poverty-related data relatively quickly; to prepare city poverty and vulnerability profiles; to assess options for citywide inclusive development; to identify development pathways; and to prepare strategies and plans as well as to prioritize actions to support IUD in developing cities. The use of the tool kit is not restricted to cities. The framework can be scaled up for inclusive development plans at the subnational, regional, and national levels. Community-based organizations will also find the guide useful for preparing community development plans.

\section{What Does This Tool Kit Contain?}

This tool kit presents concepts and strategies for addressing technical and institutional challenges related to shelter, infrastructure, transport, climate change, and disaster risk management-all of which are essential for IUD.

Chapter 1 presents an IUD framework that sets out the underlying principles of accessibility, affordability, resilience, and sustainability for an integrated approach to IUD investments. It outlines the process for undertaking an inclusive urban assessment. The assessment has two basic components: (i) policy and planning that informs detailed sectoral components and incorporates the learning from needs and capability assessments back into the policy agenda and planning process, and (ii) a sectoral assessment that determines needs, options, and priorities within sector and provides a basis for establishing the integrated 
investment program. These components are implemented across the three phases of the IUD process, as summarized in the figure. The three distinct phases are

1. understanding the urban context,

2. identifying priorities, and

3. projects and program development.

Chapter 2 sets out a toolbox that includes assessment methodologies, implementation tool kits, and other resources for each step in the process. The tools are designed to mesh across three phases of the development of an inclusive urban redevelopment project-the initial data gathering, the assessment and options development, and the prioritization of preferred options. The toolbox contains an inventory of tools that assist the user to collect, structure, and analyze data for the various steps in the process.

\section{How to Use This Tool Kit}

This tool kit is organized around the three phases of the IUD process and guides the user through the three-step process (Figure 1):

1. Understanding the urban context:

- understanding the economic, social, and physical environments;

- understanding the concepts, issues, and constraints related to various sectoral components of urban infrastructure projects that have a direct or an indirect impact today and in the future on the lives of the urban poor; and

- assessing the policy and regulatory framework that creates constraints to inclusive urban service delivery or enables it through proper incentives.

2. Identifying priorities:

The programmatic options available to address the needs and issues identified in Step 1:

- $\quad$ supporting participatory and consensus-driven decision making that initiates prioritization of inclusive urban investments in cities that support sustained economic growth, competitiveness, and environmental sustainability; and

- identifying strategies for addressing technical and institutional challenges to inclusive urban infrastructure development and service delivery.

3. Project and program development:

- $\quad$ assisting local government officials, sector specialists, and project officers to think programmatically on setting a vision for a city and the means to achieve the objectives, formulate projects and/or programs, explore partnership options, secure financing, and ensure implementation.

The process outlined above is sequential, and each step requires information, awareness, and tools that remain at the service of the DMC partners, provided appropriate capacities are built to replicate and learn from project implementation. 


\section{Process Flow for Integrated Urban Development Assessments}

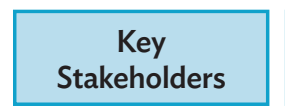

Expert Assessment

- ADB staff

- Business groups

- Professionals

- Governments

- R\&D/academic

- Special interest groups

- ODA

Stakeholder

Assessment

- Government

- Private sector

- Business groups

- Professionals

- Microbusiness

- SMEs

- Civil Society

- CBOs

- Special interest groups

Financier Assessment

- Public and private investors

- Developers

- ODA

- Not-for-profit organizations

\section{Data
Inputs}

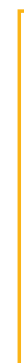

\section{Stage 1: Understanding the Urban Context} POLICY AND PLANNING COMPONENT

1. Policy and regulatory audit

2. Institutional and governance assessment

3. Capacity needs assessment

4. Municipal finance assessment

5. Stakeholder analysis

6. City poverty and vulnerability profile

a. Economic profile

i. Sectoral distribution

ii. Income and affordability analysis

7. Social equity profile

a. Poverty and gender profile and mapping

8. Environmental profile

a. Spatial risk data and mapping

b. Disaster risk management assessment and mapping

c. Climate change assessment

\section{SECTORAL COMPONENT}

9. Inclusive economic analysis a. Income and affordability analysis

10. Inclusive infrastructure assessment

11. Pro-poor shelter strategy

12. Inclusive service delivery assessment

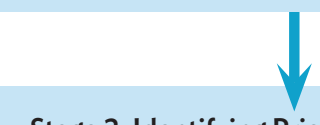

Stage 2: Identifying Priorities

1. Inventory of IUD programs

2. Sectoral assessment and indicative costs

3. Prioritization of inclusive infrastructure

4. Assessing training needs and capacity building for IUD

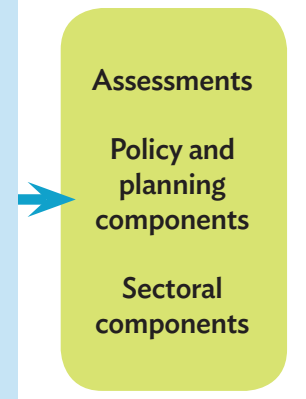

Key Outputs

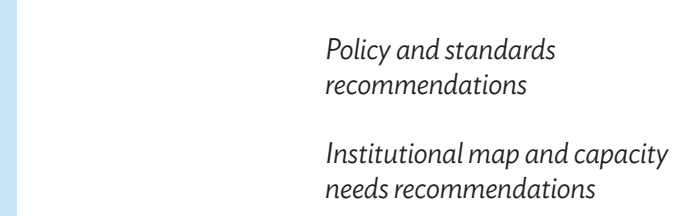

Consolidating a city poverty and vulnerability profile

Determining "affordability" and "capacity to pay" for low-income families

Urban and vulnerability assessments on topics presented above regarding the existing built environment and future growth

An inventory of recent-past, current, and future IUD-related projects

Report on consultations covering stakeholder discussion, and validation or disagreement with priorities identified in the establishing priorities process

An annotated list of priorities with descriptions of principal purpose, illustrative budget, institutional roles and responsibilities, and expected results
A set of priority project profiles to be prepared as detailed project reports

Proposed technical and planning innovations in project design and development

An understanding of how to construct a commercially viable project

$\mathrm{ADB}=$ Asian Development Bank, $\mathrm{CBO}=$ community-based organization, IUD = inclusive urban development, ODA = official development assistance, $R \& D$ = research and development, $S M E s$ = small and medium-sized enterprises.

Source: R. Naik Singru. 



\section{INCLUSIVE URBAN DEVELOPMENT FRAMEWORK}

$\mathrm{P}$ overty reduction has been the overarching goal of the Asian Development Bank (ADB) since 1999. This concern for poverty reduction is articulated in Strategy 2020, ADB's corporate-wide planning document, as a vision of "an Asia and Pacific free of poverty." The mission of ADB under Strategy 2020 is to help its developing member countries (DMCs) reduce poverty and improve living conditions and quality of life. Given the scale of urbanization in Asia, urban development is increasingly difficult to manage in the DMCs of ADB. Poverty, disparities in well-being, environmental pressures, and climate change remain the key issues confronting the Asia and Pacific region. Moreover, with urban population explosion, the challenge to ADB lies in its ability to respond to the aforementioned issues. Urbanization is placing a strain on the environment, affecting the quality of life of everyone, particularly the poor.

The dimensions of urban poverty (Figure 1) annotate the conditions that have a direct or indirect impact on the quality of life for the urban poor. Unless alternative approaches to address urban poverty are put in place, the poor will remain the most vulnerable.

\section{Figure 1: Dimensions of Urban Poverty}

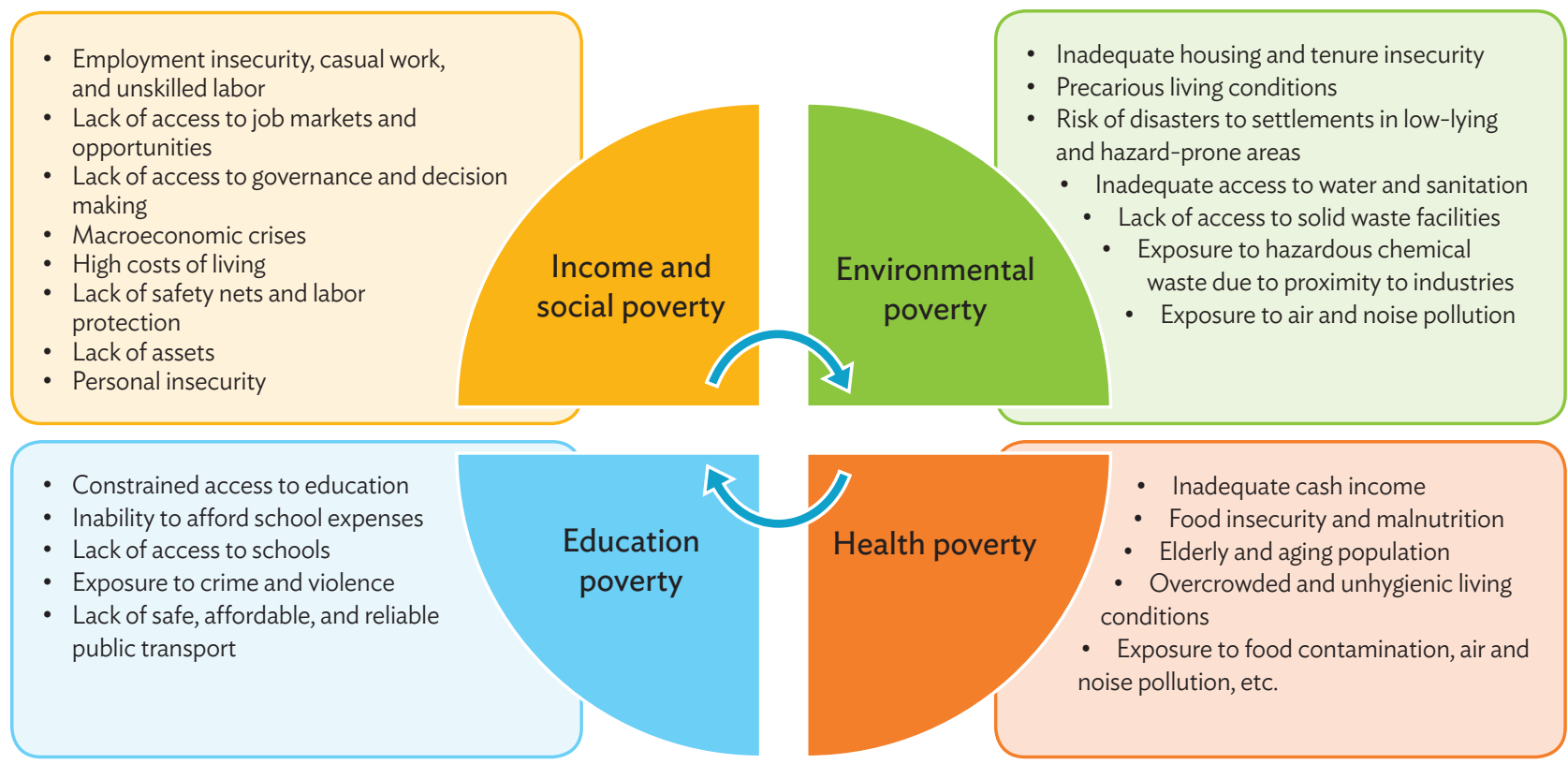

Source: R. Naik Singru based on World Bank. 2002. A Sourcebook for Poverty Reduction Strategies. Vol. 2. Washington, DC. 


\subsection{Enabling Inclusive Development}

Asian nations have experienced rapid economic progress to lift millions out of poverty facilitating a quality of life hitherto unknown to its urban inhabitants. The poor have benefited from the economic opportunities that have accompanied such growth. While the incidence of income poverty has decreased across the region, empirical evidence shows that the wealth production in cities has not necessarily contributed to improved living conditions for the vast majority of Asia's urban population (Lindfield and Steinberg 2011). Constricted supply of affordable and resilient housing, inefficient public transport, poor traffic management, inefficient provision and delivery of urban services, and the inadequate urban infrastructure place severe constraints on inclusive development and economic growth. Emerging spatial patterns with the merging of city regions beyond administrative boundaries adds to the urban management issues of fragmented institutional structures and delivery mechanisms. Assessing urban governance and management to streamline institutional arrangements becomes a key platform for inclusive delivery of urban services to ensure a good quality of life for all citizens.

\subsection{Creating Resilient Environments}

Urban areas with employment opportunities act as magnets for population migration, placing a huge demand on scarce urban resources and urban environments. Asian cities are highly vulnerable to the impacts of extreme weather events, such as floods and tropical storms, and expected impacts of climate change, such as rise in sea level and heat waves. Urban areas in low-elevation coastal zones are threatened by inundation and flooding, saltwater intrusion affecting drinking water supplies, increased coastal erosion, and reduction in livable land space. The effects of urbanization and climate change are converging in ways that have unprecedented negative impacts on urban quality of life, and economic and social stability (UN-Habitat 2011). Many cities are also at risk from geophysical hazards such as earthquakes. The urban poor live in overcrowded areas with precarious housing, outdated drainage systems, inadequate infrastructure, and urban services that delineate unsafe urban environments, highly susceptible to the risk of disaster. Thus, there is a need for a conscious change in the approach toward inclusive urban development (IUD) by mainstreaming disaster risk reduction and climate change adaptation into urban planning and management strategies.

\subsection{Developing an Integrated Approach for Inclusive Urban Development}

It has become increasingly clear from detailed sociological work in the 1990s (Moser, Gatehouse, and Garcia 1996) and more recent anecdotal but synthesizing work (Saunders 2010) that successful interventions for pro-poor development require an integrated approach to building the assets of the poor and the vulnerable. The approach requires both openness to building businesses and strong government redistributive action. It requires tenure security and strict enforcement of basic regulatory frameworks. It requires 
Figure 2: Critical Aspects of Inclusive Urban Development

\section{Integrated Development}

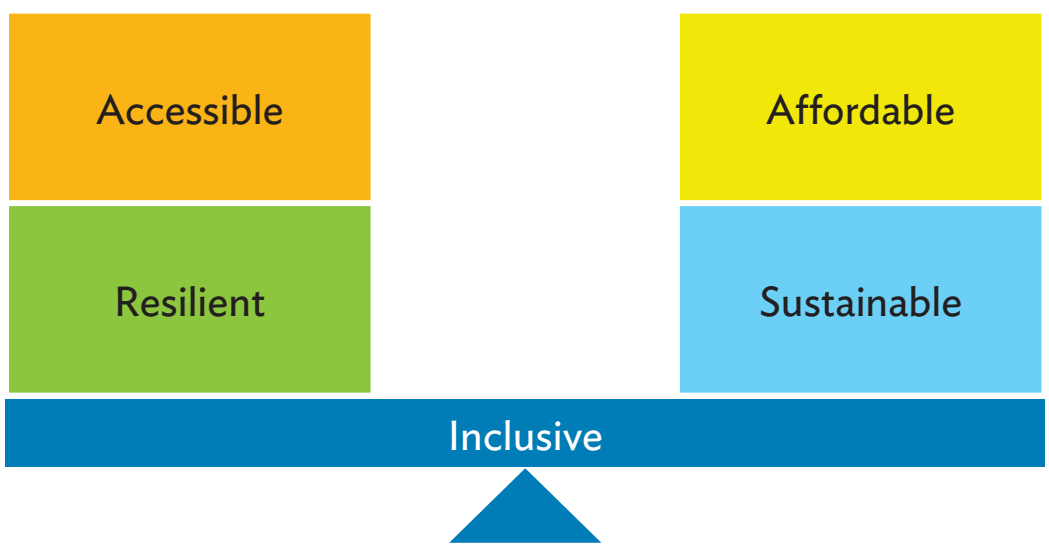

Source: Authors.

relocation from dangerous areas, and sensible and sensitive handling of both relocation and redevelopment. As such, the correct course of action is counterintuitive to many urban managers. Crosscutting the analysis set out earlier are underlying principles for an integrated approach to IUD investments: accessibility, affordability, resilience, and sustainability (Figure 2).

Accessibility: It is defined as the opportunities for safe, secure housing and reliable basic services for all individuals and communities structured within projects and programs that include credit and technical support required for their operation, maintenance, and expansion. Accessibility means enabling these opportunities within social structures and cultural norms that may constrain individual or collective access to a service.

Affordability: It is viewed in its broadest sense to include not only the affordability of families to benefit from the shelter, services, and transport solutions offered to them, but also the affordability of local and national governments to benefit from and have the capacity to support the systematic delivery of shelter, services, and transport to their communities.

Resilience: It is an integral part of urban investments. It is not a reactive notion that appears after disasters, but is a proactive approach to strengthen the ability to resist, absorb, recover from, and reorganize in response to natural hazards without jeopardizing sustained socioeconomic advancement and development. Resilience comes from the awareness of the context in which investments are to be made, of the affordability of the product provided, of the vulnerabilities based on historical record and projections of climate change, and of the planning and project development innovations and technologies that support resilience. 
Sustainability: It is the capacity of the responsible entity, be it a family or a local or national government, to service debt, operate, maintain, renew, and/or expand its shelter or service delivery system and pro-poor infrastructure. Sustainability also calls for access to the technical, financial, and human support required for shelter and service delivery through ongoing systems and programs.

\subsubsection{What Does "Inclusive" Mean?}

An inclusive city has been defined by UN-Habitat as the one that promotes growth with equity. It was defined as a place where everyone, regardless of their economic means, gender, race, ethnicity, or religion, is enabled and empowered to fully participate in the social, economic, and political opportunities that cities have to offer. Participatory planning and decision making are at the heart of the inclusive city (UN-Habitat 2001a). ADB expanded the definition of an inclusive city to bring an operational focus (Box 1).

"Inclusive" urban infrastructure development is defined as an integrated approach encompassing sustainable, resilient, accessible, and affordable solutions to the challenges faced by the urban poor and vulnerable groups by enhancing their access to urban services and infrastructure through targeted investments. This integrated approach encourages an institutional delivery mechanism that brings together all institutions and stakeholdersgovernment, the private sector and civil society-who have the capacity to deliver systems for inclusive urban service delivery. The approach proposes that the capacity of the urban poor communities, slum networks, and nongovernment organizations (NGOs) should be effectively used in conjunction with the city government and the private sector.

\section{Box 1: What Is an Inclusive City?}

An inclusive city creates a safe, livable environment with affordable and equitable access to urban services, social services, and livelihood opportunities for all the city residents and other city users to promote optimal development of its human capital and ensure the respect of human dignity and equality. ${ }^{\text {. }}$

An inclusive city is built on (i) joint strategic visions of all stakeholders through a participatory planning and decisionmaking process incorporating universal design, integrated urban planning, transparent accountability mechanisms, and the use of the city's inherent assets; (ii) knowledge and information sharing; (iii) public participation and contribution; (iv) mechanisms, such as cross-subsidies, social protection, and gender balance, to ensure an adequate standard of living to the most economically disadvantaged and vulnerable population; (v) geographical and social mobility; (vi) business environment and pro-poor financing services that attract capital investment and allow everybody the possibility to undertake economic activities; (vii) resilience to global environmental and socioeconomic shocks and threats; and (viii) mechanisms to ensure the sustainable use of its resources. ${ }^{b}$

Notes:

a Urban services include water supply, sanitation, solid waste management, housing, and transport facilities; social services are typically health, education, culture, and public space.

b Stakeholders are government, communities, civil society, and the private sector. Social protection includes systems for upholding the rights of children, youth, women, elderly, and indigenous peoples.

Source: ADB 2014, Urban Sector Group, Inclusive Cities Working Group. 
Inclusive casts a wide net to bring the poor, the underemployed, and the nonsalaried people into urban investment projects and programs to improve their lives. Inclusive investments should incorporate concepts and technical and planning innovations that include climate adaptation issues, especially flood risk management, site protection from landslides, raised walkways, and erosion control. These investments must be initiated with accessibility and affordability as the starting point for project design. Furthermore, where possible, they should use building materials and other locally sourced inputs that are from renewable, sustainable production processes that support low-income families and community selfhelp initiatives.

Inclusive investments should be sensitive to the needs of the elderly, women, children, and the youth. They are important stakeholders and can be active participants in the design and development of inclusive infrastructure. Given the increasing incidence of gender-based violence in urban contexts, attention needs to be paid to women's safety and security issues in the development of urban projects. Gender and development issues should be considered an integral part of urban assessments prior to project preparation. Good urban

\section{Box 2: Amar Jyoti-An Inclusive School}

Started as an experiment more than 2 decades ago, the integrated school run by the Amar Jyoti Research and Rehabilitation Centre in Delhi has become a model that is attracting much attention, not only in India but also in other parts of the world. Under the motto "Education for All," Amar Jyoti provides integrated, holistic educational services to students with diverse abilities. The school educates able-bodied and differently abled students alongside one another, paving the way for an inclusive society.

Of the 450 students attending the school, 50\% are differently abled. Strikingly, the school is completely barrier free. Children who are orthopedically, mentally, visually, and hearing-wise differently abled can access all corners of the specially structured, four-storied building.

The school is a true example of inclusive education: able-bodied and differently abled children play and learn alongside one another, using the same facilities. This concept has been shown to work at many levels. Able-bodied children are sensitized to the needs of others, while their differently abled peers develop confidence.

A workshop provides assistive devices and mobility appliances to the differently abled with grant-in-aid received from the Ministry of Social Justice and Empowerment of the Government of India. To reach the unreached, Amar Jyoti also had community-based rehabilitation projects in 30 urban slums of Delhi and organizes periodic medical camps where necessary services for rehabilitation of the differently abled persons are provided as per needs.

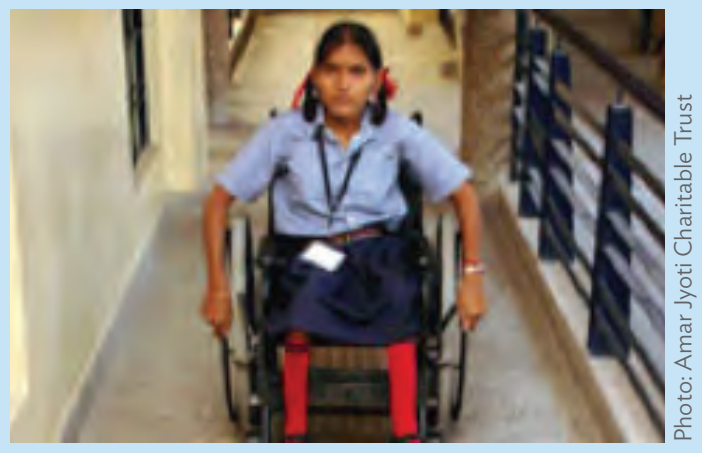

Sources: U. Tuli. 2003. Amar Jyoti Inspires Confidence. UN Special. No. 617; Narotam Sekhsaria Foundation. 2010. Civil Society Initiatives. http://www.nsfoundation.co.in/civilsintivatives.html (accessed June 2012). 
design of public spaces can play a critical role in reducing crime and incidence of genderbased violence in cities. Gender-based analysis of public spaces should be undertaken to ascertain safety and security issues and to identify "hot spots" for gender-based violence.

Casting the inclusive net wider, it is recognized that accessibility is a very important part of the inclusion of people who are differently abled (Box 2). An accessible, barrier-free environment is the first step toward fulfilling the right of differently abled people to participate in all areas of community life. Universal accessibility is a broad term covering all aspects toward assuring that differently abled people can participate and have the same choices as able-bodied community members. This includes access to transportation, water supply and sanitation, education and technology, appropriate sources of communication and media to ensure information, the electoral process, and an infrastructure that removes all physical barriers, thereby ensuring equal participation of all differently abled persons as the members of a community (World Bank 2012).

An inclusive approach should address the needs of differently abled people to ensure accessibility to all urban services. In the physical context, it is necessary to retrofit the city to create a barrier-free environment for people with mobility or visual impairments. There is a need for increasing awareness and sensitivity in DMCs toward the needs of differently abled people. The first step is to start with enumeration of the differently abled population to understand the magnitude of the issue. Policies pertaining to access to education, employment, and urban services are still in their nascent stage in most developing countries. Hence, it is important to draw on the learning experience of progressive nations to create a barrier-free environment to enable differently abled people to participate and productively contribute to the city's economy as respected members of society.

\subsubsection{Inclusive Urban Redevelopment}

The Urban Sector Group of ADB undertook a diagnostic study of urban redevelopment (often referred to as "urban renewal") and slum rehabilitation. This inclusive urban redevelopment perspective views slum rehabilitation as an integral part of the urban development agenda of $A D B$, regardless of whether it comprises on-site upgrading or redevelopment. Furthermore, it argues that (i) slum rehabilitation is required for urban renewal in Asia and the Pacific and that (ii) a multisector approach to slum rehabilitation combining water management (provision of drinking water, sanitation, drainage, and flood control facilities); solid waste management; urban transport; and urban redevelopment is necessary if the goal of livable cities is to be achieved. Inclusive urban redevelopment overlaps with revitalization of historic inner-city areas, but only insofar as historic inner-city areas have become slums (Lindfield and Steinberg 2011).

\subsubsection{Framework for Inclusive Cities}

It is critical for decision makers and project officers to understand the interlinked aspects of urban development while designing projects and programs for inclusive cities. Building inclusive cities requires a multisector and integrated approach as the impacts of policies and projects in one sector can often affect the functioning of other sectors, sometimes with detrimental impacts for the urban poor. For example, the design of a mass transit system that reduces the travel time to central areas of the city is generally beneficial for all citizens; however, it has an impact on the functioning of land markets as it increases land values and rents along the routes. As a consequence, the urban poor may be pushed out 
of inner-city areas unless complementary public housing or urban upgrading programs are undertaken along with the development of the mass transit system. Likewise, the benefits of the interdependency of sectors can be utilized in a sustainable manner if projects are developed through a cross-sectoral perspective.

Waste-to-energy is one such application of cross-sectoral benefits that create sustainable synergies between sectors. Sustainable transport initiatives and passive heating and/or cooling can be fueled through energy produced as a by-product of waste treatment. Biogas digesters connected to sanitation facilities in rural areas in Cambodia, the People's Republic of China, India, Nepal, and Viet Nam have produced cheap energy sources for lighting and cooking. Harvesting nutrients for fertilizers; methane and biogas for energy and carbon credits; and water for irrigation, power cooling, industrial, and other nonpotable uses offer income-generating opportunities in the peri-urban areas. Biosolids (by-products of wastewater treatment) can be treated such that they can be used as safe, organic soil conditioners. Methane captured in wastewater treatment facilities not only contributes to climate change mitigation efforts but also generates renewable energy for use by the facilities and the nearby communities (Ebarvia, Maria Corazon, and A Chiplunkar. "Environment and Poverty Times." Agderposten Trykk, Feb 2012).

Strategy 2020, the long-term strategic framework of ADB, recognizes that inclusive growth is essential to provide all people with a chance to benefit from economic growth. It also states that Asia and the Pacific must promote greater access to opportunities by expanding human capacities, especially for the disadvantaged, through investments in education, health, and basic social protection. To develop inclusive cities, there is an urgent need to invest in a strategic and targeted manner to address the poverty dimensions of income, education, environment, and health (Figure 1). This tool kit adopts an integrated approach for IUD (Figure 3) designed to build the assets of the poor, and focuses on livelihood development, housing, basic urban services, inclusive infrastructure, and social capital of the poor. The tool kit is structured by activities designed to determine the most effective means of building these assets and to prepare the basis for bankable investment projectssuitable for financing by $A D B$ and other financial institutions.

Figure 3 outlines the critical sectors for inclusive investments that can trigger positive outcomes for poverty reduction in the urban environment.

Income and social aspects of poverty can be addressed by building the financial assets and social capital of the urban poor. This can be built through investments for income generation (microfinance and small- and medium-scale enterprise development), social protection, and education. The policies and programs of ADB's social protection strategy aim to help people in the region break the cycle of poverty, enhance growth through investment in human capital, increase productivity, and reduce their vulnerability to risk. Three major elements constitute ADB's social protection strategy:

(i) Labor market policies and programs designed to promote employment, the efficient operation of labor markets, and worker protection.

(ii) Social insurance programs to cushion the risks associated with unemployment, catastrophic out-of-pocket health costs, disability, work injury, and the growing ranks of the elderly. 
(iii) Social assistance and welfare service programs for the most vulnerable with no means of support, including single mothers, the homeless, or people with physical and mental impairments.

IUD can be further aligned with the social protection strategy through investments in accessibility and barrier-free environments, gender-inclusive programs, and capacity development of community-based organizations that empower poor urban communities to undertake community-driven development projects.

To address the education and health dimensions of poverty, investments in basic and vocational education as well as primary health are crucial as they bolster the incomegeneration opportunities for the urban poor. However, the critical areas for investment to address environmental poverty are through targeted investments in the key sectors: water and sanitation, solid waste management, energy, transport, land management, and housing.

Figure 3: Inclusive Urban Development Approach

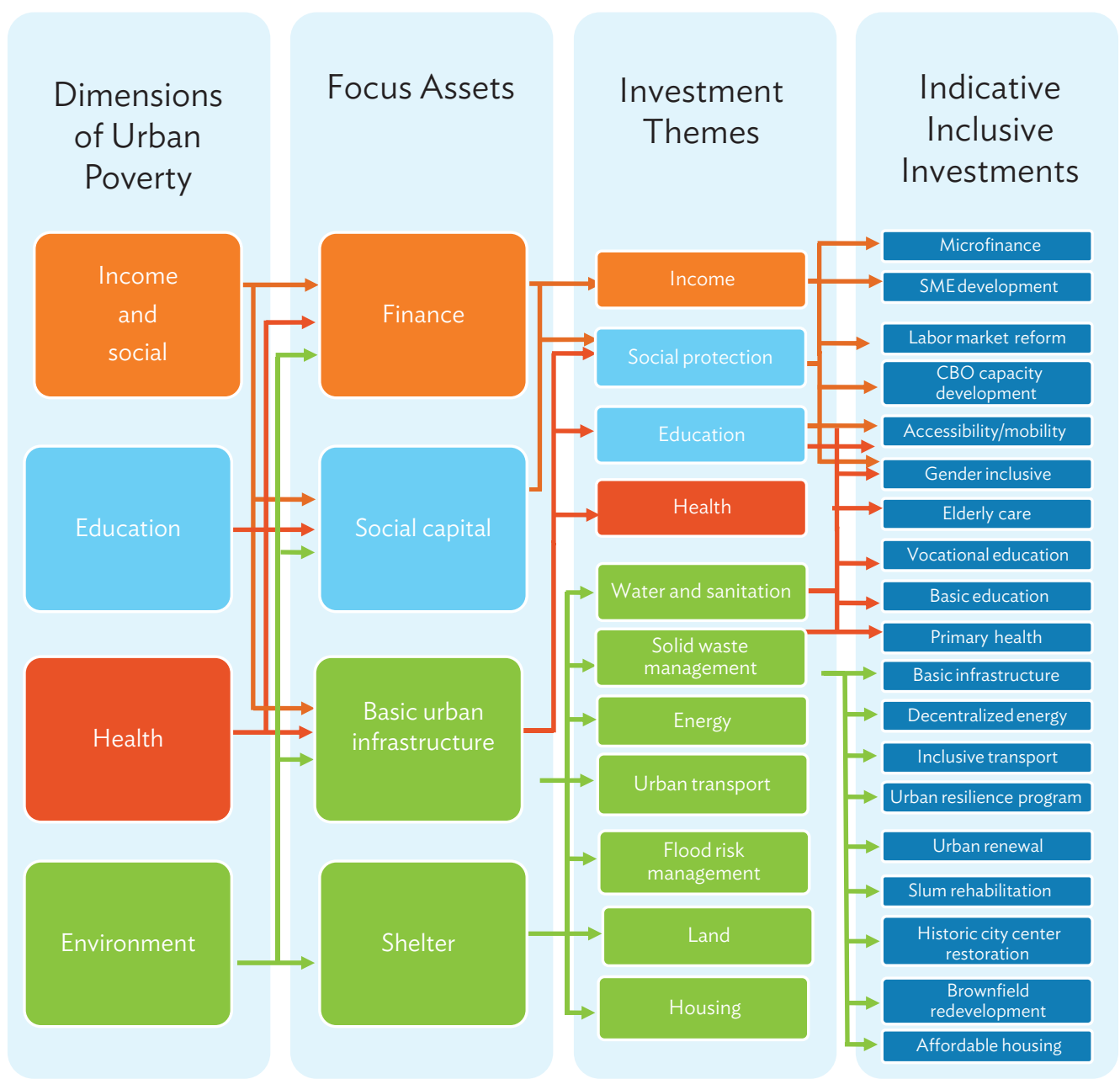

$\mathrm{CBO}=$ community-based organization, $\mathrm{SMEs}=$ small and medium-sized enterprises .

Source: R. Naik Singru. 
Upgrading and retrofitting basic infrastructure and providing universal access to urban services is not only essential for creating inclusive cities but also instrumental for generating competitive, resilient, and sustainable green cities. Investments in urban renewal, slum upgrading, historic conservation, and brownfield redevelopment can stimulate growth in the urban economy while addressing the environmental poverty dimensions.

\subsection{Inclusive Urban Assessment Process}

The inclusive urban assessment process has two basic components:

(i) A policy and planning component, which informs detailed sectoral components and incorporates the learning from needs and capability assessments back into the policy agenda and planning process.

(ii) A sectoral assessment component, which determines needs, options, and priorities within a sector and provides a basis for establishing the integrated investment program.

These components are implemented across three phases: (i) urban context, (ii) sector assessments and options, and (iii) cross-sectoral prioritization and project programming. For each step in the process, appropriate tools are available and are set out in the Toolbox chapter. The tools are designed to mesh across the aforementioned three phases of inclusive urban redevelopment. The detailed steps and activities within the three phases are outlined in the process flowchart shown in Annex 3, Figure (a) maps the activities under the planning component, and Annex 3, Figure (b) maps the activities designed to build specific assets within each sectoral component. Both diagrams refer to specific tools and show how each tool relates to others. The detailed activities to be undertaken in the three phases are described in the following sections.

\subsubsection{Phase 1: Urban Context}

This phase ensures that the assessments take into consideration the existing urban realities and the future needs and concerns of the growing urban poor population. This phase will identify the economic, social, and environmental issues and challenges that currently constrain IUD. It identifies the key drivers of urban growth, outlines the existing urban conditions, and evaluates the future trends and patterns of urbanization that are likely to influence poverty and vulnerability of poor and low-income groups. Knowledge is a crucial component in addressing these challenges. Understanding the urban context, therefore, consolidates the knowledge and information base of the city.

The key outputs of this phase are a city poverty and vulnerability profile (CPVP), an institutional assessment and an inclusive needs assessment encompassing the sectoral components (infrastructure, pro-poor shelter, and inclusive delivery of urban services) (Figure 4). The CPVP does not seek to generate fundamentally new information but helps to identify, assemble, and organize information so as to facilitate urban decision making. A profile can be used to organize information in one or several different ways (UN-Habitat 2001b): 
- Thematically: A profile could focus on the environment, poverty, urban security, disaster risk management (DRM), municipal finance, or gender. These themes can in turn be further narrowed down to more specific issues or aspects, such as waste collection, access to water supply, municipal revenue collection, flood control, urban safety for women, etc.

- Sectorally: A profile could focus on water supply, solid waste management, urban transport, or employment and livelihoods.

- Spatially: A profile might also be focused on a specific geographic area such as the central business district, a municipal watershed, a specific neighborhood, or citywide.

\section{Objectives}

- To articulate and dimension the existing urban context

- To determine the demand for and supply of urban services and shelter

Figure 4: Framework for Understanding the Urban Context

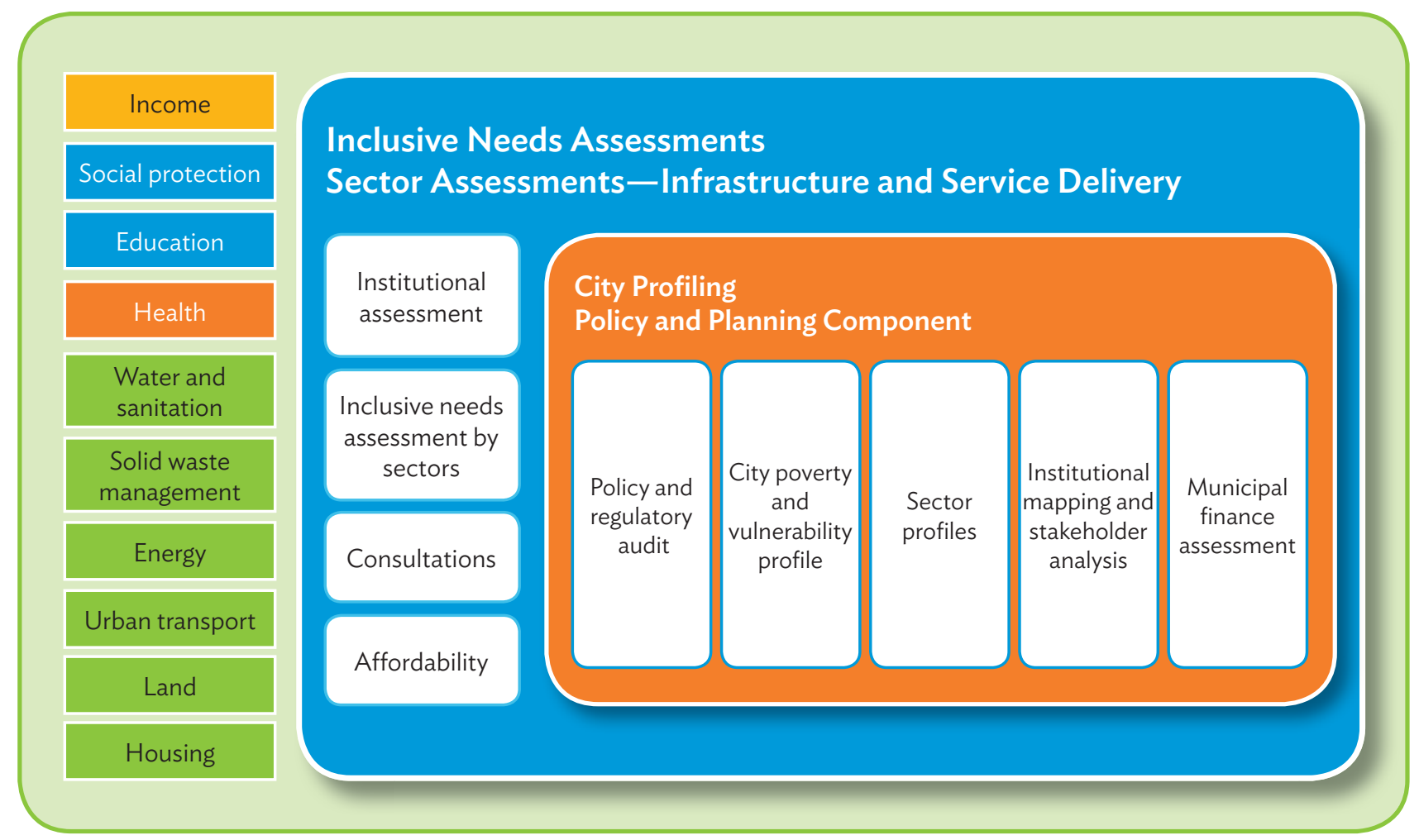

Source: Authors. 
- To map the institutional structure of local governments and partners involved in urban development projects and programs

- To identify policies, standards, and codes to be updated and/or created for urban improvement and growth

- To review the enabling environment to facilitate improvement and growth

\section{Approach and Methodology}

1. City poverty and vulnerability profile: Consolidating the CPVP through data gathering and mapping, including an annotated city base map; a sociocultural map; a vulnerabilities and/or spatial risk profile detailing the distribution of environmental and natural hazards affecting urban areas, type of environmental risk, number of people in high-risk areas, and mitigation measures in place; and a future urban expansion map. These should be included in the master plan.

2. Policy and regulatory audit: Understanding the policy framework and institutional capacity for inclusive planning, and review policies and standards for their reference to and impact on the ability of projects to be inclusive, resilient, and sustainable.

3. Institutional and governance assessment: Assessing institutional structures responsible for delivery of urban services:

- Institutional mapping: Identification and mapping of governance and institutional structures.

- Capacity needs assessment: Review of skills and capacity of project staff in city government offices; training needs assessment.

- Stakeholder analysis: Stakeholder identification and assessment of key stakeholders involved in the urban sector. Conducting a stakeholder assessment and facilitating a stakeholder workshop to gather their inputs on the needs and priorities of the communities. These can be citywide and in focus groups to discuss the needs of specific communities.

- Urban finance assessment: Urban finance matrix and municipal finance health check.

4. Inclusive needs assessment:

- Sectoral assessment: Water and sanitation, solid waste management, energy, transport, land management, shelter, education, and health.

- Inclusive infrastructure assessment: Assessing the status of infrastructure, cost of upgrading, and future growth.

- Inclusive service delivery assessment: Service, access, quality, reliability, and affordability.

- Pro-poor shelter strategy: Current status, backlog, policies, programs, resources, or lack thereof.

- Inclusive economic analysis: Employment, income, and affordability analysis; identifying and carrying out topical assessments of affordability and capacity to pay of target families to guide project planning for shelter, urban services, and historic urban areas. 


\section{Process}

1. Develop a city poverty and vulnerability profile:

- Scope: Undertake preliminary and/or scoping work of the city, including an analysis of its role in the national urban system. Consolidate the CPVP through data gathering and mapping, including an annotated city base map, a sociocultural map, a vulnerabilities and/or spatial risk data map, and a future urban expansion map. These should all be included in the master plan. Conduct urban and vulnerability assessments to identify needs and gaps in DMCs and in the ADB response to IUD.

- Review: Conduct a comprehensive review of available literature on the urban sector policies and regulatory framework; other policies and strategies for climate change and DRM; city development strategies; programs and projects, utilizing published works; and evaluation studies and project reports, identifying the determinants of a successful urban economy and poverty-alleviating growth, placing particular emphasis on the identification of mechanisms that build the assets and incomes of the poor. Review policies and standards for their reference to and impact on the ability of projects to be inclusive, resilient, and sustainable (Tool 2).

- Validate: Validation of the city development strategy or city development plan based on the following assessment criteria:
a. Time frame of the study and relevance
b. Specificity and realism of the vision (including policy constraints)
c. Nature of consultations carried out during preparation of the plan
d. Action plans identified to achieve the strategy
e. Programmatic planning of investments (rolling plans) and realistic prioritization

- Baseline audit studies: Compile quantitative and qualitative baseline information at the city and/or urban region level to assess the current state of urbanization and urban hierarchy. Generate a spatial analysis to capture the key urban economic, environmental, and social development challenges. The data and information collected and analyzed, including digital maps and imagery, should be stored in a database as part of the CPVP to enable updating of the information.

- Output: The CPVP will provide baseline data and analysis of the key urban economic, environmental, and social challenges in the city. It will also provide a policy and standards review to enable policy reform, contain sector assessments, and provide key investment shortfalls by sector.

2. Develop an institutional and governance assessment:

- Scope: An institutional assessment presents an opportunity to look more carefully at the institutional structures and the governance context for highpriority infrastructure projects and identify areas where strengthening existing arrangements could enhance the capability of the city to plan, fund, and maintain such infrastructure. An institutional and governance assessment looks at the structure and staffing (skills and capacity) of the city government, the policy and regulation context (or "enabling environment"), and the decision-making processes. By assessing the broader governance context for planning and programming, the institutional assessment identifies the range of stakeholders (see Stakeholder analysis p. 14) that have a bearing on infrastructure provision and maintenance: this will include central and regional government (ministries and agencies) decision makers, service providers, and those stakeholders without 
"formal" power (especially the urban poor). A capacity needs assessment identifies areas where planning, programming, structuring, and marketing of infrastructure investment programs and projects can be strengthened (the municipal checklist and the municipal financial assessment are a critical part of the overall assessment): the strategy can cover the need for further policy and strategy development, to identify formal and on-the-job training for the relevant city staff.

\section{- Review:}

a. Institutional mapping: Outline the institutional structure, roles, and responsibilities of the different tiers of government involved in urban service delivery. Identify and map governance and institutional structures to understand functional areas of responsibilities at the different levels of governance and management of urban affairs and to assess institutional capacity to structure and implement urban infrastructure projects. This should comprise an organizational diagram (an "organogram") that illustrates the structure, hierarchy, and overall staffing numbers of the city government, together with simple tables that record basic information (Tools 3 and 7).

\section{b. Governance context:}

(i) Municipal checklist: Identify municipal strengths, weaknesses, opportunities, and constraints to focus on issues of primary concern. Develop a simple matrix that records the main institutions and stakeholders involved in infrastructure planning, programming, structuring, and marketing of infrastructure investment programs and projects (Tool 4).

(ii) Citizen Report Card: Design and administer the Citizen Report Card to assess the quality of governance and satisfaction of citizens with the delivery of urban services. The Citizen Report Card is an effective tool for improving local governance and pro-poor service delivery (Tool 10).

(iii) Municipal finance assessment: Develop an urban finance matrix and municipal finance assessment to understand the city's resources, urban financing systems, and resource mobilization. Assess the sustainability of implementing agencies and private sector capacity (Naik Singru and Lindfield 2016). A municipal finance assessment is an analysis of the city's financial performance to understand the types and amounts of revenue and expenditure, and whether they are adequate to effectively deliver services to the targeted sector as the city's population continues to grow and the risk patterns that can affect the city change over time. The analysis also looks at the fund balances and debt levels and their impact on current city financial resources.

c. Capacity needs assessment: Undertake an assessment of capacity-building needs in planning, programming, structuring, and marketing infrastructure. This will provide baseline information on staff capacity (skills, knowledge, and experience). The assessment might also include reflections on the overall relevance of the city government structures (such as the presence or absence of departments or units) for infrastructure planning and programming. Record recent training received by city representatives and officers (CDIA and UN-Habitat 2012). 
d. Stakeholder analysis: Conduct a stakeholder assessment and facilitate a stakeholder workshop to gather their inputs on the needs and priorities of the communities. This can be citywide and in focus groups to discuss the needs of specific communities (Tool 5).

(i) Audit: Commence the collection of quantitative and qualitative baseline data and information at the city-level to assess data availability.

(ii) Output: It will identify the capacity shortfall by sectors and also outline the resources and finances available to the city for investments.

3. Conduct an inclusive infrastructure needs assessment:

- Scope: Phase 1: Municipal services and infrastructure-water, sewerage, drains, solid waste, roads, electricity, and telecommunications-are essential to develop and maintain efficient, healthy, and sustainable cities. These critical services, plus other physical and social amenities, including housing, schools, and health care, make cities livable and allow their residents to be productive citizens. Access to these services for the urban poor is critical to their inclusion into the society as productive citizens.

- Objective: To understand the status of urban infrastructure in the city with regard to adequacy, quality, and reliability for all the sectors.

- Inclusive service delivery assessment: To understand the status of urban service delivery in the city to the poor and the vulnerable groups. To assess the inclusive service delivery with regard to access to services, adequacy, reliability, and affordability.

- Steps:

a. Outline the objective of the assessment, the data to be collected, and the methodology.

b. There should be three areas for analysis - the status of the physical infrastructure assets, the institutional capacity, and the financial resources available with the city for service delivery and for the operation and maintenance of infrastructure.

c. Interview the key staff of institutions and agencies at the national and local levels responsible for and/or engaged in urban service delivery.

d. Consult private sector stakeholders for utilities, urban infrastructure finance, and development. Proposed urban renewal projects, such as slum upgrading and rehabilitation of waterways, should be aligned with the development plans of the private utility companies.

e. Consult community-based organizations and NGOs regarding their roles and capacity to be involved in urban service provision.

- Review:

a. Develop sectoral profiles for water and sanitation, solid waste management, energy, transport, land management, shelter, education, and health.

b. Conduct an urban infrastructure needs assessment taking into account the demand for infrastructure, housing, and urban services to include asset inventory performance, coverage, deficit, and the resource gap for inclusive urban infrastructure. 
c. Conduct a major asset overview and an inventory and performance assessment. Identify the need and demand for and the supply of urban infrastructure that benefit the poor.

d. Identify the roles and responsibilities of public and private NGOs and community sector institutions regarding urban service delivery to the poor. (part of institutional assessment). Present an understanding of the policies, roles, and responsibilities of the institutions involved in financing, planning, and delivery of urban services. Determine if and how low-income families participate in and benefit from national and city support programs. Collect targeted information on the quality and quantity of urban services being provided to informal settlements, inner-city tenements, and slum areas useful for establishing priorities.

e. Spatial analysis should contain the following:

(i) An updated set of annotated utility maps for coverage of urban services such as water supply, sewerage, drainage, and electricity that support inclusive, sustainable, and resilient development. These can be supported by the income and affordability analysis to assist planning for future infrastructure.

(ii) Status of infrastructure assets in poor areas, delivery of services (formal and informal), access, cost, and collection systems for services (formal and informal)

(iii) Infrastructure requirements and gaps in service delivery

(iv) An understanding through maps and text of the locations where pro-poor activities are concentrated

f. Identify and carry out topical assessments of affordability and capacity to pay of target families to guide project planning for shelter, urban services, and historic urban areas (Tool 8).

g. Conduct urban and vulnerability assessments that focus on policy and program issues regarding inclusiveness.

\section{- Output:}

a. Presents the information gathered in an inclusive infrastructure needs assessment report. It will contain the sector assessments and provide the key investment shortfalls by sector.

b. Presents an inventory of the urban infrastructure assets, current status, and capacity, assessed with respect to climate resilience and disaster preparedness.

c. Presents an overview of the status of urban service delivery in the city, especially informal settlements, inner-city tenements, and slum areas.

d. Identifies key institutions and their priorities, programs' focus, output, and source of funds and budget (municipal finance assessment).

e. Reviews and recommends modifications of policies.

f. Reviews and recommends modifications in programs and investments being made in urban services and mitigation infrastructure. 


\section{IMPLEMENTATION POINTERS}

- Gather existing information and maps from relevant sources.

- Identify information gaps and fill them through consultations and focus groups, especially with community groups and agencies dedicated to addressing the urban service needs of the poor.

- Organize working groups to validate and verify information and recommendations.

- Build the "affordability" approach into the review of the products and systems being developed.
- Present observations on the willingness-topay of users as well as willingness-to-collect of providers.

- Make recommendations for incrementally developed urban service delivery systems.

- Present financial management alternatives for services provided.

- Discuss a 24-7 approach to service supply and its appropriateness to the overall supply system.

- Include potential impacts of climate change and disaster risks on urban services.

Source: Authors.

For detailed guidance, see the following:

Tool 1: Poverty Mapping and Spatial Analysis

Tool 2: Policy and Standards Review

Tool 3: Institutional Mapping and Capacity Needs Assessment

Tool 4: Municipal Checklist

Tool 5: Stakeholder Analysis

Tool 6: Problem Tree Analysis

Tool 7: Municipal Finance Assessment

Tool 8: Income and Affordability Analysis

Tool 9: Pro-Poor Shelter Strategy

Tool 10: Citizen Report Card

Tool 12: Integrated Disaster Risk Management in Inclusive Urban Development

Tool 13: Climate Change Impacts, Resilience Options, and Indicative Costs

\subsubsection{Phase 2: Sector Assessments and Options}

This phase aligns and builds consensus for prioritization of IUD projects and programs. Based on the analysis in Phase 1, this phase evaluates the potential and opportunities for IUD in the context of the city's urban vision, taking into consideration the immediate needs of the urban poor and the long-term impacts, such as climate change. It endeavors to integrate the needs of the urban poor within existing and proposed urban development projects. Prioritization of urban development projects using an inclusive approach ensures synergistic social and economic benefits through the transformation of the physical environment of a city. It safeguards the interests of the urban poor in case the broader city vision and priorities undermine or threaten their shelter and livelihood options. The key outputs of this phase are an inclusive city development strategy (Figure 5). 
Figure 5: Sector Assessments and Options

\section{Sector Assessments and Options \\ Inclusive City Needs Assessments}
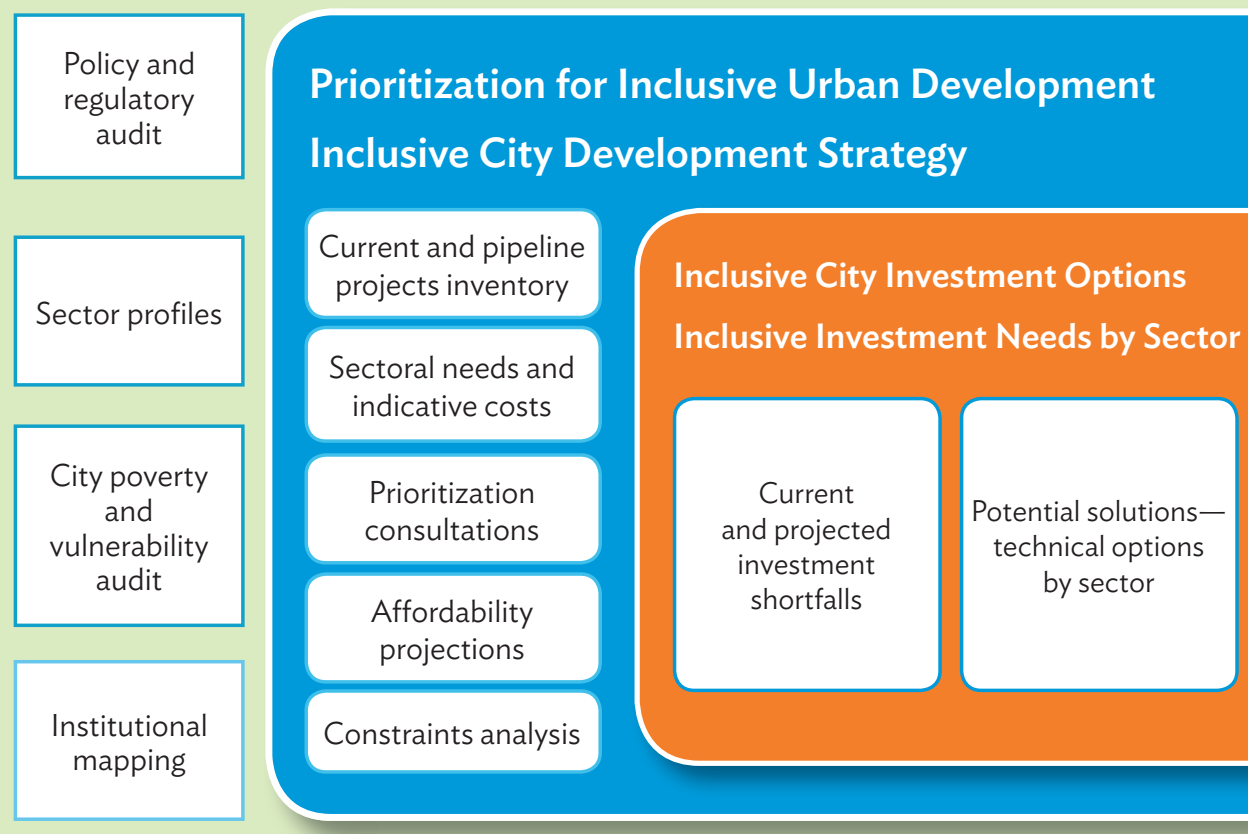

Inclusive Investment Needs by Sector

Current and projected investment shortfalls
Potential solutionstechnical options by sector
Implementation options-finance and institutional

Source: Authors.

\section{Objectives}

- To undertake sectoral assessments for water and sanitation, solid waste management, energy, transport, land management, shelter, education, and health to establish an inclusive urban needs assessment for each sector across the city.

- To identify priority areas, projects, and programs for investment and assistance.

- To establish priorities based on the targeted urban and vulnerability assessments, the focus and lessons of past experience, and stakeholder consultations for IUD program development and investments.

- To identify potential solutions - technical options by sector, based on the sectoral needs assessments. To identify potential implementation options-financial and institutional options that will address the key investment and capacity shortfalls

\section{Approach}

- To build on the initiatives in understanding the urban context that identified areas for targeted assessments useful for establishing priorities, vulnerabilities, and built and natural environmental assets. 
- To undertake sectoral needs assessments for water and sanitation, solid waste management, energy, transport, land management, shelter, education, and health based on the sector profiles conducted in Phase 1.

- To consolidate information on previous, current, and proposed programs to identify focus areas and gaps. This is a key process to avoid duplication and provide comprehensive support for IUD.

- To determine geographic and technical areas addressed in each sector studied.

- To determine and prioritize gaps in support and coverage, factoring in affordability.

- To carry out stakeholder and DMC consultations, verify and validate priorities identified, fill gaps, and add detail to initiatives that reflect the particularities of context.

- To prepare an annotated list of priorities with descriptions of principal purpose, illustrative budget, institutional roles and responsibilities, and expected results.

\section{Process}

1. Conduct an inclusive infrastructure needs assessment:

- Scope: Phase 2: To prepare and analyze future demographic projections and trends, and economic growth. Forecasting provides a basis for moving forward and developing strategies that will result in more sustainable development outcomes. A proactive voice by the local government for improved, inclusive urban service delivery will foster understanding and confidence through a decentralized system of community offices.

- Review: Conduct sector assessments that focus on urban infrastructure and service delivery for shelter, water and sanitation, solid waste management, energy, transport, and vulnerability, including climate change and DRM and/or multihazard impacts and management.

- Conduct: Conduct an urban infrastructure needs assessment, taking into account demand for infrastructure, housing, and urban services to include asset inventory performance, coverage, deficit, and the resource gap for inclusive urban infrastructure.

- Prepare an inventory of recent-past, current, and future projects that relate to IUD. The inventory project descriptions will include project results, issues of budget and implementation, and the project purpose to address the existing built environment and/or the future growth of a city.

- Prepare results and recommendations in a report that features the institutions involved and their output. Outline the sectoral needs, gaps, and priorities.

- Identify a short list of projects and programs and indicative costs for each sector. Identify opportunities for investments in "mitigation" infrastructure, such as flood control, site protection, and landslide and erosion control, in vulnerable areas occupied by the poor.

- Present an annotated list of priorities an inclusive urban service program would address, including mitigation and climate-resilient infrastructure.

- Recommend priority programs and investments to address the needs and gaps identified.

- Output: Present projections on trends, demands for infrastructure, services, resources, and other needs to support the needs of the urban poor. Infrastructure forecasting will involve the use of ratio and regression methods to predict 
future demand for infrastructure services, such as water, energy, roads, and other utilities. ADB has developed demand forecasting of water supply-a recommended set of priorities to be developed into projects and investments. ${ }^{1}$ The key output for this phase is an inclusive city development strategy.

\section{Expected Results}

1. Urban and vulnerability assessments on topics presented earlier regarding the existing built environment and future growth.

- Inclusive assessments of indicated sectors and topics that focus on the special and different types of programs, standards, and products that IUD represents.

- Programmatic priorities that will lead to inclusive project development.

- An agenda of issues to be addressed by ADB with DMC partners, the private sector, civil society, and community-based organizations for policy, training, and IUD investment program development.

- An inventory of recent-past, current, and future IUD-related projects.

2. An annotated list of priorities with descriptions of principal purpose, illustrative budget, institutional roles and responsibilities, and expected results.

\section{Sustainability}

1. Establishing priorities is an important process for cities to identify priorities through monitoring ongoing projects, updating assessments, and scheduled consultations. This is best done through stakeholder workshops. Where multisector prioritization is required, the Goals Achievement Matrix tool, based on the Development Initiative for Asia City Infrastructure and Investment Programming and Prioritization, is useful.

2. Evaluating the results of IUD initiatives and investments that build on current programming offers opportunities for scaling up successful efforts. Staff and resources need to be provided, and it requires private sector support for the government to establish a scheduled set of interviews and consultation.

3. The inventory identifies current priorities and investments being made in IUD-related projects. The inventory is a tool to consolidate information on investment and technical assistance and/or capacity-building programs, build an information based on IUD-related activities, support scaling up, and avoid duplication.

For detailed guidance on establishing priorities for IUD programs and investments, see the following:

Tool 8: Income and Affordability Analysis

Tool 9: Pro-Poor Shelter Strategy

Tool 10: Citizen's Report Card

Tool 14: Inventory of Projects/Programs and Investments

Tool 15: Capacity Needs Assessment and Capacity Development Plan

Tool 16: SWOT Analysis

Tool 17: Constraints Mapping

Tool 18: Goals Achievement Matrix (for multisector prioritization and prioritization for urban infrastructure projects [CIIPP tool kit])

\footnotetext{
1 ADB. 1999. Guidelines for the Economic Analysis of Water Supply Projects. Economics and development resource Center. Manila. http://www.adb.org/sites/default/files/institutional-document/32759/files/economicanalysis-water-projects.pdf
} 


\section{IMPLEMENTATION POINTERS}

- National and local governments with private sector support can enter into working relationships as retainers with local governments.

- The assessments are to be targeted to clarify issues related to inclusive urban development and provide guidance as to how to address the local context.

- The assessments will focus on urban and vulnerability assessments. The urban assessments include finance and credit, shelter, basic urban services, historic urban areas conservation, slum upgrading, and mitigation infrastructure assessments. The vulnerability assessments include climate change impacts, disaster risk management, and hot-spots assessments.

- The assessments of urban infrastructure, including mitigation infrastructure, the shelter sector, and transport, and vulnerabilities, including climate change impacts on the existing and future growth of built environments, and multihazard impacts and management, were considered as baseline assessments.
- Consultation builds confidence and credibility in the process to establish priorities. Consultations can be focus groups and/or workshops and interviews with targeted stakeholders to validate and verify the priorities identified.

- Partnering with local technical institutes or universities on climate change and other issues is useful. The inclusive urban development agenda could be built into the curricula of institutes and universities as a core social development activity or data collection exercise. Inquiries and information to be gathered relate to deciphering and discerning issues and opportunities that offer products and services to the poor. For example, in the Philippines, for the Manila Bay Environmental Management Project, a memorandum of understanding betwen the Department of Environment and Natural Resources and the universities was signed to allow the students to gain credits for joining in the coastal and river cleanup activities as part of the National Service Training Program. This facilitates a deeper understanding and builds the capacity of the residents in the community to ensure the sustainability of the cleanup initiatives.

\subsubsection{Phase 3: Cross-Sectoral Prioritization and Project Programming}

To achieve IUD and inclusive cities, this phase will establish specific objectives for economic, social, and environmental management that support the attainment of the vision and/or mission manifested in the inclusive city development strategy.

\section{Objectives}

- To provide an illustrative set of projects that address issues and opportunities in improving the existing built environment and future growth based on the information and priorities identified in Phases 1 and 2.

- To present information on commercially viable projects as a means of raising resources domestically to continue scaling up successful $A D B$ projects with finance from DMCs as seed capital. 


\section{Approach}

- Based on the priorities and strategies agreed upon in the previous phase, prepare capital investment projects on a "commercially viable" basis to recover capital costs as well as cover maintenance and expansion of the service systems developed.

- To consider cost recovery as a system-wide issue as opposed to charging fullcost recovery for projects for the poor when the middle and upper classes have received service on a subsidized basis.

- To prepare training and capacity-building programs to support the capital improvements and management of the systems and services provided.

- To build IUD portfolios for improvements in the existing built environment and for the future growth of target cities.

- To develop a project approval process that demonstrates accessibility, affordability, resilience, and sustainability.

\section{Process}

1. Conduct cross-sectoral prioritization and investment programming:

- Scope: To outline the strategic options to address the sectoral needs based on the inclusive urban needs assessment.

- Review: Recommend a set of priorities to be developed into projects and investments.

- Conduct a cross-sectoral prioritization and investment programming workshop, including all key stakeholders, such as the national and local government entities, the private sector, NGOs, and community groups, to identify priority projects and programs with an inclusive focus. Reach a consensus. Draw up a short list of projects and programs.

- Finalize the report on prioritized projects and strategic options for IUD in the city.

Output: The key output for this phase is an inclusive urban renewal program (Figure 6).

For detailed guidance project development, see the following:

Tool 19: Inclusive Urban Development Project/Program Preparation

Tool 20: Basic Urban Infrastructure Program

\section{Expected Results}

- A set of priority project profiles to be prepared as detailed project reports

- Proposed technical and planning innovations in project design and development

\section{Finance:}

- The project development process is a joint ADB-DMC enterprise.

- For commercially viable projects, the costs of project development and preparation should be recovered in the fee structure, where possible.

- National and state-level project development for public-private partnerships and investments funded by the private sector is a more rational use of national and local funds than fully funding projects that can be financed by bonds or loans. 
Figure 6: Approach to Cross-Sectoral Prioritization and Project Programming

\section{Cross-Sectoral Prioritization and Project Programming}

\section{Inclusive Investment Priorities by Sector}

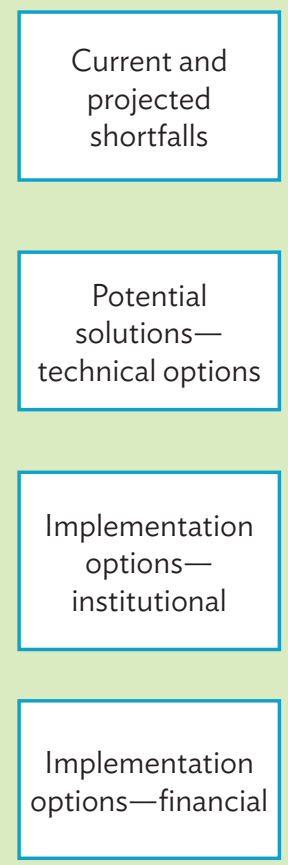

\section{Project Programming \\ Cross-Sectoral Prioritization and Investment Programming}

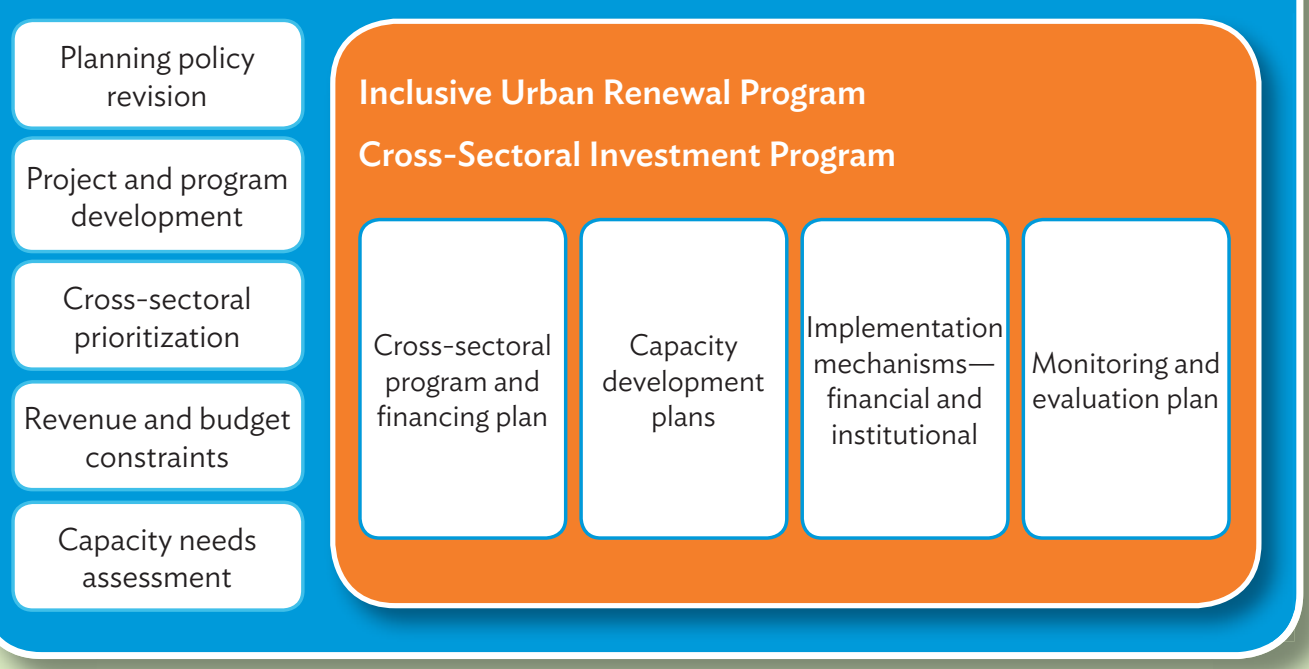

Source: Authors.

\section{Sustainability}

- Commercially viable projects are by definition sustainable.

- The projects that can be taken to the domestic capital market for financing can derive their sustainability from a basket of resources that cover project development costs, and the operation and maintenance as well as expansion of a system. Should a project not go forward, the national and/or state entity absorbs the costs; a much lower expenditure and risk than fully financing capital investment projects.

- The project development process is a logical conclusion to the ongoing work of line agencies that follow the tool kit.

\subsubsection{Undertaking Inclusive Urban Development Projects}

Developing IUD projects will thus include the following processes:

(i) Understanding the context and the issues to establish priorities an inclusive project would address. This will require that there be an information base available to inform project design and implementation, highlighting the needs and 


\section{IMPLEMENTATION POINTERS}

- An illustrative list of capital investment and training projects that may be identified for the existing built environment includes retrofit programs for site protection, urban systems upgrading, landscape restoration and housing, historic urban area conservation and upgrading, slum upgrading, and resettlement and environmental restoration.

- An illustrative list of capital investment and training projects that may be identified for the future growth of cities includes basic urban services, mitigation and adaptation infrastructure, new shelter options, urban roads and transport, and urban environmental protection.

- $\quad$ Single-purpose projects can be designed as problem-solving projects that address specific needs and are initiatives that are started and completed.
- Integrated urban development projects that are more comprehensive in design and implementation may be best considered as programs and systems that once started continue to provide services to meet new demands.

- The difference between a "project" and a "system" has implications for the institutions responsible for policies, design, and implementation.

- Cost recovery for urban services should be spread across the larger system of which a project is a part.

- Inclusive urban development can feature incrementally developed networks for water and sanitation as with shelter that reflects the affordability of the user and the provider.

capacities of the poor, with extensive consultation with stakeholders (including exports and potential project financiers).

(ii) Basing project and program development on the "affordability" of the proposed initiatives. This includes the affordability of the client, especially the poor, to acquire and/or pay for a service and/or shelter solution, as well as the affordability of the provider to operate, maintain, and expand the service provided.

(iii) Proposing solutions that can be incrementally developed or can fit the capacity to pay for and manage the systems and services provided.

(iv) Carrying out consultations between the providers and/or developers, on the one hand, and the community, family, and/or individual, on the other, participating in the program as an integral part of the project design process. Consultations are opportunities to learn to listen to potential beneficiaries as partners in the development process.

(v) Offering capacity building and training in improved, resilient construction technologies: citywide and community-scale water supply, sanitation, and solid waste management. 
For a project to be "inclusive," the following criteria should be met:

(i) The project must demonstrate improved quality of life and/or improved income opportunities for the poor or the vulnerable. Increasing the access of marginalized families and local entities to improvements, products, and livelihood training will require information on marginalized and vulnerable groups, lapses in service delivery, capacity, product development, and systems management.

(ii) Project design must be based on the "capacity to pay" of the targeted population. Affordability will be demonstrated based on the capacity of a family to pay for shelter and services. This in turn will require a range of options affordable to the whole target community. Project design will also demonstrate the capacity of a city or a community to pay for managing, operating, maintaining, and expanding the proposed services to be developed.

(iii) Project technical and management solutions must be based on available resources and skills as well as the incremental development of solutions and systems as required. An inclusive project will accommodate the skills levels and financial capacity of targeted families and governance units responsible for maintenance and growth of capital improvements and investments of a project. 


\section{TOOLBOX}

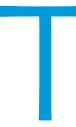

he tools in this section are grouped to follow the process of understanding the urban context, prioritization and options, and project programming. The toolbox includes assessment methodologies, implementation tool kits, and other resources and contains an inventory of tools to collect, structure, and analyze data for the various steps in the process. The inventory draws on tools referenced in the National Urban Assessments Manual and the competitive cities tool kits that have relevant application at the city level (Naik Singru and Lindfield 2016; Roberts 2015).

To strengthen analytical skills with particular focus on the poor and the vulnerable, the World Bank sourcebook on Poverty and Social Impact Analysis presents a framework and tools for institutional, political, and social analysis at the national level (World Bank 2007). Given the array of tools available, it is important that tools be used selectively, considering that a feasible framework for macro-level analysis requires the scope of the study to be kept manageable. The premise of this tool kit is that sector-specific studies and assessments are conducted in an ongoing manner by multilateral or bilateral development agencies. Extensive data and information are available from such studies. The aim of the inclusive assessment is not to replicate such assessments but to collate information and data from existing studies pertinent to the urban sector and update them as appropriate. Where applicable, the inventory links tools to the original resource websites for detailed information, manuals, and guidelines on application and best case examples. Additional information on other available tool kits is provided in Annex 2. For consistency, the tools have been presented using a standard template used for the National Urban Assessments Manual and competitive cities tool kit, as shown in the format below.

Tool \# Name of Tool

Objectives:

\section{Flowchart Reference}

Flowchart Reference

\begin{tabular}{|l|l|}
\hline \multicolumn{2}{|l|}{} \\
\hline Approach: & \multicolumn{2}{|l|}{ Insert Graph (if any): } \\
\hline Steps: & Sustainability: \\
\hline Auxiliary Steps (if any): & \multicolumn{2}{|l|}{} \\
\hline Expected Results: & \multicolumn{2}{|l|}{} \\
\hline Resources: & \multicolumn{2}{|l|}{} \\
\hline Pointers for Implementation: & \\
\hline References:
\end{tabular}




\subsection{Inventory of Tools}

Tool 1: Poverty and Vulnerability Assessment

Tool 2: Policy and Standards Review

Tool 3: Institutional Mapping and Capacity Needs Assessment

Tool 4: Municipal Checklist

Tool 5: Stakeholder Analysis

Tool 6: Problem Tree Analysis

Tool 7: Municipal Finance Assessment

Tool 8: Income and Affordability Analysis

Tool 9: Pro-Poor Shelter Strategy

Tool 10: Citizen's Report Card

Tool 11: Urban HEART

Tool 12: Integrated Disaster Risk Management in Inclusive Urban Development

Tool 13: Climate Change Impacts, Resilience Options, and Indicative Costs

Tool 14: Inventory of Projects/Programs and Investments

Tool 15: Capacity Needs Assessment and Capacity Development Plan

Tool 16: SWOT Analysis

Tool 17: Constraints Mapping

Tool 18: Goals Achievement Matrix

Tool 19: Inclusive Urban Development Project/Program Preparation

Tool 20: Basic Urban Infrastructure Program

Tool 21: Shelter/Upgrading Program

Tool 22: Shelter Program-Retrofitting Existing Structures and Urban Infrastructure

Tool 23: Shelter Program-Revitalization of Historic Areas

Tool 24: Shelter Program/Resettlement

Tool 25: Shelter Program-New Shelter Options/Sites and Services

Tool 26: Addressing Future Growth: Inclusive New Infrastructure and Guided Land Development 
Tool 1: Poverty and Vulnerability Assessment

Flowchart Reference-Phase 1: Urban Context City Poverty and Vulnerability Profile

\section{Objectives:}

- $\quad$ To support the preparation and/or consolidation of a city poverty and vulnerability profile (CPVP) to inform project planning and implementation

\section{Approach:}

- $\quad$ Consolidate the CPVP through data gathering and mapping, including an annotated city base map, a sociocultural map, a vulnerabilities/spatial risk data map, and a future urban expansion map. These should all be included in the master plan.

- Review policies and standards for their reference to and impact on the ability of projects to be inclusive, resilient, and sustainable (Tool 2).

- $\quad$ Undertake an institutional assessment and mapping (Tools 3 and 7).

- Include a municipal checklist in the assessment (Tool 4).

- Conduct a stakeholder assessment and facilitate a stakeholder workshop to gather their inputs on the needs and priorities of the communities. This can be done citywide and in focus groups to discuss the needs of specific communities (Tool 5).

- Identify and carry out topical assessments of affordability and capacity to pay of target families to guide project planning for shelter, urban services, and historic urban areas (Tool 8).

Steps:

1. Scope: Undertake preliminary/scoping work in the city, including an analysis of its role in the national urban system.

2. Review: Conduct a comprehensive review of available literature on the urban sector policies and regulatory framework and city development strategies, programs, and projects utilizing published works, evaluation studies, and project reports, identifying the determinants of a successful urban economy and poverty-alleviating growth, laying particular emphasis on the identification of mechanisms that build the assets and incomes of the poor (Tool 3).

3. Baseline audit studies: Develop a list of key basic information data that should be collected about the city. Compile quantitative and qualitative baseline information at the city/urban level to place the city in the national and urban region economy. The data and information collected and analyzed, including digital maps and imagery, should be stored in a database or a city information base as part of the CPVP to enable updating of the information. Establish an e-database for storing all the data. This database will be part of the project management information system. (see Annex 1 for the recommended urban indicators).

4. Generate a spatial analysis to capture the key urban economic, environmental, and social development challenges. Produce a set of tables and graphs showing basic socioeconomic information:

- Level of urbanization and urban hierarchy of the city in the urban region and at the national level

- Poverty profile-Human Development Index and Gini coefficient at the national level

- $\quad$ Basic indicators of urban poverty and inequality:

(i) Urban poverty incidence and poverty rate-number of poor individuals/households and percentage of individuals and/or households below the poverty line

(ii) Urban Gini coefficient

(iii) Location of the urban poor

(iv) Characteristics of the urban poor

(v) Access to urban services - shelter, water, sanitation, solid waste facilities, transport, etc.

- $\quad$ City-level spatial analysis:

(i) City base map indicating informal settlements and slum areas

(ii) Sociocultural map that indicates informal settlements or environmental hot spots

(iii) Multihazard maps and future growth map that indicates available land for resilient development

- Inclusive economic analysis: place of the urban poor in the economy, place of the rural poor in the hinterland; employment and income-jobs and livelihoods, business/small and medium-sized enterprises support and finance

- $\quad$ Education and qualification levels

- Grants, budgets, and capital expenditure of public agencies

- Level of health care and vulnerability to sickness due to physical environment

- $\quad$ Land use and status of housing 
5. Validation: Validate any existing city development strategy or city development plan based on the following assessment criteria (Tool 2):

- Time frame of the study and relevance

- Specificity and realism of the vision (including policy constraints)

- Nature of consultations carried out during preparation of the plan

- Action plans identified to achieve the strategy

- $\quad$ Programmatic planning of investments (rolling plans) and realistic prioritization

Auxiliary Steps (if any):

- $\quad$ Organize or contract a team to prepare the city profile.

- Assign responsibilities for data gathering and mapping.

- Gather and review existing information to identify gaps and guide the team in the preparation of needed information. If there is very little data available, it will be necessary to conduct socioeconomic surveys to collect baseline information. A household survey questionnaire should be designed.

\section{Expected Results:}

Prepare the CPVP as a report to present the city's priorities to donors, national governments, and nongovernment organizations (NGOs).

- The report should include the city profile, poverty and vulnerability baseline data and analysis, inclusive economic analysis, major asset inventory of infrastructure, and baseline data on access to urban services.

- The spatial analysis outlined in the master plan should include the following:

(i) Focused baseline information, spatial distribution, and graphic data on informal settlements, historic urban areas, and slum settlements. Location and distribution of the urban poor communities, vulnerable communities, and minority groups, and gender analysis

(ii) An updated set of annotated utility maps for coverage of urban services, such as water supply, sewerage, drainage, electricity, etc., that support inclusive, sustainable, and resilient development. These can be supported by the income and affordability analyses to support planning for future infrastructure

(iii) Status of infrastructure assets in poor areas; delivery of services (formal and informal); and access, cost, and collection systems for services (formal and informal)

(iv) Infrastructure requirements and gaps in service delivery

(v) Location of areas and poor communities vulnerable to disasters and climate change impacts; identification of adaption and mitigation infrastructure needs

- An institutional home for a city information base with dedicated staff and budget

- Involvement of relevant partners and working partnerships with local technical institutes and universities or private sector organizations to provide specialized information, especially climate change predictions and projections

- Consensus on key issues leading to a framework agreement

\section{Resources:}

- The Asian Development Bank with resources from developing member country programs as seed capital for the CPVP initiative.

- Local governments to create dedicated sources for CPVP updates and mapping.

- $\quad$ Project team and engagement with stakeholder resources are required to use this tool.

- $\quad$ Purchase of data and setting up of database to capture information will need to be factored into the budget. If additional socioeconomic data are to be collected, this endeavor should be costed.

\section{Sustainability:}

- Local government will need to establish a budget line item for the CPVP staff, for undertaking outreach and information updates and development.

- A "home" for the CPVP in the local government should be established. Support from local NGOs, community groups, and universities is key to keeping the CPVP current and available through outreach. 


\section{Pointers for Implementation:}

- The PFS User Manual (CDIA and UN-Habitat 2012) is a useful step-by-step guide that can be useful in many of the steps within the CPVP.

- Information to be consolidated may exist in offices scattered across government agencies. Make sure permission has been obtained to collect data from government agencies and that the data are consistent in terms of time periods.

- City-scale maps are useful for overview and systems development. Community-level maps are useful for upgrading and improvement projects as well as vulnerability and disaster risk management mapping.

- $\quad$ For community-level mapping, NGO support will be useful to support community groups in preparing their maps as requested. Tools such as the Participatory Approach for Safe Shelter Awareness (PASSA) developed by the International Federation of Red Cross and Red Crescent Societies and applied by Habitat for Humanity for community mapping, can be used. (International Federation of Red Cross and Red Crescent Societies, Geneva, 2011)

- Working groups that include a wide array of stakeholders will benefit the process for the participation they represent and the support they can provide.

- Focus groups need to be organized for specific information on slum settlements and new low-cost shelter programs.

- Maps will need to include areas not included before, especially informal settlements and slums.

\section{References:}

J. L. Baker. 2008. Urban Poverty: A Global View. Urban Papers. Washington, DC: World Bank.

J. Baker and N. Schuler. 2004. Analyzing Urban Poverty: A Summary of Methods and Approaches. World Bank Policy Research Working Paper. No. 3399. http://siteresources.worldbank.org/INTURBANPOVERTY/Resources/ analyzingurbanpoverty.pdf

International Federation of Red Cross and Red Crescent Societies, Geneva, 2011. PASSA Participatory Approach for Safe Shelter Awareness http://www.ifrc.org/PageFiles/95526/publications/305400-PASSA\%20manual-EN-LR.pdf

ICLEI. 1998. Environmental Management Instruments for Local Authorities: A Guide for Local Authorities. Freiburg, Germany.

World Bank. 2009. Climate Resilient Cities: A Primer on Reducing Vulnerabilities to Disasters. Washington, DC.

\section{Examples:}

Oxfam. 2009. Urban Poverty and Vulnerability in Kenya. http://www.irinnews.org/pdf/Urban_Poverty_and_Vulnerability_ in_Kenya.pdf

World Bank. 2009. Approaches to Urban Slums: Adaptive and Proactive Strategies. http://info.worldbank.org/etools/ urbanslums/index.html.

\section{Tools for Poverty Mapping and Spatial Analysis:}

The Sourcebook on Tools for Institutional, Political, and Social Analysis of Policy Reform (World Bank 2007) is a useful resource for choosing appropriate methodology and the tools available for development practitioners in conducting poverty and social impact analyses as also for spatial analysis. The methodologies presented in the book can be used to develop the CPVP.

Source: World Bank. 2007. Tools for Institutional, Political and Social Analysis of Policy Reform. Washington, DC: International Bank for Reconstruction and Development/World Bank. 
Tool 2: Policy and Standards Review

Flowchart Reference-Phase 1: Urban Context

\section{Objectives:}

- To assess the operational constraints in the enabling environment supporting an inclusive urban development (IUD). Identify and assess the main policy and governance issues, with a bearing on the planning, programming, structuring, and marketing of infrastructure investment programs and projects, and make recommendations for policy reform. The city is responsible for ensuring adequate information and reports are made available.

\section{Approach:}

Understanding the policy framework and institutional capacity for inclusive planning; and reviewing policies and standards for their reference to and impact on the ability of projects to be inclusive, resilient, and sustainable. The policy and standards review looks at the policy and regulation context (or "enabling environment") and the decision-making processes.

- Review: Conduct a comprehensive review of available literature on the urban sector policies and regulatory frameworks, and city development strategies, programs, and projects utilizing published works, evaluation studies, and project reports, identifying the determinants of a successful urban economy and poverty-alleviating growth, laying particular emphasis on the identification of mechanisms that build the assets and incomes of the poor. Review the policies of the urban infrastructure sector to determine their positive and/or negative guidance for providing urban services to the poor. Also, review the policies that support strengthening the resilience of vulnerable populations from disasters and climate change.

- Validation: Validate any existing city development strategy or city development plan based on the following assessment criteria:

a. Time frame of the study and relevance

b. Specificity and realism of the vision (including policy constraints)

c. Nature of consultations carried out during the preparation of the plan

d. Action plans identified to implement the strategy

e. Programmatic planning of investments (rolling plans) and realistic prioritization

\section{Steps:}

1. Create a Policy and Standards Review Working Group.

2. Identify and contact government agencies responsible for the preparation and implementation of policy and technical and development standards that impact IUD programming.

3. Assign specific responsibilities to team members to document and summarize policies and standards.

4. Organize information gathered in an IUD Policy and Standards Guide.

5. Organize a workshop with key entities to initiate a discussion on IUD policy and standards on a way forward:

(i) Identify policy and standards modifications for the development of IUD programs.

(ii) Identify and summarize national and local standards and policies of institutions that impact IUD and improve the existing urban environment and the future growth of cities.

(iii) Carry out consultations with stakeholders on policy and standards implementation and compliance to identify both support for and obstacles to engaging in IUD.

(iv) Identify through assessments and consultations with stakeholders improvements in policy and standards that support IUD, affordability, and incremental development of shelter and services.

(v) Identify policies that address disaster risk management (DRM) and assess if they are integrated into IUD project development.

(vi) Prepare a policy review and a policy reform agenda in support of IUD. Make recommendations on how to integrate DRM into IUD policies.

Auxiliary Steps (if any): Analysis of country context

Country context analysis is important because policy reform takes place in a particular context and not in a historical vacuum. Understanding the country context better means investigating and assessing the inherited and evolving mix of political, economic, and social variables that influence policy agendas and change. Concepts such as "lack of political will" that are often used to describe these situations are inadequate because, although they identify a problem, they fail to explain the reason for these failures or to suggest viable solutions. Conditionality, associated with development assistance and intended to change the behavior of recipient governments, is a blunt instrument. Aid effectiveness increases when aid supports national efforts, making the local situation the point of departure, rather than preconceived policies. This means giving greater attention to analysis of the country context and the ways in which it is changing (World Bank 2007). 


\section{Expected Results:}

- A report on the policy and regulatory framework that summarizes identified policies and standards that impact the ability of local governments to prepare and implement IUD. Recommendations can span the need for further policy and strategy development.

- A workshop that focuses on improving policies to support the development of IUD projects and develops an approach to integrating DRM and climate change adaptation into IUD project planning and development.

- Identification of institutional bottlenecks - that delay or prevent timely infrastructure delivery-provides an agenda for onward institutional and governance reforms (Tools 3 and 4).

\section{Resources:}

- The Asian Development Bank and developing member countries (DMCs) can undertake the policy reviews during country partnership strategy preparations.

- Local governments assign resources to assess capacities from their human resources budget.

\section{Sustainability:}

- The IUD working group, established to continue the initiatives that the Asian Development Bank with DMC partners supported, will meet at least annually to review results and update information.

- $\quad$ DMC and local government sponsors will support with staff and fund annual events.

\section{Pointers for Implementation:}

- Consult government line agencies at the national, state, and local levels.

- Collate official policy statements into an IUD policy guide.

- Create a dialogue with appropriate agencies in focus group sessions to review and make recommendations for IUD supportive policies, as needed.

- Policy summaries should include urban growth, social development, housing, slum upgrading, home improvement, environmental management, historic urban area conservation, transport, and finance and credit.

- Maintain the focus of "inclusive" in amending current policy or creating new policies for agencies at the national and local levels.

- The experiences and "lessons of history" of other countries regarding development and poverty reduction can provide insights and learning for current international development.

\section{References:}

ADB. 2008. Managing Asian Cities. Manila.

Cities Development Initiative for Asia (CDIA) and UN-Habitat. 2012. Pre-Feasibility Studies (PFS) User Manual. Manila.

Cities Alliance. 2006. Guide to City Development Strategies: Improving Urban Performance. Washington, DC.

World Bank. 2007. Tools for Institutional, Political and Social Analysis of Policy Reform. Washington, DC: International Bank for Reconstruction and Development/World Bank.

\section{Examples:}

ADB. 2006. Urban Sector Strategy and Operations Evaluation Study, Operations Evaluation Department. Manila. p. 14.

R. Buckley and J. Kalarickal. 2006. Thirty Years of World Bank Shelter Lending. What Have We Learned? Washington, DC: World Bank.

F. Steinberg. 2008. Revitalization of Historic Inner-City Areas in Asia: The Potential for Urban Renewal in Ha Noi, Jakarta, and Manila. Urban Development Series. Asian Development Bank. Manila.

United Nations Development Programme. 1996. Living in Asian Cities: The Impending Cities-Causes, Consequences and Alternatives for the Future. Report of the Second Asia-Pacific Urban Forum. New York, NY.

United Nations Human Settlements Programme (UN-Habitat). 2006. State of the World's Cities 2006/7. Earthscan.

UN-Habitat. 2010. State of the World's Cities: Bridging the Urban Divide 2010/11. Earthscan.

World Bank. 2009. Urban and Local Government Strategy: Systems of Cities: Harnessing Urbanization for Growth and Poverty Alleviation. Washington, DC. 
Tool 3: Institutional Mapping and Capacity Needs Assessment
Flowchart Reference-Phase 1: Urban Context Institutional and Governance Assessment

\section{Objectives:}

- To assess the operational constraints in the enabling environment supporting an inclusive urban development.

- To conduct an institutional and governance assessment and develop an institutional map to inform project planning and implementation.

- To identify and assess the main institutional and governance issues with a bearing on the planning, programming, structuring, and marketing of infrastructure investment programs and projects, and make recommendations for enhancing the capacity of the city government and identifying the context for infrastructure investment. The city is responsible for ensuring adequate information and data collection.

\section{Approach:}

Institutional mapping is part of the institutional and governance assessment, as defined in Phase 1.

A capacity needs assessment identifies areas where planning, programming, structuring, and marketing of infrastructure investment programs and projects can be strengthened (the municipal checklist and the municipal financial assessment is a critical part of the overall assessment): the strategy can span the need for further policy and strategy development to identify formal and on-the-job training for relevant city staff.

\section{Steps:}

1. Undertake an institutional assessment.

2. Institutional mapping: Outline the institutional structure, roles, and responsibilities of the different tiers of government involved in urban service delivery. This should comprise an organizational diagram (an "organogram") that illustrates the structure, hierarchy, and the overall staffing numbers of the city government, together with simple tables that record basic information.

3. Capacity needs assessment: Undertake an assessment of capacity-building needs in planning, programming, structuring, and marketing infrastructure. This will provide baseline information on staff capacity (skills, knowledge, and experience). The assessment might also include reflections on the overall relevance of the city government structures (such as the presence or not of relevant departments or units) for infrastructure planning and programming. Record relevant recent training received by city representatives and officers (CDIA and UN-Habitat 2012).

\section{Expected Results:}

- A broader and more detailed understanding of infrastructure planning and programming builds future competence in project programming and investment cycles.

- Organizational strengthening - through building the capacity of staff, modifications in organizational structure, and policy and regulatory development - has broader positive ramifications on the efficiency in planning and managing the city.

- Identification of institutional bottlenecks - that delay or prevent timely infrastructure delivery-provides an agenda for onward institutional and governance reforms.

- An emphasis on including a range of stakeholders in an analysis of governance issues helps focus attention on the urban poor groups that are often excluded from decision-making processes and/or are negatively affected by the delivery of infrastructure.

\section{Resources:}

- Developing member country resources for urban development programs can be supported by ADB to prepare the city poverty vulnerability profile as part of investment programming.

- Local governments assign resources to assess institutional capacities from their human resources budget.

\section{Sustainability:}

Understanding how the city is managed is critical to estimating the sustainability of proposed infrastructure investments, and urban management. 
Pointers for Implementation:

- Institutional mapping is an important exercise to understand the internal working of government. This should be done in consultation with the agencies involved. While the organogram may show a reporting relationship, it is essential to know if there are reporting mechanisms in place and if relevant agencies are in contact with each other. Often, it is seen that they tend to work in silos, and it is important to draw them into discussion to prepare inclusive and integrated projects.

- $\quad$ Do not reinvent the wheel. Institutional and governance assessments may have already been completed by the city, or other concerned institutions or organizations (central government, donors, nongovernment organizations, or the academe). These can be identified (often through webbased searches), adapted, and verified for the city.

\section{Sample Format:}

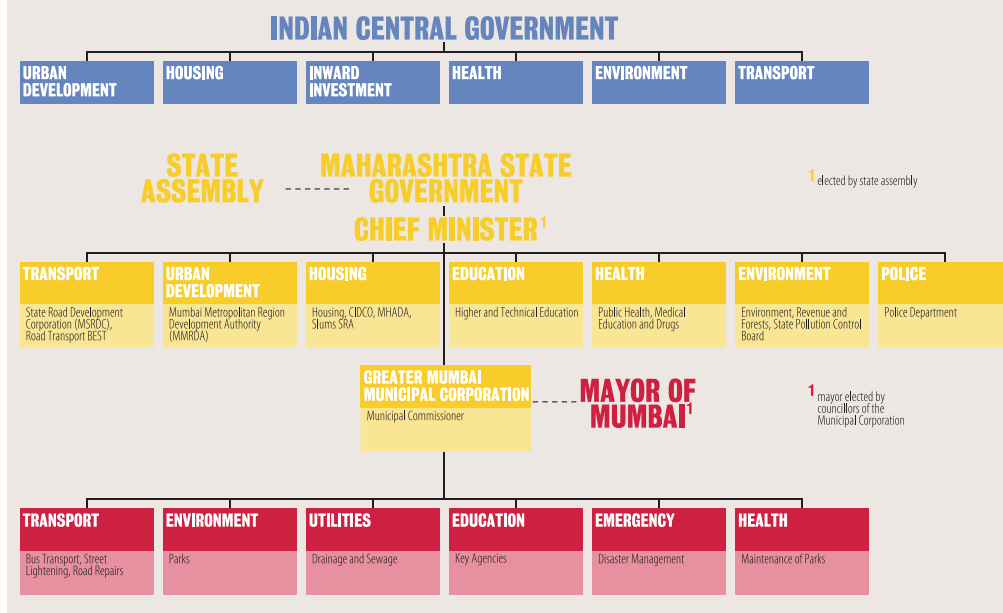

Source: Urban Age. 2007. Urban India: Understanding the Maximum City. London: London School of Economics.

\section{References:}

ADB. 2008. Managing Asian Cities. Manila.

Cities Development Initiative for Asia (CDIA) and United Nations Human Settlements Programme (UN-Habitat). 2012. Pre-Feasibility Studies (PFS) User Manual. Manila: CDIA.

Cities Alliance. 2006. Guide to City Development Strategies: Improving Urban Performance. Washington, DC.

World Bank. 2007. Tools for Institutional, Political and Social Analysis of Policy Reform. Washington, DC: International Bank for Reconstruction and Development/World Bank.

\section{Example:}

Urban Age. 2007. Urban India: Understanding the Maximum City. London: London School of Economics. 
Tool 4: Municipal Checklist

\section{Objectives:}

- To examine the conditions and local realities and provide the necessary information to better design projects through an inclusive and participatory decision-making process.

\section{Approach:}

The aim is to identify municipal strengths, weaknesses, opportunities, and constraints, and to focus on issues of primary concern. The tool, therefore, supports the diagnosis of municipal needs and helps to identify corresponding areas and types of possible intervention. A key principle of the municipal checklist tool is that it facilitates discussion and dialogue with local stakeholders in order to identify the benefits of external support as well as municipal and partner commitments. It should not be perceived as an institutional audit, but rather as a tool to support self-assessment, discussion, and engagement of partners in collaboration.

It forms part of the governance assessment.

\section{Steps:}

1. Analysis and discussion:

a. Level of political will, political capacity, and therefore local political "ownership"

b. Institutional conditions for operationalizing stakeholder involvement

c. Type and relevance of priority issue and scope for improvement

d. Potential for mobilizing local and other resources

e. Existing local capacity for monitoring, and capturing and sharing lessons of experience

2. Terms of reference for a memorandum of understanding

\section{Expected Results:}

The municipal checklist analysis and the local discussion of its outcomes should lead to agreement on the priority issue(s) and on the scope, content, and form of the participatory decision-making process to be applied. This agreement should then be translated into actor-specific and concrete operational procedures and actions, embodied in a formal memorandum of understanding or similar instrument.

\section{Resources:}

- The city government and the city poverty and vulnerability profile team should mobilize stakeholders and interested partners for this collective scrutiny.

- The Asian Development Bank and developing member country governments can collaborate with the national partner organizations of Cities Development Initiative for Asia to support the self-assessment process for city councils.

- Collaboration with development partners.

\section{Sustainability:}

In applying the municipal checklist, the self-assessment process helps city managers and their partners to reflect on their governance structure, operations, and capacities, encouraging them to develop ways of improving local governance within the bounds of what can be realistically achieved. Such collective reflection engages local governments with partners for constructive scrutiny and forward-looking dialogue.

\section{References:}

UN-Habitat. 2001a. From Participation to Partnership: Lessons from UMP City Consultations. Published for the Urban Management Programme. Nairobi.

UN-Habitat. 2001b. Tools to Support Participatory Urban Decision Making. Nairobi. 


\section{Examples:}

The participatory process/city consultation in Colombo, Sri Lanka, stands out from other city consultations in Asia in the areas of complete commitment at the political and administrative levels. National ministers, the provincial chief minister, the chief secretary of the province, the mayor, and the chief city functionaries attended the city consultations. Because of the high level of commitment on all sides, obstacles were absent.

The results of the Colombo City consultation were attributed to the strong support and commitment from all sides, especially to the excellent work and contributions of the local partner institution, SEVANATHA. Founded in 1989, its mission is to provide an improved living environment for the urban poor in Colombo by implementing communitybased resources management and poverty alleviation programs through participatory development approaches. It has been playing a complementary role to the government's development program and has been introducing innovative methods and practices for the development of low-income settlements. SEVANATHA is very strong in working with the community, and through the city consultation process became equally strong in working with the city council. It established excellent rapport with the community as well as the city council and has developed fruitful partnerships with donor agencies working in Colombo (UN-Habitat 2001b). 
Tool 5: Stakeholder Analysis

Flowchart Reference-Phase 1: Urban Context

\section{Objectives:}

- To identify all the stakeholders that are affected (directly/indirectly) or can affect the outcome of any proposed project because opinions matter. Opinions get converted to actions that can lead to opposition or participation that determines project outcome and impact. Stakeholder consultations lead to a consensus-building approach.

Approach:

Stakeholder analysis is a vital tool for identifying those people, groups, and organizations who have significant and legitimate interests in specific urban issues. Stakeholder analysis is an effective development management technique to identify and assess the importance of key people, groups, or institutions that may significantly influence the success of a project. This is the first step in scanning the city landscape. It will help in identifying key target groups/beneficiaries and spatial areas for targeted interventions. The exercise called mapping produces a stakeholder matrix that provides information on the degree of influence exercised by an individual or group on the outcome of the project. This exercise is part of the city profiling/reconnaissance activity. It is conducted as an important part of the situational analysis.

\section{Steps:}

Facilitate a stakeholder workshop to gain an understanding and gather inputs on the needs, expectations, and priorities of poor communities. This can be citywide and in focus groups to discuss the needs of specific communities.

1. Identify all stakeholders and the degree of interest of each stakeholder. Ensure inclusion of all relevant stakeholders. This stakeholder analysis tool encourages a far-reaching review of all potential stakeholder groups, including special attention to marginalized and excluded social groups such as the poor, women, elderly, youth, disabled, or others.

2. Maximize the role and contribution of each stakeholder.

3. Identify the key spatial areas and target groups/beneficiaries for targeted investments.

4. Define the sector focus for intervention. Through a problem tree analysis, identify key problems, issues, and constraints. Understand their views of the main issues and concerns with due consideration of acceptable and potential responses.

5. Provide, if available, clear information and details on any proposed project, including technical options, costs, and financial implications for the same.

6. Specify the resources that stakeholders have to consider while estimating their ability to support the inclusive urban development process (during and after). Identify the potential for employment and livelihood options for the affected community during construction, operation, and maintenance of the project or program. For example, during the Pasig River cleanup and rehabilitation of Estero de Paco by the Pasig River Rehabilitation Commission in Manila, the poor community living alongside the waterway enrolled into the River Warriors program, where they were taught to clean the estero and maintain the linear pathways alongside the river. This provided them a livelihood as well as ensured participation in the cleanup and acceptability of the project.

7. Ensure that the stakeholders' mandates are understood and that their "stake" (legal right, power and capacity) in the process is recognized.

8. Map the stake and influence of each stakeholder on a simple chart.

9. Identify sectoral issues and feed into the sectoral assessments. Identified spatial areas and communities for targeted investments will be input during the prioritization phase.

Auxiliary Steps (if any):

See 2.2 Stakeholder Analysis Tool in Tools to Support Participatory Urban Decision Making (UN-Habitat 2001) and the PFS User Manual (CDIA and UN-Habitat 2012) for further guidance.
Influence-Interest Matrix:

\begin{tabular}{|l|l|l|}
\hline \multirow{2}{*}{ Low Stake } & Low influence & High Influence \\
\cline { 2 - 3 } & $\begin{array}{l}\text { Least priority } \\
\text { stakeholder group }\end{array}$ & $\begin{array}{l}\text { Useful for decision } \\
\text { and opinion } \\
\text { formulation, } \\
\text { brokering }\end{array}$ \\
\hline High stake & $\begin{array}{l}\text { Important } \\
\text { stakeholder group } \\
\text { perhaps in need of } \\
\text { empowerment }\end{array}$ & $\begin{array}{l}\text { Most critical } \\
\text { stakeholder group }\end{array}$ \\
\hline
\end{tabular}




\section{Expected Results:}

Report on stakeholder interests, priorities, and capacity. Include the identified stakeholders' availability and degree of commitment to meaningful participation in the process. Identify key target groups/beneficiaries and spatial areas for targeted interventions.

Strategize for project implementation and for mobilizing and sustaining effective participation of stakeholders.

Such strategies should be tailored to suit the different groups of stakeholders as analyzed and classified in the abovementioned Influence-Interest Matrix. For example, empowerment strategies could be applied to those stakeholders with high stake but little power or influence.

\section{Pointers for Implementation:}

- If a full-scale exercise is not possible, ensure that a first cut is generated by the city and shared with other stakeholders.

- Stakeholder analysis is not an "exact" exercise-it relies on intuition and balanced judgment.

- To ensure a balanced representation, the analysis should examine and identify stakeholders across a number of different dimensions. For example, the analysis should separately identify relevant groups and interests within the public sector, within the private sector (service providers, developers, and construction firms), and within social and community sectors (particularly the poor communities) and potential financial institutions.

- Stakeholder analysis can be conducted independent of the stakeholder workshop. Observations can be made on the group dynamics to ascertain the Influence-Interest Matrix.

\section{Resources:}

A stakeholders' workshop should be organized. Ensure all stakeholders are invited. The city government should provide the resources, venue, and equipment required for the workshop.

Carefully planned and executed facilitation is an essential prerequisite for successful participatory mechanisms. A good facilitator is essential for the workshop and should ideally be one of the experts from the team conducting the city poverty and vulnerability profile.

\section{Sustainability:}

- Helps build a participatory approach right at the start of the process.

- Helps build consensus among the stakeholders and creates the right working environment.

- Best approach to ensure that the strategies developed get the most effective support possible for the project and to minimize any obstacle in the successful implementation of any program.

- Ensures that stakeholders are actively engaged in the prioritization of projects.

- Inclusiveness and the right mix of roles and instruments are key elements of successful stakeholder participation. Where participation is generated through careful analysis of the key players, their roles, and contributions, the process becomes more effective and efficiency as well as equity gains will be maximized.

\section{References:}

Cities Development Initiative for Asia (CDIA) and United Nations Human Settlements Programme (UN-Habitat). 2012. Pre-Feasibility Studies (PFS) User Manual. Manila: CDIA.

UN-Habitat. 2001. Tools to Support Participatory Urban Decision Making. Nairobi.

\section{Example:}

UN-Habitat. 2001. Tools to Support Participatory Urban Decision Making. Nairobi. 


\section{SECTORAL ASSESSMENTS}

\begin{tabular}{l} 
Tool 6: Problem Tree Analysis $\quad$ Flowchart Reference-Phase 2: Sector Assessments \\
\hline Objectives: \\
The problem tree analysis is used to conduct sectoral assessments to identify the constraints and challenges leading \\
to the establishment of priorities and subsequent project development. The problem tree analysis is the first step in \\
understanding and creating a consensus among stakeholders regarding the city's problems, issues, and constraints. This \\
then allows the problems (issues) to be converted into objectives (actions) to define the strategic vision of the city. The \\
city is responsible to ensure transparency in identifying the participants for the design monitoring framework/situational \\
analysis workshop in collaboration with the consultants and the Asian Development Bank. The objectives of the problem \\
tree analysis are to \\
- $\quad$ identify a key problem and its effects (ends) and root causes (means) in economic development; \\
- identify objects and strategies to address identified problems; \\
- $\quad$ prioritize issues, problems, and projects; and \\
- identify key target groups/beneficiaries and spatial areas for targeted interventions.
\end{tabular}

\section{Approach:}

Problem tree analysis is a diagnostic tool used widely by official development assistance that assists in analyzing an existing situation by identifying the major problems and their main causal relationships. This, along with stakeholder analysis, forms the core part of the situational analysis essential in the design monitoring framework. The output of a problem tree analysis is a graphical arrangement of problems differentiated according to "causes" and "effects," joined by a core, or focal, problem. This technique helps understand the context and interrelationship of problems, and the potential impacts when targeting projects and programs toward specific issues. The problem tree is closely linked to the objectives tree, another key tool in the project planner's repertoire.

It involves a participatory process to translate these causes and effects into objectives and strategies to provide planning solutions. The MDF Tool for problem tree analysis has a useful template that is easy to follow for this method of analysis. While going through the process, there is continuously room for introducing opportunities, new ideas, and contributions from the parties involved.

Problem tree analysis should be followed by actual project planning, for example, with the logical framework approach (LFA).

One of the best tools using problem tree analysis was the evaluation situational analysis, strategy prioritization, and project design developed by New Zealand Aid (NZAID 2007). The tool uses a LFA which involves

- $\quad$ the application of robust analysis and a logical approach to activity design;

- $\quad$ the integration of participatory processes;

- $\quad$ the identification of clear and relevant objectives that are agreed to by all parties;

- the identification of inputs and resources and explaining how these will be used to achieve the objectives; and

- $\quad$ agreeing upon clear, accountable, and well-defined management arrangements.

These basic principles in the LFA are common to most other bilateral and multilateral development agencies. The LFA can also be used to help promote more harmonized and better-aligned engagement processes. The logical framework matrix is an output of the LFA that summarizes the key elements of an activity:

\begin{tabular}{|l|l|}
\hline Objectives & $\begin{array}{l}\text { The main objectives of the activity, how they will be achieved, and the larger goal to which they } \\
\text { will contribute. }\end{array}$ \\
\hline Assumptions & $\begin{array}{l}\text { The external factors outside the direct control of those managing the activity that is critical for } \\
\text { the activity's success. }\end{array}$ \\
\hline Indicators & The agreed "signposts" that will be used to track progress toward agreed outcomes. \\
\hline $\begin{array}{l}\text { Sources of } \\
\text { verification }\end{array}$ & $\begin{array}{l}\text { An outline of how the information that will be used to measure the activity's success will be } \\
\text { collected. }\end{array}$ \\
\hline
\end{tabular}

Interwoven with the steps of problem analysis (at the target group level) and project planning (for the target group), the capacity and intentions of stakeholders and the wider institutional context should be analyzed, so that relevant and realistic choices can be made on who does what in addressing the problems identified. 
Steps:

1. Start with a brainstorming session on the major problems (or potential problems) impeding the achievement of the desired vision for the city or urban area. Together with the group, choose a starter problem such as inadequate water supply or air pollution. It is important to have a precise definition of the framework and the subject of analysis. Identify the development problem(s) or issues faced by target groups and beneficiaries. Visualize problems in the form of a diagram, called a "problem tree," to establish cause-effect relationships. Draw a tree and write the starter problem on the trunk. If you want to look at more than one problem, then you will need to draw one tree per problem. Encourage people to brainstorm on the causes of the starter problem. To ensure that a few people do not dominate, give each person 3-5 blank cards and ask everyone to write down one idea per card.

2. Define the nature and the underlying cause of the core problem. To focus on the root causes of the problem, discuss the factors that possibly contribute to it. Write these causes on sticky notes. This task is made easier by continually asking the question "Why?" for each of the causes identified. Keep asking "Why?" until you have reached the basic root cause of the problem.

3. Connect the notes with lines to show linkages between the causes. These connections become the roots of the tree.

4. Follow the same procedure to determine the effects/impacts of the problem and write the primary effects on the branches of the tree. Identify improvements that may be made within a given time frame (objectives analysis). The problem tree can be converted into an "objectives tree" by rephrasing each of the problems into positive desirable outcomes. The chart then shows a "means-ends" relationship. For example, "lack of sufficient water" becomes "improve water supply," "clean water" becomes "purification," and so on.

\section{Expected Results:}

- A clear and graphically documented understanding of the root/underlying causes of a particular problem impeding the achievement of a particular objective or vision.

- A better understanding of the causes and effects of the problem, from which participants can further explore driving and/or restraining forces that may be impacting on governance reform.

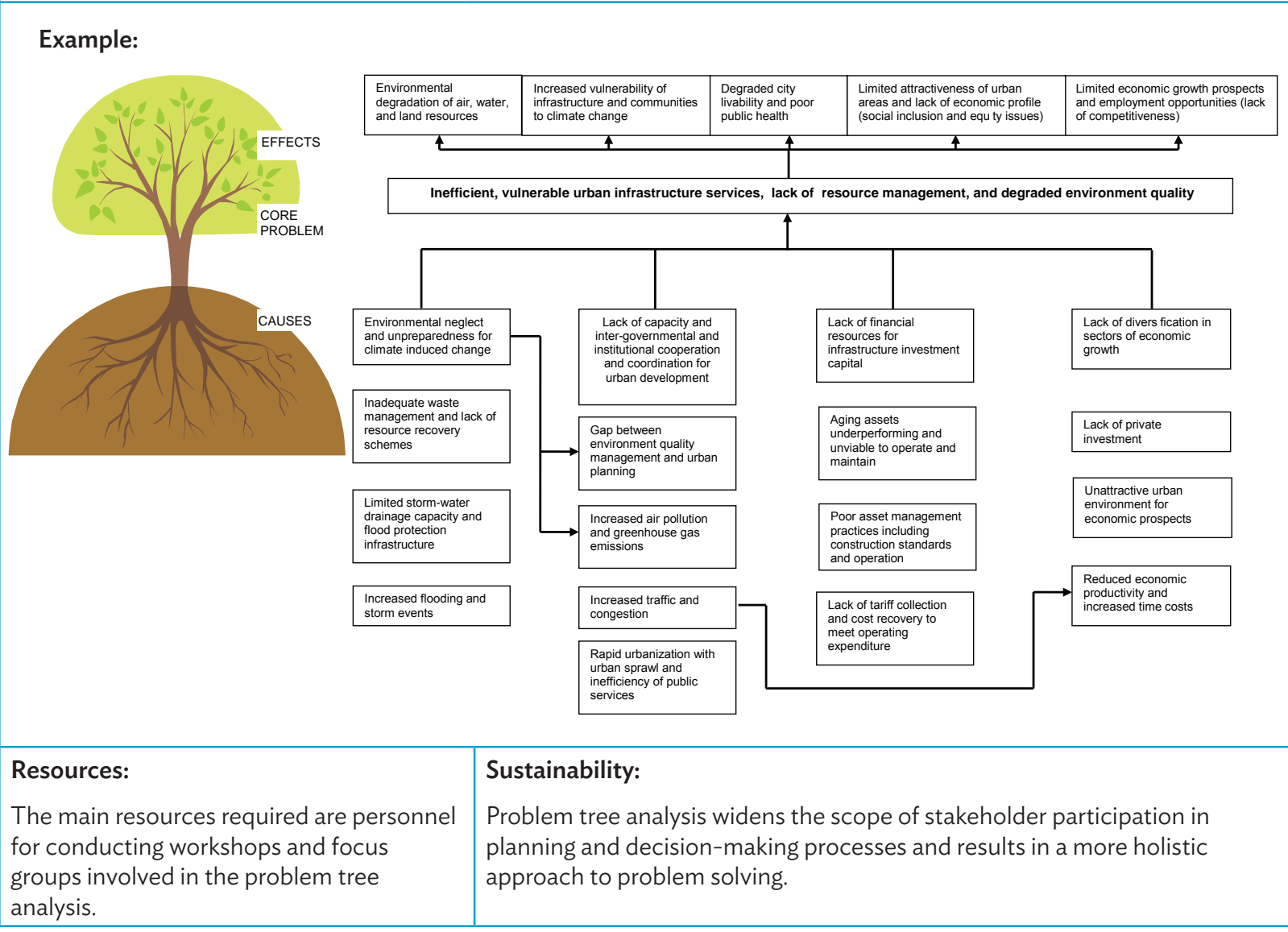




\section{Pointers for Implementation:}

There is often confusion between a cause and an effect: A cause is what starts something; an effect is what happens or is the result of the cause. Care should be taken during facilitation sessions while conducting the analysis to ensure that the

differences between the two factors are clearly distinguished. Discussion questions might include the following:

- Does this represent the reality? Are the economic, political, and sociocultural dimensions to the problem considered?

- Which causes and consequences are getting better, which are getting worse, and which are staying the same?

- What are the most serious consequences? Which are of most concern? What criteria are important to the city in thinking about a way forward?

- What possible solutions or options might there be? Where could a policy change help address a cause or consequence, or create a solution?

- What decisions have been made, and what actions have been agreed upon?

\section{Problem Solving:}

- $\quad$ Choose the right path. Looking from the top down, there could be many paths. Are you viewing the real problem?

- Trace the path thoroughly. Go to the root of the problem and ensure that you do not stop at a superficial level.

- Integrate perceptions. The impact of the analysis is good when prepared through a stakeholder workshop.

\section{References:}

Cities Development Initiative for Asia and United Nations Human Settlements Programme (UN-Habitat). 2012. Pre-Feasibility Studies (PFS) User Manual. Manila: CDIA.

B. Douthwaite, S. Alvarez, K. Tehelen, D. Cordoba, G. Thiele, and R. Mackay. 2009. Participatory Impact Pathways Analysis: A Practical Method for Project Planning and Evaluation. Institutional Learning and Change (ILAC) Initiative. Cali, Colombia: International Centre for Tropical Agriculture. https://cgspace.cgiar.org/bitstream/handle/10568/33649/11.5\%20 Participatory\%20impact\%20pathway\%20analysis.pdf? sequence=1

Government of New Zealand, New Zealand Agency for International Development (NZAID). 2007. NZAID Logical Framework Approach Guideline. Brisbane.

MDF. MDF Tool: Problem Tree Analysis. Washington, DC: World Bank. http://www.toolkitsportdevelopment.org/html/ resources/91/910EE48E-350A-47FB-953B-374221B375CE/03\%20Problem\%20tree\%20analysis.pdf

Overseas Development Institute. 2009. Planning tools: Problem Tree Analysis - Toolkits. London. http://www.odi.org.uk/ resources/download/5258.pdf (accessed 10 June 2012).

World Bank. 2001.Upgrading urban communities: A Resource for Practitioners. Online tools. Washington, DC: World Bank. http://web.mit.edu/urbanupgrading/upgrading/issues-tools/tools/problem-tree.html (accessed 10 June 2012).

\section{Example:}

Government of New Zealand, New Zealand Agency for International Development (NZAID). 2007. NZAID Logical Framework Approach Guideline. Brisbane. 
Tool 7: Municipal Finance Assessment

Flowchart Reference-Phase 1: Urban Context

CIIPP Toolkit (CDIA 2010)

\section{Objectives:}

- To assess the condition of the municipal resources of the city and its capacity to borrow and service any loans.

- To examine the financial resources and options, providing critical information to design commercially viable and sustainable projects through an inclusive and participatory decision-making process.

\section{Approach:}

A municipal finance assessment is an analysis of the city's financial performance to understand the types and amounts of revenues and expenditures, and whether they are adequate to effectively deliver services to the targeted sector as the city's population continues to grow. The analysis also looks at the fund balances and debt levels and their impact on current city financial resources. Municipal finance is the key to the overall progress of service delivery. Poor financial management results in low capital investment, low credibility of the local government, poor revenue generation efficiency, corruption, and ultimately poor delivery of basic services. It also provides an indication of the city's credit worthiness (CDIA and UN-Habitat 2012).

\section{Steps:}

1. Collect financial data, including information about existing financial arrangements, using surveys and/or by extracting data from existing records, such as annual financial reports, budget documents, council resolutions, etc.

2. Identify key indicators or tools and methodologies to be used to measure the financial performance of the city government and analyze the data.

3. Make an inventory of assets owned and managed by the city.

4. Map the financial inflows and outflows and determine budgetary surplus or gaps and show how the gaps were supported.

5. Once it is determined that the city cannot finance future projects, assess the city's potential to generate more revenues by accelerating the growth of own-source revenues or develop strategies to tap additional financing sources.

\section{Sample Graphs:}
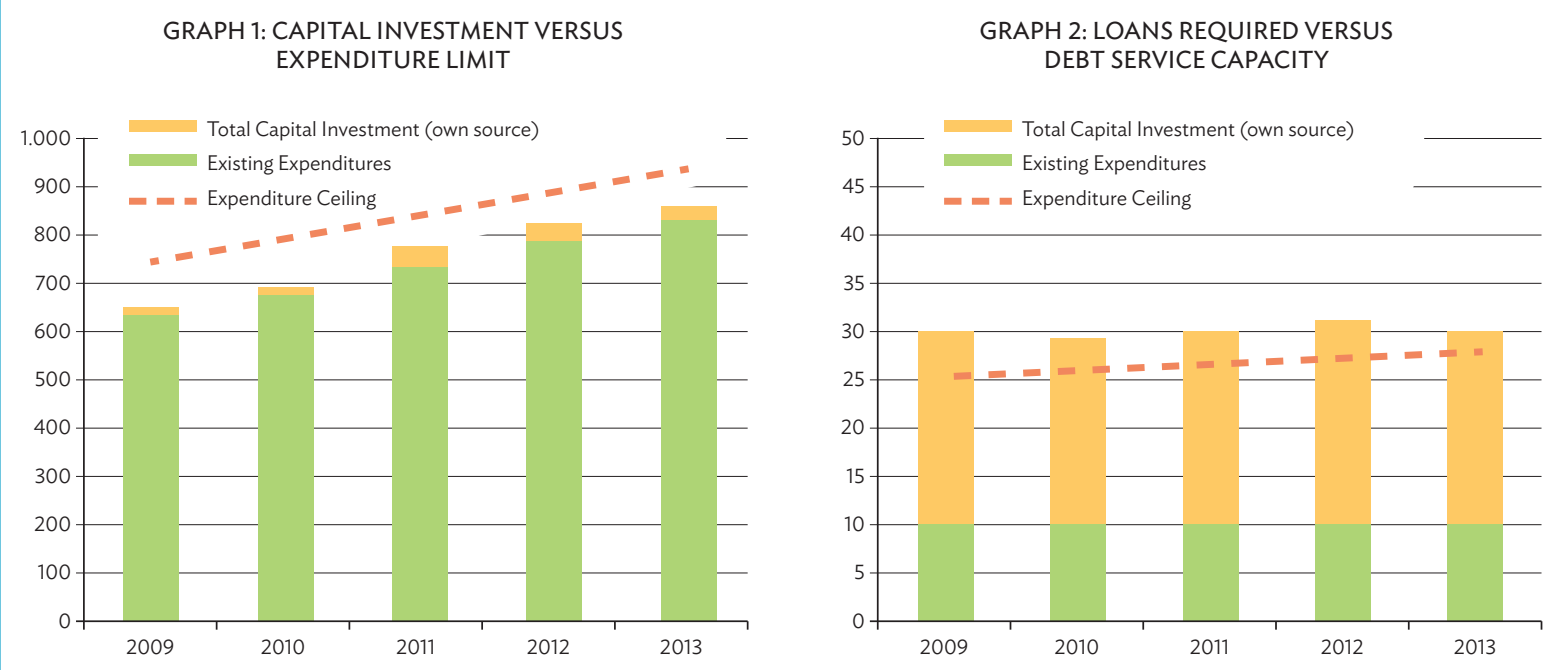

Source: Cities Development Initiative for Asia. 2010. City Infrastructure Investment Programming \& Prioritisation Toolkit (CIIPP). http://cdia.asia/wp-content/uploads/User-Manual-Generic-version-2010.pdf (accessed 31 October 2011).

\section{Expected Results:}

- The municipal checklist analysis and the local discussion of its outcomes should lead to an agreement on the priority issue(s) and on the scope, content, and form of the participatory decision-making process to be applied. This agreement should then be translated into actor-specific and concrete operational procedures and actions, embodied in a formal memorandum of understanding or a similar instrument. 


\section{Pointers for Implementation:}

A checklist can be prepared to ensure that important questions pertaining to inclusive urban development are considered.

- $\quad$ Are current funding sources and methods of raising resources adequate?

- What is the level of current and future government financial support through grants, donations, and loans?

- What additional resources will be required to implement new projects? Is there enough fiscal space for additional expenditure?

- Does the city have the capacity to borrow from financing institutions? Can the city access preferential loans or commercial loans? Are there any dedicated financing for broader poverty reduction strategies that can be tapped for inclusive infrastructure?

- $\quad$ Are there other financing options available to the city? Can the city explore public-private partnership and secure grants from the national government or other donor agencies?

- What is the potential for community-driven development and what are the available financing mechanisms?

\section{Resources:}

- The city government and the team of experts can conduct this exercise. It can be part of the prioritization exercise if not conducted earlier.

- A financial expert is required to conduct the assessment.
Sustainability:

- Continuously improve financial performance. A review of the yearly financial performance and condition provides a platform to benchmark the current performance against past performances and even against other cities. It therefore helps the city determine the extent to which newly introduced reforms, if any, are generating improved performance.

- Self-assessment of own resources. Analyzing the city's cash inflows and outflows helps determine if the current fund balances are sufficient to finance strategic projects or if the city has the ability to raise additional resources.

\section{References:}

Cities Development Initiative for Asia (CDIA). 2010. City Infrastructure Investment Programming \& Prioritisation Toolkit (CIIPP). http://cdia.asia/wp-content/uploads/User-Manual-Generic-version-2010.pdf (accessed 31 October 2011).

CDIA and United Nations Human Settlements Programme (UN-Habitat).. 2012. Pre-Feasibility Studies (PFS) User Manual. Manila: Cities Development Initiative for Asia.

\section{Example:}

United States Agency for International Development (USAID). 2011. Guidebook: Developing Sustainable and Inclusive Infrastructure Services in India. http://www.urbaninfrastructureindia.org/guidebook.html 
Tool 8: Income and Affordability Analysis

Flowchart Reference-Phase 1: Urban Context

Objectives:

- To identify and carry out topical assessments of affordability and capacity to pay of target families to guide project planning for shelters, urban services, and historic urban areas.

- To determine how household income is distributed in cost centers of food, health, shelter, education, water, sanitation, electricity, and solid waste collection.

- To determine what percentage of household income can be dedicated for shelter and services.

- To establish household willingness-to-pay criteria.

- To determine the affordability of shelter, site protection, and infrastructure options that reflect family capacity to pay.

\section{Approach:}

- Gather information on local family expenditure patterns.

- Identify percentages of family income for shelter and services.

- Identify an array of shelter, site protection, and infrastructure products based on capacity to pay.

- Calculate loan and monthly payment amounts based on income dedicated to shelter and urban services.

- Review lending policies of local banks, credit unions, and community-based financial institutions.

- $\quad$ Explore support inclusiveness.

Steps:

1. Organize or contract a team to prepare estimates for affordability and capacity to pay. Prepare a household expenditure questionnaire to understand the expenditure patterns of poor households, particularly with respect to access to urban services including constraints, service connection fees (formal and informal markets that operate), and the preferences with respect to access, willingness, and capacity to pay.

2. Assign a specific percentage of family income for shelter and infrastructure based on current practice. Base figures on the socioeconomic and cultural practices in the poor community.

3. Identify a set of shelter, site protection, and infrastructure products based on capacity to pay that can be improved and incrementally developed over time as needed.

4. Calculate loan amounts that can be serviced with specified payments and term periods.

\section{Expected Results:}

- An understanding of and estimate for monthly percentage of income for shelter, site protection, and infrastructure is established.

- A set of incrementally developed products are developed as part of inclusive urban development programs.

- Loan tables are prepared that relate loan amounts, monthly payments, interest rates, and repayment periods.

- A report on the lending criteria of local banks, credit unions, and community-based financial institutions regarding selfemployed and low-income workers.

\section{Resources:}

- Local governments carry out annual affordability updates. Budget line items in the local budget are established to cover costs for data collection, assessment, and staff.

\section{Pointers for Implementation:}

- $\quad$ Build initiatives that are sensitive to and recognize the reservations of low-income families to take on credit responsibilities.

- Start program and/or project development with a focus on affordability criteria and calculations for loans, terms, and conditions.

- Direct technical and financial staff to coordinate on incrementally developed solutions.

- Identify lending regulations that are exclusive.

\section{References:}

International Finance Corporation. 2010. International Accountability Project. Key Issues for Upholding Housing, Land and Property Rights in the International Finance Corporation's Review of the Environmental and Social Policy and Standards. Washington, DC.

United States Agency for International Development (USAID). 2007. Municipal Finance: A Guide for USAID Staff and Partners. Washington, DC.

USAID/India. 2011. Developing Sustainable and Inclusive Urban Infrastructure Services. Washington, DC: The Communities Group International. 
Tool 9: Pro-Poor Shelter Strategy

Flowchart Reference-Phase 1: Urban Context

\section{Objectives:}

- To identify in the shelter sector's policies obstacles to addressing the shelter needs of the poor.

- To review existing programs' guidance, incentives, and support for improving existing settlements and offering new shelter options to the poor.

- To establish a typology of home improvements and new shelter options that reflects affordability and the capacity to pay of the poor.

Approach:

- To review the policies of the shelter sector to determine their limitations in addressing the shelter needs of the poor.

- To identify the roles and responsibilities of public, private, nongovernment, and community-based organizations and institutions engaged in providing shelter for the poor.

- To identify the need and demand for and the supply of affordable shelter options that benefit the poor, including home-ownership and rental housing.

- To prepare an annotated list of priorities for improving existing shelter and settlements and developing new shelter projects.

- To develop a training and capacity-building agenda for resilient shelter construction for self-help and formal construction companies.

\section{Steps:}

1. Prepare a terms of reference for an inclusive shelter assessment focused on the poor.

2. Collect and analyze the basic data on urbanization, population growth, household numbers and formation, housing stock, housing construction, tenure status, and land supply by market segment.

3. Assess the housing requirements and the housing deficit, and identify options for bridging the gap.

4. Conduct citywide consultations to raise awareness on urban poverty issues and assess the built-in capacity of the urban poor to address their own issues in partnership with local governments. Interview key staff of institutions and agencies at the national and local levels responsible for and engaged in the improvement of existing and new shelter options. Consult private sector stakeholders in shelter finance and development on conditions and incentives for engaging in shelter development at scale. Consult community-based and nongovernment organizations on their shelter policies and programs.

5. Prepare city shelter profiles to map the characteristics of the urban poor community and the opportunities for shelter and community infrastructure improvements; use the participatory governance processes to select an urban poor community for sustained settlement upgrading in each city; and form local area development committees (UN-Habitat 2012).

6. Present the information gathered in an pro-poor shelter strategy that

(i) presents an overview of the status of shelter delivery in the city, especially informal settlements, inner-city tenements, and slum areas;

(ii) identifies key institutions and their priorities, programs' focus, output, and source of funds and budget;

(iii) reviews and makes recommendations for modifications of policies to be proactive in shelter development and improvements;

(iv) reviews and makes recommendations for affordable products for programs and investments being made in slum upgrading and new shelter options; and

(v) recommends priority programs and investments to address the needs and gaps identified.

\section{Expected Results:}

- An inclusive assessment of the shelter sector and the needs of the poor.

- $\quad$ Shelter profiling and strategies are prepared for the city. Targeted information on the quality and quantity of housing being provided to informal settlements, inner-city tenements, and slum areas will be useful for establishing priorities.

- An understanding of the policies, roles, and responsibilities of the institutions involved in shelter finance, planning, and construction.

- $\quad$ Priority urban poor communities are identified for upgrading through the community action planning process. City consultations are held and areas for community action and shelter upgrading identified.

- A recommended set of priorities for improvements in existing settlements and shelters, and new shelter programs will be developed into projects and investments. 


\section{Resources:}

- The Asian Development Bank with developing member country resources will provide the guidance, budget, and oversight for the inclusive assessment.

- Local governments with national and other partners will provide staff and finances to maintain and update the assessments carried out.

- Mobilize the necessary resources and support for project implementation by the communities and the city governments.

\section{Sustainability:}

- Develop the capacity of each community to upgrade their settlements through community action planning and community contracting mechanisms.

- Support the settlements' upgrading initiatives through the creation of supplementary income-earning opportunities.

- $\quad$ Prepare proposals for follow-up investments in settlement upgrading, livelihood development, and community infrastructure improvements.

\section{Pointers for Implementation:}

- Gather existing information and maps from relevant sources on informal settlements and slums.

- $\quad$ Establish a typology of existing shelter, its location, building materials, plan, and space.

- Identify information gaps and fill them through consultations and focus group discussions, especially with community groups and agencies dedicated to addressing the shelter needs of the poor.

- Organize working groups to validate and verify information and recommendations.

- Build an "affordability" approach into the review of the products and systems being developed.

- Present observations on the willingness to pay of users as well as a willingness to collect of providers for improvements.

- Make recommendations for site protection improvements.

- Present financial options for home improvements and new shelter alternatives.

- Discuss the issues and locations that may need to be relocated.

- Present potential impacts of climate change and disaster risks on building material standards and shelter development.

\section{References:}

M. Lindfield and F. Steinberg. 2011. Inclusive Cities. Manila: Asian Development Bank..

R. Buckley and J. Kalarickal. 2006. Thirty Years of Shelter Lending: What Have We Learned? Washington, DC: World Bank.

H. Caminos and R. Goethert. 1983. Urbanization Primer. Cambridge, MA: MIT Press.

H. Caminos, J. F. C. Turner, and J. A. Steffian. 1969. Urban Dwelling Environments: An Elementary Survey of Settlements for the Study of Design Determinants. Cambridge, MA: MIT Press.

Government of India. 2005. Jawaharlal Nehru National Urban Renewal Mission: Towards Better Cities: Guidelines for Basic Services for the urban Poor (BSUP). New Delhi.

Government of India, Ministry for Housing and Urban Poverty Alleviation. 2009. Modified Guidelines for Integrated Housing and Slum Development Program. Jawaharlal Nehru National Urban Renewal Mission. New Delhi. http://mhupa. gov.in/writereaddata/IHSDP\%20revised\%20guidelines\%202009.pdf (accessed 15 June 2012).

United Nations Human Settlements Programme (UN-Habitat). 2012. Pro-Poor Partnerships for Participatory Settlement Upgrading. http://www.fukuoka.unhabitat.org/projects/sri_lanka/detail08_en.html (accessed June 2012).

B. Yuen. 2005. Squatters No More: Singapore Social Housing. Third Urban Research Symposium: Land Development, Urban Policy and Poverty Reduction. Washington, DC: World Bank. 


\section{Example:}

Philippine Business for Social Progress, a private, nonprofit foundation promoting commitment by private business to social development in the Philippines, proposed an initiative for guiding corporate involvement in integrated urban poverty reduction. Known as the Strategic Private Sector Partnership for Urban Poverty Reduction in Metropolitan Manila (or more commonly, the STEP-UP project), this initiative aimed to improve the quality of life of an estimated 35,000 individuals living in 5,823 households in 25 communities located in eight of Metro Manila's municipalities: Caloocan, Malabon, Marikina, Muntinlupa, Navotas, Pasig, Quezon City, and Taguig.

The central assumption of the STEP-UP project was that the scale of Metro Manila's urban poverty problem is such that neither the government alone nor the government working together with nongovernment organizations and the affected communities can effectively address urban poverty in the metropolis. Thus, the project created a framework for introducing private sector participation into the urban poverty reduction effort.

Ultimately, the STEP-UP project was funded by a $\$ 3.6$ million grant from the Japan Fund for Poverty Reduction, administered by the Asian Development Bank. The executing agency for the STEP-UP project was the Housing and Urban Development Coordinating Council, while the implementing agency was Philippine Business for Social Progress (Lindfield and Steinberg 2011).

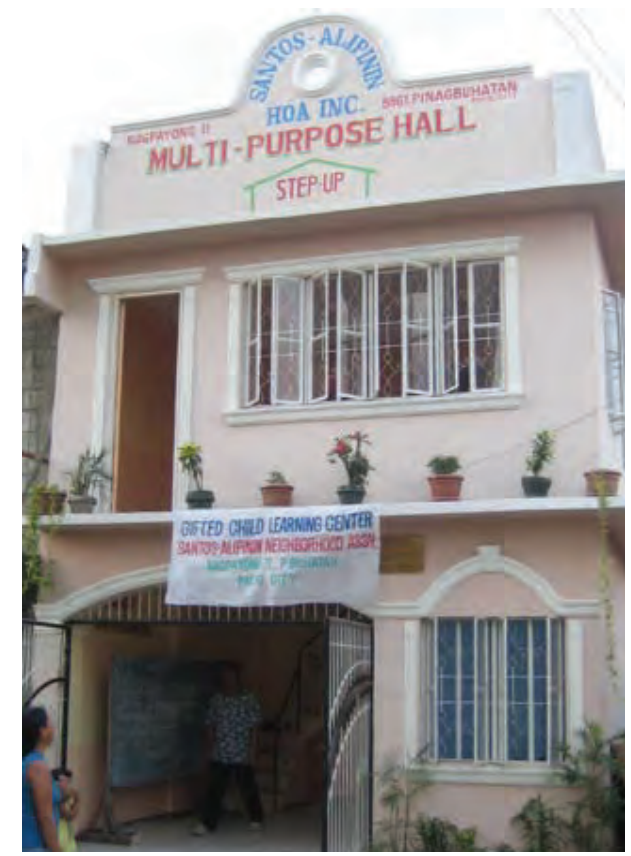

Community Multi-purpose hall built from the STEP-UP project. Lindfield and Steinberg. 2011 


\section{Tool 10: Citizen Report Card}

\section{Objectives:}

- To understand the status of urban service delivery to the poor and vulnerable groups.

- To assess inclusive service delivery with respect to access to services, adequacy, reliability, and affordability.

\section{Approach:}

The assessment can be conducted by developing and administering household surveys, stakeholder workshops, and focus groups. This can be in the form of the Citizen Report Card (CRC) to assess the satisfaction of citizens with the delivery of urban services. The $\mathrm{CRC}$ is a tool to

- collect citizen feedback on public services from actual users of a service (and not opinions from the public),

- $\quad$ assess the performance of individual service providers and/or compare performance across service providers, and

- generate a database of feedback on services that are placed in the public domain.

The CRC is an effective tool for improving local governance and pro-poor service delivery. The CRC addresses critical themes in the delivery of public services, such as access to services, quality and reliability of services, problems encountered by service users and their responsiveness in addressing these problems, transparency in service provisions such as disclosure of service quality standards and norms, and costs incurred in using a service including hidden costs such as bribes (http://www.citizenreportcard.com/).

\section{Steps:}

Institutional mapping: Outline the institutional structure, roles, and responsibilities of the different tiers of government involved in urban service delivery. This should comprise an organizational diagram (an "organogram") that illustrates the structure, hierarchy, and the overall staffing of the city government, together with simple tables that record basic information.

Design and administer the $\mathrm{CRC}$ to assess the quality of governance and satisfaction of citizens with the delivery of urban services.

\section{Expected Results:}

- $\quad$ Public service agencies supported in facilitating open and proactive discussion on their performance.

- Citizen groups empowered to play a watchdog role to monitor public service agencies and local governments.

- Federal Ministries and planning departments enabled to streamline and prioritize budget allocations and monitor implementation.

- Social capital deepened by converging communities around issues of shared experiences and concerns.

\section{Resources:}

- The Asian Development Bank, with resources from developing member country programs as part of the city poverty and vulnerability profile.

- $\quad$ Local governments to assign dedicated resources to anchor and manage the CRC processes.

- Some critical institutional capacities required to make CRCs effective are analytical staff well-versed in quantitative methods. Since a large part of the CRC involves sample surveys and analysis of data, a major prerequisite is that the organization should have either in-house capabilities to understand and interpret numbers or have resources to locate external support.

- Dedicated resources for communication and outreach.

\section{Pointers for Implementation:}

- The CRC's main report should include an executive summary, survey objectives, methodology, and major findings.

- Ensure that the main report includes both the positive and negative findings (especially the negative findings, as there may be a desire to suppress negative findings if the local partner is a government body). Urge the local lead institution to present a holistic picture of the findings in the main report and in the subsequent dissemination efforts. 


\section{References:}

ADB. 2007. Improving Local Governance and Pro-Poor Service Delivery: Citizen Report Card Learning Toolkit. Manila: ADB and ADB Institute.

ADB. 2008. Managing Asian Cities. Manila.

\section{Examples:}

The initial reach of the CRC in India was limited to Bangalore, Ahmedabad, and Pune, with Delhi, Mumbai, Chennai, Kolkata, Sehore, and Bhubaneshwar having recently introduced the CRC. At the international level, the CRC has been implemented in Ukraine in Eastern Europe; Bangladesh, the People's Republic of China, Indonesia, Nepal, the Philippines, Sri Lanka, and Viet Nam in Asia; Ethiopia, Gambia, Ghana, Nigeria, Rwanda, and Uganda in Africa; and Argentina and Peru in South America.

Overall Satisfaction, Bangalore CRC 2003 Slum Household

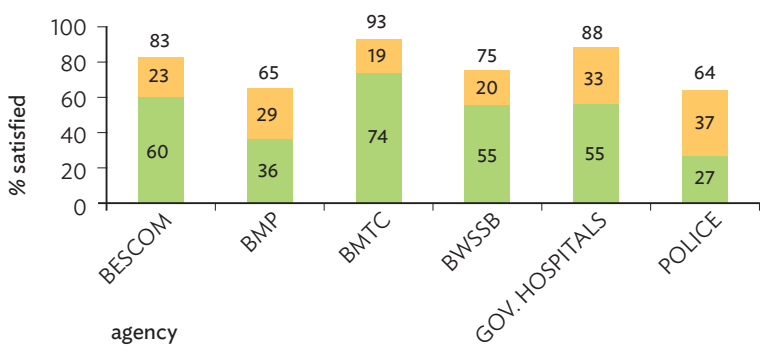

Completely Satisfied Partly Satisfied
Bangalore Water Supply \& Sewerage Board, 2003 Service Quality

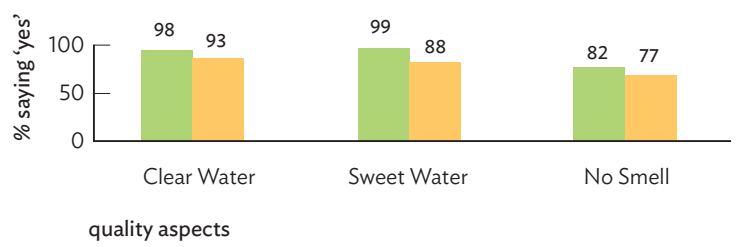

General Households Slum Households

Source: ADB. 2007. Improving Local Governance and Pro-Poor Service Delivery: Citizen Report Card Learning Toolkit. Manila: ADB and ADB Institute. 
Tool 11: Urban HEART

Flowchart Reference-Phase 1: Urban Context

\section{Objectives:}

- To understand the status of health care services in the city to the poor and vulnerable groups.

- To identify and reduce health inequities in the city.

\section{Approach:}

The Urban Health Equity Assessment and Response Tool (Urban HEART) is a decision-support tool to identify and reduce health inequities in cities. Urban HEART enables local communities, program managers, and municipal and national authorities to

- $\quad$ better understand the unequal health determinants, unequal health risks, and unequal health outcomes faced by people belonging to different socioeconomic groups;

- $\quad$ identify socioeconomic groups within a city (or across cities);

- use evidence when advocating and planning health equity interventions;

- $\quad$ participate in intersectoral collaborative action for health equity; and

- apply a health equity lens in policy making and resource allocation decisions.

Steps:

Urban HEART Integrated into the Local Planning Cycle

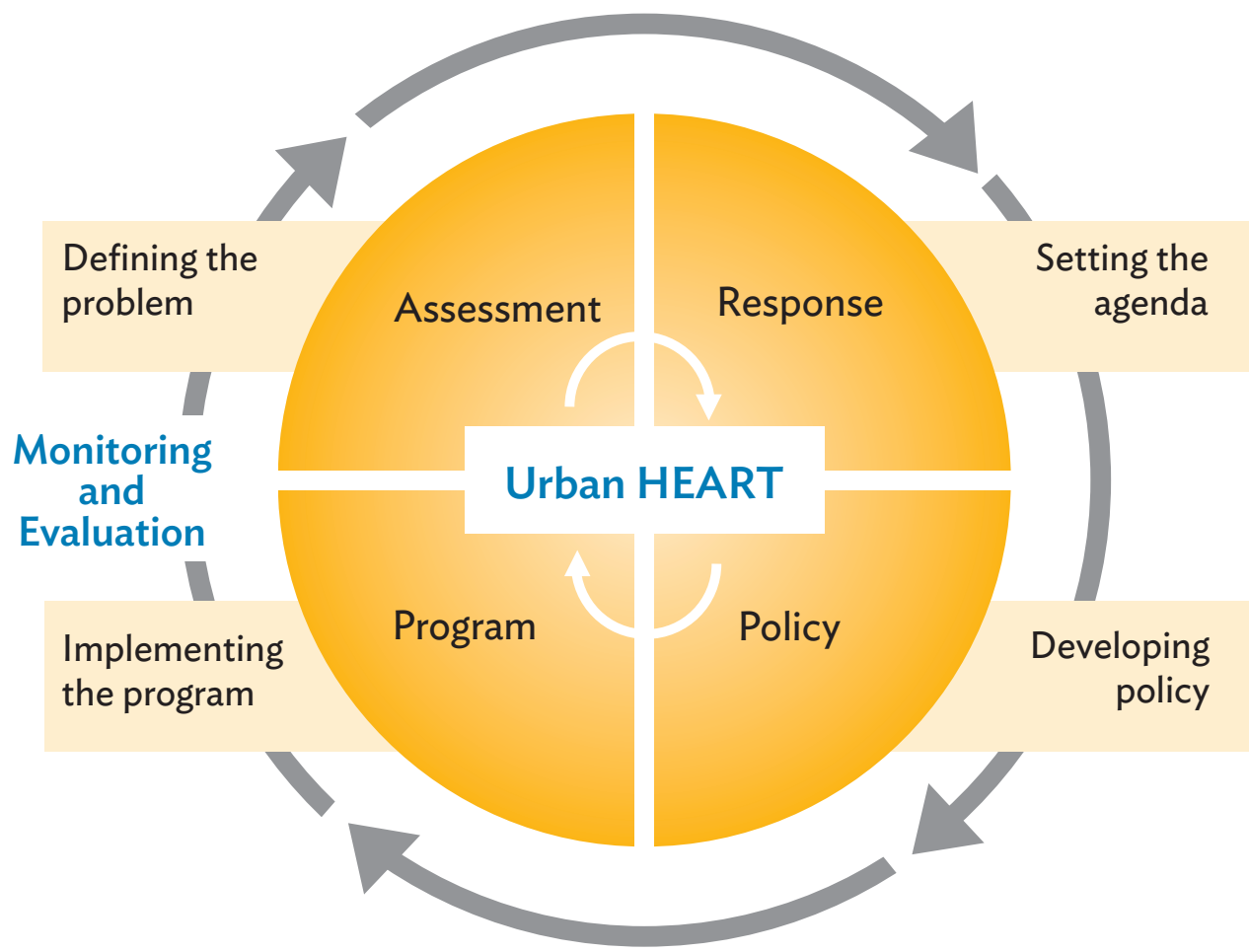

Source: World Health Organization. 2010. Urban HEART User Manual. Kobe: The WHO Centre for Health Development. 


\section{Build an inclusive team}

- The goal is to build political commitment to pursue a health equity agenda for the city. Building an inclusive team may be the most time-consuming step in the Urban HEART process, but it may also be the most important step. Core activities include partnership building, education, and advocacy.

- Obtain buy-in from influential champions.

- Raise awareness in other sectors about the importance and relevance of Urban HEART.

- Form a core team of individuals who will have dedicated time to implement Urban HEART. Promote the sustainability of the use of the tool by integrating Urban HEART into existing structures and responsibilities.

\section{Define the local indicator set and benchmarks}

- A health equity indicator set will enable the team to effectively and efficiently collect information on the major health equity issues facing the city.

- $\quad$ Adopt the Urban HEART core indicators. These have been vetted as valid and reliable health equity indicators. Select other indicators to address special issues in the city. Make these choices in consultation with stakeholders.

- Identify the best disaggregation variables to assess inequities.

- Determine benchmarks and targets for evaluating performance of the indicators.

- $\quad$ Find a data source for each indicator. Data from a range of policy sectors will be needed.

\section{Assemble relevant and valid data}

- Urban HEART should rely as much as possible on the use of available datasets and should not require extensive new data collection or surveys. Data sharing may be politically sensitive. Use contacts on the intersectoral team to support the process.

- Assess the quality and validity of available datasets, in consultation with data experts and communities. Take steps to choose the best-quality data and to manage data quality problems.

- Negotiate formal data-sharing agreements with data custodians and set up a repository or server to hold the collected datasets. Legal and information technology advice may be needed. Prepare the data for analysis.

\section{Generate evidence}

- Using the indicator set, the data assembled, and simple charting and graphing software, the team can produce easy-to-read charts (the MATRIX and the MONITOR) to illustrate health inequities in the city.

- $\quad$ Start by developing the MATRIX. Use the MATRIX to identify priority indicators that should also be reviewed through the MONITOR.

- $\quad$ Be sure to register numeric results for each indicator, in addition to using color codes. This will help stakeholders to understand the relative urgency of different problems.

\section{Assess and prioritize health equity gaps and gradients}

- This is a highly critical stage whereby all stakeholders participate in identifying priority issues by assessing the Urban HEART evidence. Although the MATRIX and MONITOR provide quantitative results, this phase should include qualitative assessment as well.

- Ensure that stakeholders can interpret the charts. Focus on numeric results as well as the color codes.

- Facilitate careful and deliberative discussion. There are several strategies for reviewing the charts, depending on stakeholders' concerns. Focus on trends and pockets of deep inequities, understanding the causes and consequences of inequities (using qualitative approaches).

- $\quad$ Prioritize key equity problems. 
6. Identify the best response

- Once the equity issues needing attention have been identified, the appropriate response. This step should be highly consultative, involving relevant policy sectors and communities. The goal is to develop an evidence-based plan for action that will be persuasive to decision makers and can be adopted and implemented.

- Draw upon the Urban HEART menu of strategy packages and interventions for ideas. These have been tested in other cities for their effectiveness.

- Assess the relative strengths of potential interventions. Consider a wide range of factors, including potential impacts on equity, community preferences, available resources, and alignment with existing government priorities.

- $\quad$ Finalize the response plan. The Urban HEART process will help ensure that the plan is evidencebased, feasible, relevant, and widely supported.

\section{Auxiliary Steps:}

1. Draw a "network map." Getting started and knowing who to engage can be a challenge. It may be necessary to begin by conducting an environmental scan or stakeholder analysis to identify people who should join the team. In Parañaque City, Philippines, the start-up group held brainstorming sessions to identify potential stakeholders. The result was a network map of the many agencies, departments, and communities relevant to Urban HEART, and a plan for contacting these groups.

2. Mobilize influential champions. Communicate with, and meet as often as needed, influential decision makers (and "gatekeepers") to secure their support and to prepare them to receive the results of data analysis later on. When national and local executives (e.g., city mayor, town clerk, district council chiefs, or other types of officials) become champions for Urban HEART, they can encourage or mandate their agencies to get involved. City council adoption of Urban HEART has been an important milestone in pilot cities and has stimulated more activity. Use the Urban HEART policy brief (Annex 1) and other educational materials that are available at http://www.who.or.jp/urbanheart.

3. Educate. Many groups will be unfamiliar with concepts such as the "social determinants of health" or "health equity." The first step in cultivating champions and a team is to ensure that potential stakeholders understand the issues. Emphasize opportunities for collaboration. It is important not to alienate groups whose participation may be needed. Educational materials are available at the Urban HEART website. These materials can be tailored to suit different groups and offer learning workshops and consultations.

4. Look for synergies to promote sustainability. Competing responsibilities are one of the biggest challenges to starting and sustaining Urban HEART. Pilot cities recommend integrating Urban HEART within established programs, policy agendas, time lines, workplaces, and job descriptions. Be explicit with all potential stakeholders that Urban HEART is a planning tool that can be adopted by existing organizations and programs. It is not intended to be a new program requiring substantial new resources.

5. Use informal networks. In addition to the formal route, team builders in pilot cities used their personal contacts to identify participants for Urban HEART. In some cities, third-party agencies or centralized statistics organizations have provided access to relevant datasets, when an individual policy contact is not available.

6. Create terms of reference. Writing this document together with the community will be an important way to build commitment and knowledge in the team. It will also help to identify potential synergies with existing roles and responsibilities. Clearly describe the Urban HEART plan and define concrete measures of success, time lines, and the roles and goals for working together. Ensure that roles for affected communities are expressed in the terms of reference, including the strategies that will be pursued to ensure their meaningful participation.

7. Organize the team efficiently. It is possible to decide to establish small subteams to focus on particular issues or policy domains. This approach can speed up the activity and ensure that the expertise of the team members is being used efficiently. A steering committee can coordinate the activities of the subteams.

8. Document the process. This information can be used for evaluation and monitoring, and to advise future Urban HEART cities on how to get started.

\section{Expected Results:}

- Help public service agencies to facilitate open and proactive discussions on their performances.

- Empower citizen groups to play a watchdog role to monitor public service agencies and local governments.

- Enable federal ministries and planning departments to streamline and prioritize budget allocations and monitor implementation.

- Deepen social capital by converging communities around issues of shared experiences and concerns. 


\section{Resources:}

- Use developing member country program resources as part of the city poverty and vulnerability profile.

- $\quad$ Set a realistic budget. Include costs for meeting spaces, travel, meals, stipends, materials, and personnel.

- Aim to integrate most costs of Urban HEART within existing programs. It may be necessary to cover costs for new data analysis. Seek out funding from government agencies, nongovernment organizations, and foundations.

- Use debriefing documents and educational materials. A policy brief is included in Annex 1 of the Urban HEART Manual. It can be tailored to suit the respective context and also translated. The final report of the Commission on Social Determinants of Health can also be used.

- Provide access to relevant stakeholders.

- Prepare terms of reference template. A sample is included in Annex 2.

- Allot time to meet with diverse individuals and groups to explain Urban HEART and encourage their participation.

\section{Sustainability:}

- Look for synergies. A relevant, intersectoral team, which could adopt the Urban HEART process, may already exist. In Ulaanbaatar, Mongolia, Urban HEART was launched by the World Health Organization Healthy Cities Committee. This helped raise the profile of Urban HEART and encouraged central government participation.

- Be prepared for resistance. The causes of health inequities in cities are complex. It may be difficult for organizations that do not have a direct health care mandate, such as labor, utilities, or police, to see a role for themselves in Urban HEART. Engaging groups that do not see the relevance of health equity to their work may take longer than any of the other steps in the Urban HEART process, but it is essential.

- Cultivate demand. Urban HEART works best when representatives from affected communities and relevant sectors want the process and believe that Urban HEART is needed. It is possible to help cultivate demand early on by explaining the social determinants of health to stakeholders. Later, Urban HEART data analyses can be used to demonstrate health inequities faced by particular communities and equip them to advocate change.

- $\quad$ Prepare for succession. Over time, individual participants and champions can be used (e.g., due to staff turnover or elections). Work to integrate Urban HEART into organizational systems and formal job descriptions to minimize the effects of personnel changes. Be prepared to continue to advocate Urban HEART with political incumbents. The demand cultivated among other participants, communities, and the media can influence incoming officials to support Urban HEART.

\section{Pointers for Implementation:}

- Urban HEART requires (and fosters) strong coordination among diverse policy sectors, levels of government, and communities to address health inequities. Although it is likely that a health agency may first become interested in using Urban HEART (or may become the focal point for the process), it is essential to build partnerships with others as early as possible. Getting an early start on inclusive team building during this pre-assessment phase is both practical and strategic. In the practical sense, data will be needed from a wide range of sectors and levels of government to analyze health inequities in the city. Strategically, an inclusive approach helps build political commitment. It is more likely that agencies and communities will take ownership for responding to problems if they have participated throughout the process and have played a key role in identifying problems. While team building may be the most time-consuming step in the process, it may also be the most important step. Creating an inclusive team sets the foundation for the productive implementation of Urban HEART.

- Think about the size of the team. The exact size and composition of the team will depend on the unique context and cannot be prescribed in advance. As a rule of thumb, the team should be as broad as necessary to achieve the goals, but not so broad as to become irrelevant or difficult to coordinate. A team that is well connected to the range of relevant stakeholders is optimal. In some cases, it may be appropriate for an agency to share data without participating actively on the team. Aim to build a team of 10-20 participants.

- Remember that team building is an ongoing process. The team does not need to have everyone on board in order to get started. Pilot cities, such as Ho Chi Minh City, Viet Nam, and Nakuru, Kenya, attracted new participants by sharing interim Urban HEART results.

- Keep stakeholders informed. Ideally, the team will include representatives from all relevant stakeholder groups. Use these contacts to ensure that stakeholders are regularly updated about the activities throughout the Urban HEART process. This will ensure that stakeholders do not forget about Urban HEART and will prepare them to participate in Steps 5 and 6 -reviewing and responding to evidence.

Reference:

World Health Organization. 2010. Urban HEART User Manual. Kobe: The WHO Centre for Health Development. 


\section{Examples:}

The working group first identified the rich and poor barangays (neighborhoods) of the city based on the percentage of depressed areas per barangay. San Dionisio, Santo Nino, and San Martin de Porres (SMDP) have been identified as the poorest barangays and Tambo, Merville, and BF homes have been identified as the richest barangays. SMDP has the highest percentage of depressed areas (61\%). The team then plotted the data gathered for the identified rich and poor areas on Form 123, the Urban Health Assessment Record. The data of the barangays were plotted against the national and city average data to facilitate comparison of the different indicators. Of the 28 indicators in the Urban HEART, there were 16 indicators with available data, 11 indicators of these data were gathered within the City Health Office, and 5 were requested from agencies within City Hall. Twelve of the 28 indicators had no available data, and needed a survey.
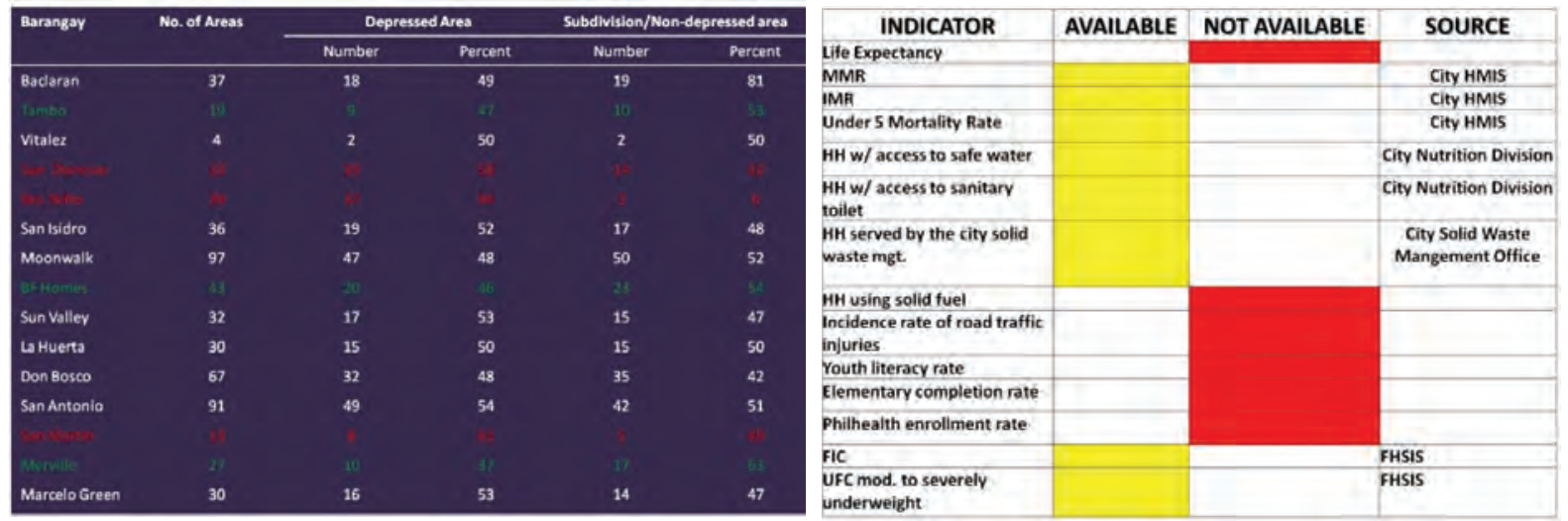

Color coding the data using the Urban HEART Equity Matrix, Health Outcome reveals mostly reds and yellows in the six barangays for infant mortality rate in 2007.
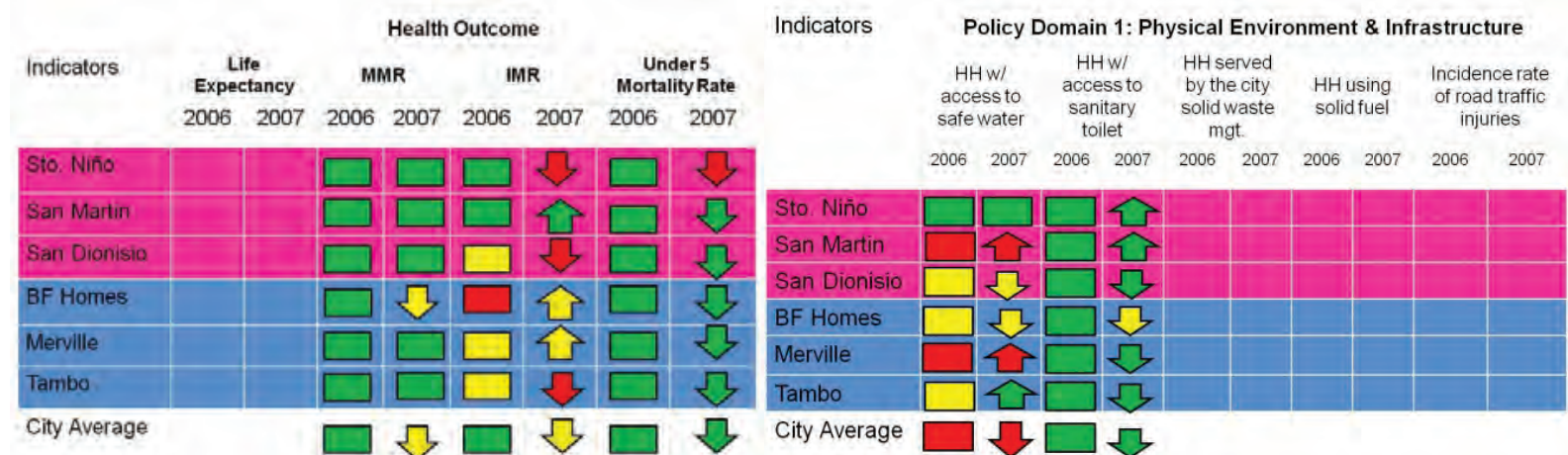

City Average

In Policy Domain 1, data were gathered for only two of the five indicators, of which "households (HH) with access to safe water" was a problematic indicator. Two of the six barangays are marked in red (one rich and one poor). For the year 2007, two barangays are marked in yellow and two in green. While in Policy Domain 2, the fully immunized children indicator reveals mostly reds and yellows for the year 2006, which has since improved in 2007. The city average, however, for the fully immunized children indicator has improved from 2006 (red) to 2007 (yellow upward arrow). Four indicators have no data: youth literacy rate, elementary completion rate, Philippine Health Insurance Corporation enrollment rate, and prevalence rate of tobacco smoking among 13-15-year-olds. Three barangays are marked in red in the facilitybased deliveries (two rich barangays and one poor barangays, SMDP). The picture of the matrix makes it easier to draw the yardstick or the equity monitor to check the equity gaps among the different indicators for the rich and the poor barangays. 
Chart 1: Households with Access to Sanitary Toilet Facilities

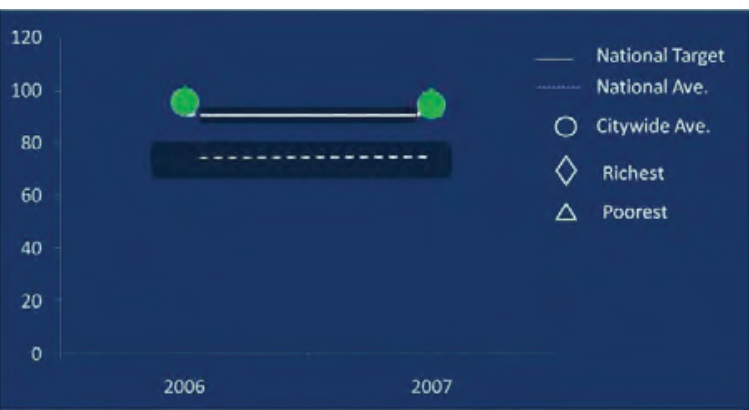

Chart 2: Households with Access to Safe Drinking Water

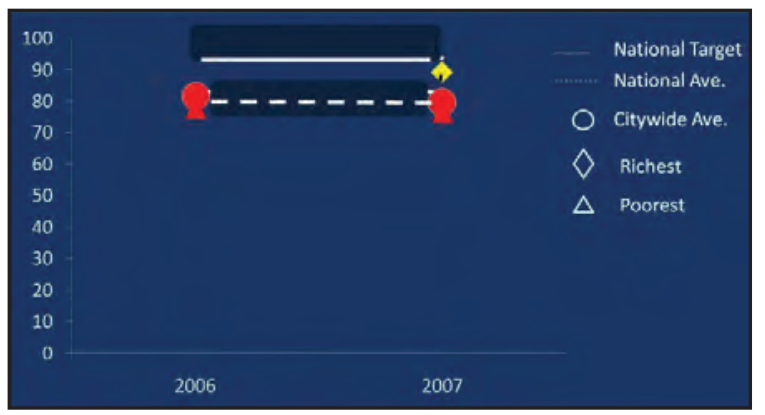

However in Policy Domain 1, HH with access to safe water, this monitor would show that the rich are better served compared with poor. The yellow diamond indicates that the national target of access to safe water has not been achieved. The bigger problem, however, is the fact that the city has not even reached the national average of $96 \%$ for the urban setting, as shown by the red circle.

In all the four policy domains, identifying the most problematic domain and indicator will help in zeroing in on the particular intervention that will address the equity gap. Problem indicators identified in health outcome are maternal mortality ratio and infant mortality rate; Policy Domain 1, $\mathrm{HH}$ with access to safe water; Policy Domain 2, facility-based deliveries and fully immunized children. There were no data for index crime rates for Policy Domain 3, and for Policy Domain 4, government spending allocated to health and voter participation rate were problematic. Based on the equity matrix and the equity monitor, three indicators showed inequity: $\mathrm{HH}$ with access to safe water, facility-based deliveries, and index crime. This assessment led to projects being identified to bridge the equity gap.

\begin{tabular}{|l|l|c|c|}
\hline \multirow{2}{*}{ Category } & \multicolumn{1}{|c|}{ List of Problem Indicators } & \multicolumn{2}{|c|}{ Does Equity Gap Exist? } \\
\cline { 2 - 4 } & & Equity Matrix & Equity Monitor \\
\hline Health Sector Indicators & $\begin{array}{l}\text { Infant Mortality Rate } \\
\text { Maternal Mortality Ration }\end{array}$ & No & Yes \\
\hline $\begin{array}{l}\text { 1. Physical Environmental } \\
\text { and Infrastructure }\end{array}$ & Households with access to safe water & Yes & Yes \\
\hline 2. Social and Human & Fully immunized Children & No & Yes \\
\hline Development & Facility based deliveries & Yes & Yes \\
\hline 3. Economics & No data & No data & No data \\
\hline 4. Governance & Government spending allocated to health & No & No \\
\hline
\end{tabular}

Source: O. Virtusio. 2009. Urban HEART Philippine: The Parañaque City Experience. Presentation at Asian Institute of Management, Manila. 
Tool 12: Integrated Disaster Risk Management in Inclusive Urban Development

Flowchart Reference-Phase 1: Urban Context

\section{Objectives:}

- To create an awareness of potential adverse effects of all hazards, including climate extremes, on existing communities, especially vulnerable groups, and on current and future growth areas in the city.

- To proactively document root causes of vulnerabilities of communities and assets to natural hazards.

- To expand the scope of urban infrastructure to include interventions for disaster risk reduction as an essential component of inclusive urban investments.

- Where necessary, to undertake stand-alone investments on disaster risk reduction that would be essential for achieving inclusive urban development (IUD).

- To identify and employ resilient technologies in shelter and urban service delivery systems.

- To identify technical partnerships for climate change and hazard analysis as part of the IUD project development team.

\section{Approach:}

- To create an awareness of the relationship between disaster risk management (DRM) and IUD project design and implementation.

- To maintain a multihazard perspective for information base development, mapping, and analysis.

- To identify partners to support technical inputs for climate change predictions and projections to complement the historical disaster record.

- To create information on and access to technological innovations for mitigation and adaptation for IUD project development.

- To include preparedness, mitigation, and adaptation investments in IUD projects

- To focus on mitigation and adaptation programs that address home improvements for resilience, site protection, and infrastructure protection.

\section{Steps:}

1. Develop a city- and community-level multihazard profile as part of a consolidated city information base to guide resilient project development.

2. Undertake an awareness program on potential impacts of disaster risk, including impact of climate extremes on shelter, livelihoods, site protection, and urban services.

3. Prepare a list of most vulnerable communities and areas for IUD project preparation and potential resettlement initiatives.

4. Identify and contract with a roster of partners for technical, financial, and management support for DRM in IUD projects.

5. Consider global practice and imbibe DRM technical innovations in IUD project design and development.

6. Include disaster risk as one of the decision-making factors in the project review process to embed resilience.

\section{Expected Results:}

- A city multihazard profile will be developed that guides location and type of future investments related to IUD. Identify partnerships to carry out disaster risk assessment and interventions to reduce disaster.

- An inclusive shelter, site development, and infrastructure project development process that reflects resilient planning and employs resilient technologies.

- $\quad$ Finance mechanisms to reduce disaster risk by embedding resilience in shelters, community facilities, and site retrofit and new construction; and finance to manage residual risk.

- An online resilient planning and support mechanism for DRM technologies.

- IUD investments that reflect a resilient approach to project development.

- Infrastructure related to disaster risk reduction becomes a legitimate IUD investment.

- Community-based and formal sector housing finance companies offer home improvement lending to retrofit shelters, site protection, and basic services. 


\section{Resources:}

- IUD project investments include resilient planning, site development, and technologies for shelter and basic service delivery systems.

- $\quad$ City and national budgets include incentives to invest in resilient home improvement programs for community-based and formal sector housing finance companies.

\section{Sustainability:}

The DRM office of a city participates in the urban planning process.

The maintenance and update of a multihazard profile is built into the city poverty and vulnerability profile.

Partnerships with technical institutes can share financial and staff responsibilities for DRM investments.

\section{Pointers for Implementation:}

- The most vulnerable populations need to be identified to design targeted interventions to reduce risk and manage residual risk by creating safe haven programs and escape routes.

- The role of the community is key for establishing a consensus on sensitive issues such as resettlement.

- Community mapping exercises support understanding and gather detailed information on vulnerable populations, locations, and livelihoods.

- $\quad$ Site protection investments are an important element of resilient and sustainable planning that completes the urban picture with shelter and urban services.

- Investigate the feasibility of making resilient design and planning necessary to access credit.

\section{References:}

Asian Disaster Preparedness Center. 2005. A Primer: Disaster Risk Management in Asia. Bangkok.

Asian Disaster Preparedness Center. 2005. A Primer: Integrated Flood Risk Management in Asia. Safe Cities Series. Bangkok. United Nations Development Programme (UNDP). 2009. Post-Tsunami Aceh-Nias Settlement and Housing Recovery Review. Jakarta.

N. von Einsiedel, F. Bendimerad, A.S. Rodil, and M. Deocariza. 2010. The Challenge of Urban Redevelopment in Disaster-Affected Communities. Environment and Urbanization Asia. National Institute of Urban Affairs. New Delhi: Sage Publications.

World Bank. 2009. Climate Resilient Cities: A Primer on Reducing Vulnerabilities to Disasters. Washington, DC.

World Bank. 2010. Safer Homes, Stronger Communities: A Handbook for Reconstructing after Natural Disasters. Washington, DC.

\section{Example:}

F. Steinberg and P. Smidt, eds. 2010. Rebuilding Lives and Homes in Aceh and Nias, Indonesia. Urban Development Series. Manila: ADB. 
Tool 13: Climate Change Impacts, Resilience Options and Indicative Costs

\section{Flowchart Reference-Phase 2: Prioritization and} Strategies

\section{Objectives:}

- To identify and create an awareness of climate change impacts on existing communities and future growth areas.

- To proactively document and address vulnerabilities to climate change impacts in inclusive urban development (IUD) project development and preparedness assessments.

- To identify technical partnerships for climate change analysis as part of the IUD project development team.

- To identify most vulnerable communities and areas.

\section{Approach:}

- To build climate impacts into IUD project design and implementation.

- To include climate change predictions and projections in information base development, mapping, and analysis.

- To identify partners to support technical inputs for climate change predictions and projections.

- To create information on and access to technological innovations for mitigation and adaptation for IUD project development that addresses densification, home improvements, site protection, and infrastructure protection.

- To identify more secure and available land and employ resilient technologies in shelter and urban service delivery systems using climate change impact data.

\section{Steps:}

1. Conduct a citywide and community-level annotated climate change impacts mapping program as part of a consolidated city poverty and vulnerability profile (CPVP) (Tool 1).

2. Prepare a list of most vulnerable areas and settlements for IUD project preparation and potential resettlement initiatives (Tools 1 and 9). Based on the climate resilience of urban infrastructure, outline resilience options and indicative cost.

3. Identify a roster of partners for technical, financial, and management support for addressing potential climate change impacts in IUD projects.

4. Develop technical guidelines for higher density, low-rise development for future growth of cities.

5. Prepare an awareness program on climate change impacts on shelter, site protection, and urban services as information to conduct IUD training programs.

6. Include climate change impacts in the project review process to demonstrate resilience.

\section{Expected Results:}

- A CPVP that includes annotated climate change data and maps

- Partnerships to carry out climate change predictions and projections

- Climate resilience options, adaptation programs, and mitigation infrastructure requirements with indicative costs

- An inclusive shelter, site development, and infrastructure project development process that considers climate change impacts

- Community-based and formal sector housing finance companies offer home improvement lending to retrofit shelter, site protection, and basic services. Finance mechanisms for shelter, community facilities, site retrofit, and resilient new construction

- IUD investments that reflect a resilient approach to project design and development

\section{Pointers for Implementation:}

The assessment should aim to answer the following questions:

- What is the expected nature of impacts because of climate change?

- Which sectors are likely to be affected the most?

- What are the recommendations to reduce the intensity of these impacts?

- How should the future costs of the impacts be evaluated?

- Which other cities are experiencing similar impacts and what are they doing?

- What are the expected benefits and cobenefits of an action plan?

- What kind of information is required for prioritizing fund allocation? 


\section{Resources:}

- The Asian Development Bank with developing member country support contracts with a technical institute or university for climate change information.

- IUD project investments include climate change resilient planning, site development, and technologies for shelter and basic service delivery systems.

- Incentives are built into IUD programs to respond to climate change guidance for higher density development.

- Resilient home improvements programs for community-based and formal sector housing finance companies.

\section{Sustainability:}

- High-level commitment to supporting climate change resilient infrastructure and retrofit of the city with commensurate policy directives and dedicated resources

- Greater awareness of networks and partnerships to tap resources

- City officials to increase awareness and support climate change studies

- The maintenance and update of climate change vulnerability assessments to be built into CPVP

- Partnerships with technical institutes to share financial and staff responsibilities for disaster risk management investments

\section{References:}

Cities Development Initiative for Asia (CDIA) and United Nations Human Settlements Programme (UN-Habitat). 2012. Pre-Feasibility Studies (PFS) User Manual. Manila: CDIA.

UN-Habitat. 2001. Tools to Support Participatory Urban Decision Making. Nairobi.

\section{Example:}

Eco2 city-Hai Phong City, Viet Nam. 
Tool 14: Inventory of Projects/Programs and Investments

\section{Objectives:}

- To prepare an inventory of recent past, ongoing, and proposed pipeline of projects and programs.

- To identify investment gaps, sector focus, geographic concentration of activities, and support of successful program continuity.

- To identify key target groups/beneficiaries and spatial areas for targeted interventions.

\section{Approach:}

- To contact public, private, university, nongovernment, and community groups to compile and consolidate an annotated list of projects, programs, and courses related to inclusive urban development (IUD) in an annotated inventory of IUD-related programs.

- To review the inventory to identify gaps and areas of concentration of investment and activities.

- To prepare tools for analysis such as an inventory matrix.

- To implement an IUD planning workshop to present the findings of the inventory.

- To carry out consultations with partner institutions to prepare strategies for filling the gaps identified and scaling up successful initiatives.

- To present sector and geographic focus and concentrations.

\section{Steps:}

1. The city poverty and vulnerability profile team will be responsible for preparing an inventory of IUD programs

2. Establish a typology of activities, including basic urban services, shelters, slum improvement, historic urban areas, disaster risk management, climate change impacts, urban transport, training and capacity building, and urban environmental restoration

3. Prepare short descriptions of each project, program, and/or training course, indicating if the activity is a capital investment or technical assistance/training event, its purpose, size, implementing agencies, and expected outputs

4. Identify gaps and areas of concentration

\section{Expected Results:}

- An annotated inventory of recent, ongoing, and future plans for IUD activities that grow/change over time prepared by the working group as existing projects are completed and new ones initiated

- An understanding of where programs are concentrated, their locations, and how many are operational

- A report that documents gaps in programming and training as well as in the geographic coverage of activities

- A program development document to inform potential partners and investors of areas of need and opportunity

\section{Pointers for Implementation:}

- For each activity, identify if that activity is a short-, medium-, or long-term initiative.

- The inventory matrix shows areas of concentration and gaps in coverage and investment.

- "Inclusive" activities or the lack thereof are the focus of the inventory.

- Gaps serve as and will be developed into an agenda for consultations with partner institutions.

- Populate an annotated inventory matrix with the typology programs and others that are identified.

- Prepare the inventory in a report format to be disseminated as a handout by national and local officials to identify partnerships and attract and inform investments.

- Focus attention on and create the inventory as a priority and an essential component of the IUD initiative. 


\section{Resources:}

- $\quad$ The developing member country will provide staff and financial support to the preparation of the inventory and the consultations to follow.

- National and local governments with partners will take over the management and budget requirements to continue to track programs and promote activities in areas not well addressed.

\section{Sustainability:}

- The inventory is an important tool in representing a city's needs to investors and support groups and, therefore, its continuity depends on having the requisite staff and budget to update and be proactive in addressing successes and the gaps identified.

- The inventory requires a home and that it become part of an explicit set of responsibilities for dedicated IUD staff.

- A reward system for the maintenance of the inventory is a useful means of keeping interest and efforts at the level of the local staff who are usually overwhelmed with tasks and other responsibilities.

\section{References:}

ADB. 2008. Managing Asian Cities. Manila.

Cities Alliance. 2005. Guidance Framework: Integrating Monitoring and Evaluation into City Development Strategies. Washington, DC.

Cities Alliance. 2006. Guide to City Development Strategies: Improving Urban Performance. Washington, DC. 
Tool 15: Capacity Needs Assessment and Capacity Development Plan

\section{Objectives:}

- To improve and/or create skills and capacity to understand and engage in inclusive urban development (IUD) project development.

- To ensure implementation by national and local governments; universities; and private sector, nongovernment, and community-based organizations.

\section{Approach:}

The approach suggests that government (country and subnational) capacity is found in different levels-individual, organizational, and enabling environment.

1. The individual level is the first and basic unit of capacity, in whom skills and knowledge are vested.

2. The organizational level provides the framework for individual capacities to connect and achieve goals beyond the capability of one or even a few people. They also offer continuity and act as repositories of knowledge and experience, reducing dependency on single individuals, while enabling access to accumulated knowledge.

3. The enabling environment level encompasses society as a whole, especially of a country and its governance. It provides an ethos that largely determines the value system within which people and the economy function-embracing elements such as trust, honesty, or concern for the poor, and conversely corruption and greed. The importance of this level of capacity was not fully appreciated until quite recently, with most efforts focusing on individuals and/or institutions. However, experience has shown that externalities such as corruption, governance systems, or conflict-prone attitudes are extremely resilient to change and have impeded many capacity development initiatives.

It should be noted that "these layers of capacity are interdependent. If one or the other is pursued on its own, development becomes skewed and inefficient." UN-Habitat. 2001b.

The assessment is further differentiated into two types of capacity:

1. Technical capacities, also referred to as "hard" capacities, are associated with particular areas of professional expertise or knowledge, such as economics, fiscal management, engineering, architecture, etc. Technical capacities vary and are closely related to the sector or organizational context in focus. This is based on the level and quality of education and skills.

2. Functional capacities, also referred to as "crosscutting" capacities, are associated with program, policy, development, and change management expertise or knowledge that are relevant regardless of sector, profession, or organization.

3. The tool supports the diagnosis of capacity needs and helps to identify corresponding areas and types of possible capacity development.

\section{Steps:}

Articulate well the objectives for capacity assessment. Identify the most appropriate entry point (individual, organizational, or enabling environment). Identify core issues that need to be addressed initially within the identified entry point to support the objective. Identify the functional capacities that need to be enhanced to address the core issues, which will include defining capacity indicators to determine current capacity assets and project-desired future capacity levels. In this step, it may be necessary to zoom in or zoom out, as necessary, to the other levels to address relevant core issues and functional capacities.

1. Prepare a terms of reference for an IUD training and capacity-building assessment.

2. Contract a team to carry out the assessment.

3. Establish an annotated list of IUD terms and concepts to guide the assessment.

4. Develop a survey, including capacity assessment worksheets, based on technical capacity and functional capacity required by the city government staff and those professionals involved in the delivery of IUD projects and programs.

5. Administer the survey and conduct consultations with national and local governments; universities; and private sector, nongovernment, and community-based organizations.

6. Assess the institutional and individual capacities to identify areas for improvement that deal with IUD project preparation and implementation.

7. Assess the degree curricula of institutes and universities for IUD in planning, social services engineering, architecture, and environmental management departments.

8. Identify a set of training institutions and their areas of expertise as partners to address and implement a skills and capacity-building agenda to develop understanding of IUD terms and concepts that include affordability, incremental development of urban services and shelters, improved building technologies, site protection initiatives, and vulnerable settlements, among others .

9. Document findings in an IUD capacity needs assessment report. 


\section{Expected Results:}

- A capacity needs assessment for IUD with indicated entities is prepared.

- An agenda of key terms and concepts forms part of a training manual for IUD (Phase 3).

- A roster of training institutions and partnerships to carry out training needs assessments as well as to implement training and capacity-building programs

- A training schedule that identifies the subject, frequency, and content of illustrative training programs.

- An online IUD training support program

- $\quad$ Recommendations for university-level professional training and capacity building for IUD programs

\section{Pointers for Implementation:}

- $\quad$ Present examples of key IUD terms and concepts to support understanding, including

- affordability leads to incremental development of services and shelter,

- new shelter options are an adaptation strategy that join technology with participation,

- disaster risk management and climate change are integral issues for IUD projects,

- urban transport can run on clean energy, and

- $\quad$ slum upgrading and retrofitting are elements of a comprehensive urban strategy that addresses the existing built environment and future growth requirements.

- Identify a diverse group as IUD training-of-trainers (T-O-T) participants.

\section{Resources:}

Ideally, the assessment management team should include a combination of expertise, specifically those familiar with (i) the national/local context, (ii) the specific content or sector under assessment, and (iii) the capacity assessment methodology. The team could also be complemented with experts in crosscutting issues, that is, an approach based on human rights and gender equality. Regardless of the approach, an assessment "owner" (ideally the government requesting the assessment) should be assigned to manage the overall process. In addition, a facilitator (usually the team leader) should be assigned to facilitate the capacity assessment process and liaise between the owner/ requesting partner and the capacity assessment team. The capacity assessment team leader (usually a consultant) manages the overall technical part of the assessment, including discussions regarding assessment scope and scale; adaptation of the capacity assessment framework; execution of the assessment, including quantitative and qualitative data collection; and interpretation of assessment results as they lead to the formulation of capacity development response strategies. From experience, it is ideal to have a combination of international and national consultants in the team.

\section{Sustainability:}

- The priority capacity needs defined in the capacity assessment drives the creation of capacity development response strategies and related action plans - the second step in the capacity development process (Phase 3, UNHabitat 2001b).

- The capacity assessment exercises need not be a onetime activity-they are designed in fact to be introduced at any particular stage of a program or project and should be conducted regularly (e.g., every 2 years, 5 years, etc.) to monitor changes, whether positive or negative, in the capacity of the clients because of the capacity development strategies introduced.

- Training and capacity building are ongoing activities.

- Partnerships with technical and training institutes can share financial and staff responsibilities for training investments.

\section{References:}

United Nations Development Programme (UNDP). 2008. Capacity Development and Capacity Assessment Training Course. http://asia-pacific.undp.org/practices/capacitydevelopment/documents/ATRAININGGUIDETOCAPACITYASSESSMENT. pdf (accessed 26 June 2012).

United Nations Human Settlements Programme (UN-Habitat). 1986. UN-Habitat Urban Management Programme. http:// www.unhabitat.org/content.asp?typeid=19\&catid=374\&cid=188 (accessed 1 September 2011).

UN-Habitat. 2001a. From Participation to Partnership: Lessons from UMP City Consultations. Published for the Urban Management Programme. Nairobi.

UN-Habitat. 2001b. Tools to Support Participatory Urban Decision Making. Nairobi. 
Tool 16: SWOT Analysis

Flowchart Reference-Phase 2: Prioritization and Strategies

\section{Objective:}

- To evaluate strengths, weaknesses, opportunities, and threats (SWOT) for inclusive urban development.

\section{Approach:}

The SWOT analysis is a well-established analytical method used for strategic planning. As a first-cut rapid assessment technique, it is useful in identifying priority issues. A useful template is the SWOT Analysis Questions and Data Analysis Template (World Bank 2004). This template is used as part of the city development strategy planning process. Another very useful tool is political, economic, social, and technical analysis (PESTA)(Chapman 2010).

The SWOT analysis can be used as a simple tool for conducting overall assessments of the strengths, weaknesses, opportunities, and threats. In the tool kit, the SWOT elements are used in separate parts of the analysis.

\section{Steps:}

1. Collect all the relevant information to be used by an expert group to conduct the SWOT analysis.

2. Identify strengths, weaknesses, opportunities, and threats using the SWOT analysis template.

3. Draw up a matrix chart listing SWOT elements.

\begin{tabular}{|c|c|}
\hline Strengths & Opportunities \\
\hline $\begin{array}{l}\text { List and group these } \\
\begin{array}{l}\text { - } \\
\text { - } \\
\text { B }\end{array}\end{array}$ & $\begin{array}{l}\text { List and group these } \\
\begin{array}{l}\text { - } \\
\text { - }\end{array}\end{array}$ \\
\hline Weaknesses & Threats \\
\hline List and group these & List and group these \\
\hline $\begin{array}{l}-\quad \mathrm{A} \\
-\quad \mathrm{B} \\
-\quad \mathrm{C}\end{array}$ & $\begin{array}{ll}- & \mathrm{A} \\
- & \mathrm{B} \\
- & \mathrm{C}\end{array}$ \\
\hline
\end{tabular}

Auxiliary Steps (if any):

- $\quad$ Rank significance of SWOT factors using a scale system, for example, 1-5 or A-E relative importance. This is helpful in identifying priority areas that may need to be targeted in the strategic planning process.

- A useful variation on SWOT is PESTA and multisector SWOT analysis (see references).

\section{Expected Results:}

Matrix assessment strengths, weaknesses, opportunities, and threats to an economy

\section{Finance:}

Minimal resources are required.

\section{Pointers for Implementation:}

The SWOT analysis is best undertaken by experts with specialist knowledge.

\section{References:}

A. Chapman. 2010. PESTA Market Analysis Tool. http://www.businessballs.com/pestanalysisfreetemplate.htm

A tool for conducting Multiple Industry Sector SWOT Analyses. Details on this methodology can be found in: R. J. Stimson, R. R. Stough, and B. H. Roberts. 2006. Regional Economic Development: Analysis and Planning Strategy. New York: Springer Verlag.

World Bank. 2004. SWOT Analysis Questions and Data Analysis Template. Washington, DC.

\section{Example:}

G. Swinburn, S. Goga, and F. Murphy. 2006. Local Economic Development: A Primer Developing and Implementing Local Economic Development Strategies and Action Plans. Washington, DC: World Bank, Cities of Change. p. 26.

http://siteresources.worldbank.org/INTLED/Resources/led_primer_bookmarked.pdf 


\begin{tabular}{l|l|}
\hline Tool 17: Constraints Mapping & Flowchart Reference-Phase 2: Prioritization and Strategies \\
\hline Objective: & - To develop an appreciation of the main constraints and barriers to local economic development. \\
\hline
\end{tabular}

Approach:

Various barriers and risks add to the constraints and costs of doing business in Asian cities. These constraints can be geographic, natural, political, financial, human, environmental, and technical in nature. Geographic barriers can restrict the expansion and form of a city and have a significant impact on operations and development costs. Singapore and Hong Kong, China are examples of economies constrained by geographic factors, which have been overcome through high-rise and spillover development into neighboring states and territories. Risks are factors that can be confined to climate zones or lines of tectonic activity. Climate change factors are placing many port city economies at higher risk of storm and damage because of rise in the sea level (Nicholls et al. 2007).

An assessment of the constraints affecting the operation and development of cities is an important informationgathering exercise in planning for the development of local economies. McHarg (1969) introduced a concept of sieve mapping, which involved layering a series of landscape constraints maps to identify which area of land might be suitable for development. Geographic information system technology has enabled these techniques to include overlays of social and economic constraints maps.

Threat analysis as part of strengths, weaknesses, opportunities, and threats (SWOT) analysis is used widely for strategic planning purposes in Asian cities. However, there are limitations in the use of SWOT analysis for identifying constraints to local economic development, in that the results tend to be holistic. Many constraints to economic development are sector and geographic in nature. For example, the enabling environment is primarily a government sector issue. To overcome this problem, other analytical techniques can be used (Fitzgerald and Meyer 1986) based on a qualitative assessment of the relative significance of barriers to the efficient operation of activities that support local economic development.

The rapid assessment techniques described for economic governance, community capital, linkages, and dynamics tend to reveal a range of constraints that impact the competitiveness and performance of local economies. These can be compiled with other constraints into a matrix to create a Competitiveness Index for a city.

\section{Steps:}

1. Map the physical constraints to local economic development using geographic information system resource maps using the McHarg or other methods.

2. Use a focus or expert group to brainstorm significant economic, social, behavioral, and other nonphysical constraints upon the development of the economy.

3. List the physical, economic, social, and other constraints in a matrix table used for multisector analysis (MSA).

4. Using the MSA tool, evaluate the level of impact each constraint factor is having on the economy.

5. Evaluate the results using the MSA technique.

Auxiliary Steps (if any):

- $\quad$ Start the sieve mapping of physical environment constraints early in the process.

- As an alternative to the steps described above, undertake a simple "threats analysis" as part of the general SWOT analysis.

\section{Expected Results:}

A systematic analysis of the physical, economic, social, political, governance, and other constraints impacting on the development of the city's economy

\begin{tabular}{l|l} 
Finance: & $\begin{array}{l}\text { Sustainability: } \\
\text { Minimal resources are required to use this tool. }\end{array}$ \\
$\begin{array}{l}\text { Important, as it will identify barriers to sustainability that must } \\
\text { be overcome to develop the economy. }\end{array}$
\end{tabular}

\section{Pointers for Implementation:}

It is important to separate constraints into exogenous and endogenous ones. It may be possible to overcome or relieve endogenous constraints; however, the economic system will need to be developed to reduce the effects of the exogenous constraints. 


\section{References:}

J. Fitzgerald, and P. Meyer. 1986. Recognizing Constraints to Local Economic Development. Journal of the Community Development Society 17: 115-126. Columbus: Community Development Society

I. McHarg, 1969. Design With Nature. American Museum of Natural History. Garden City, New York: Doubleday.

R. Nicholls, S. Hanson, C. Herweijer, N. Patmore, S. Hallegatte, J. Corfee-Morlot, J. Chateau, and R. Muir-Wood. 2007. Ranking Port Cities with High Exposure and Vulnerability to Climate Extremes Exposure Estimates. Paris: Organisation for Economic Co-operation and Development. http://www.oecd.org/dataoecd/16/58/39720578.pdf

\section{Examples:}

1. For a discussion, see Barriers to Growth: Local Economic Governance in Bangladesh, You Tube, http://www.youtube .com/watch?v=_DjiBm1LvD4

2. Macquarie Bank. 2008. Constraints and Opportunities Mapping for the Wollondilly Development Site. New South Wales. http://jrpp.nsw.gov.au/LinkClick.aspx?fileticket=V3_hUj-c2Vo\%3D\&tabid=105\&mid=478\&language=en-AU 
Tool 18: Prioritization - Goals Achievement Matrix Objective:

- To prioritize cross-sectoral program and financing.

Approach:

Multicriteria analysis (MCA) attempts to compare proposals for an organization or the whole of government against a set of commonly agreed overall evaluation criteria. The Goals Achievement Matrix (GAM) facilitates the evaluation of multiple alternatives against multiple objectives or goals. The GAM analysis method essentially evaluates how well a series of alternative projects, programs, or actions achieve or satisfy a set of planning goals or criteria across all departments or agencies. The method also indicates the degree to which one alternative is better or more attractive relative to all other alternatives being evaluated. GAM represents a significant improvement over MCA in that it can accommodate almost any unit format that measures the performance of alternative proposals against a specific goal or objective.

\section{Procedures for Using Goals Achievement Matrix to Evaluate Alternative Proposals}

\section{Proposals Classified by Sector Orientation}

In setting up the GAM, proposals and projects from all agencies are gathered by a central coordinating planning agency and compiled in a list. The proposals are organized by their sector orientation. Multisector agency projects are listed according to the lead or nominated agency responsible for the overall budget for the proposal. The assignment of specific proposals to an appropriate sector is not always clear. The following broad "sector" categories provide a useful classification of the wide range of projects that may be proposed by provincial and district government agencies:

- Environment/science: Proposals related to the environment, river cleanup and rehabilitation, modernization of technology, solid waste disposal, drainage, climate proofing, etc.

- Government/finance: Proposals related to government laws, management, licensing, financial policy, taxation, land management, etc.

- Industry: Proposals related to industries, export processing zones, employment and livelihoods, etc.

- Infrastructure: Proposals for infrastructure and development projects, such as. water and power supply, etc.

- Social infrastructure/services: Proposals for education, health, livelihoods, women, youth, etc.

- $\quad$ Spatial policies: Special sector related to proposals that are spatially focused

- Transport: Proposals for roads, bridges, airports, seaports, etc.

The above classification seeks to group projects that may have a multiple agency or interdisciplinary component. In cases where a sector has a minimal number of proposals, they can be allocated to the next most appropriately related sector. An alternative approach is to have proposals and projects listed by agency or department.

\section{Sector Evaluation of Projects}

This process involves designing a set of criteria related to the planning goals of the organization to evaluate projects within a given sector (similar to MCA). The selection of common goals against which all projects will be evaluated is difficult as goals can vary between agencies. As the government is responsible for allocating public resources for development and other programs, it is essential that agencies define and agree upon a common set of goals against which all types of projects will be assessed and prioritized. The goals criteria used in GAM need to be broad enough to accommodate differences in a wide range of proposals and projects to be evaluated against each other. The assessment used to evaluate the planning goals may be related to finance or performance (i.e., the number of units produced). Useful criteria that might be used in this evaluation process are the following:

Instrumentality: An assessment of the extent to which the proposal can be implemented gradually or in increments over time.

Independence: An assessment of the extent to which a proposal can be implemented independently from other proposals or projects. In other words, is a proposal dependent on the completion of several prerequisite projects? Complexity: An assessment of the extent to which a proposal needs to be dealt with by several government agencies. Funding attractiveness: An assessment of the potential for the proposal to be funded by nongovernment entities (private funding, official development assistance, grants, etc.).

Multiplier effects: An assessment of the extent to which the project has the potential to add value to the organization or the community it is designed to serve. 
Sustainability: An assessment of the sustainability of the project-are the benefits short term or long term?

Beneficiaries: An assessment of the extent to which the project benefits a small or larger group.

Dispersal: An assessment to measure how well a proposal promotes dispersal of benefits, ideas, technologies, etc.multiplier effects of these.

Environment: An assessment criterion to measure whether a proposal is likely to have a negative or a positive impact on the environment.

Poverty alleviation: An assessment to measure a proposal's ability to alleviate poverty, reduce income disparity, and generate wealth.

Growth: An assessment to measure a proposal's ability to promote economic growth.

Implementation: An assessment to measure a proposal's ability to be implemented within the plan's time frame.

There is a need to ensure that all criteria can be assessed against measurable units for scoring purposes. A numeric scale scoring system with a range of 1-5 or similar could be used to assess each project against the selection criteria. It is important to identify measurable units that can be logically associated with each criterion, such as the cost of projects expressed in dollars, employment, time scale, etc. Although the formats for criteria may differ, it should not be a cause for concern as these differences will be dealt with later as part of the overall procedure of evaluation.

\section{Scoring of Proposals against Evaluation Criteria}

Each project is scored by the review team. A general indication for evaluating scores might be:

- $0=$ Not applicable, the proposal cannot be evaluated against this criterion.

- $1=$ The proposal is likely to have a strong negative impact relevant to the criterion.

- 2 = The proposal is likely to have a moderate negative impact relevant to the criterion.

- $3=$ The proposal is likely to have no particular impact relevant to the criterion.

- $4=$ The proposal is likely to have a moderate positive impact relevant to the criterion.

- $5=$ The proposal is likely to have a strong positive impact relevant to the criterion.

Care must be taken to ensure positive and negative assessments criteria do not cancel each other out. For example, a project with high environmental impacts should be given a low score. Negative scoring should be avoided as it is very easy to confuse negative and positive impact scores.

\section{Weighing Goals}

The next step in the process involves developing a set of weighted goals. Not all goals will carry the same weight. For example, growth goals might carry a higher weight than poverty alleviation goals, since economic growth is necessary to reduce poverty. The weighing of goals is a judgment process and is therefore subjective. It can be carried out by individuals or groups. Participants awarding weights can do so, similar to allocating a budget, by distributing a given set of points over the full set of objectives.

\section{Steps:}

\section{Calculating the Result}

The following four basic steps are used to calculate a GAM score.

1. The lists of sector proposals and projects are given to specialized evaluation teams. All proposals or projects are evaluated against the planning goals criteria based on a $0-5$ scale. The score will be tabulated in rows. These scores are known as the "raw scores." An average score is then derived by summing each row and dividing this sum by the number of score entries greater than 0 . For example, if there were 12 planning goal criteria, of which only 10 were valid, the row score would be divided by 10 . The average of the scores shown in the summed column is known as the "raw score" for the project. The average raw project scores can be ranked and listed in order of priority.

2. All sector teams meet to discuss and derive a set of weights to be applied for each planning goal. It is important to involve key politicians and decision makers in this process, as the weight applied to planning goals are very political. Unless politicians are committed to setting priorities for evaluating proposal and projects, it is very difficult to get a systematic approach to decisions that affect development and management of the environment. The technique used for developing weights is the same as that used for MCA. 
3. The raw scores for each proposal or project are multiplied by the weight criterion scores to derive a matrix of weight scores. The raw scores are tabulated and an average score derived using the same method described in Step 1. It is important to divide each row by the number of valid responses to avoid the average score being underestimated. (In some cases, one or more of the criteria used in the evaluation may not be applicable to the scoring process.) The average scores are then ranked and a list of priority projects generated, which in turn becomes the basis for developing the annual action plan for an organization. Sector lists for projects are then generated for different sector agencies.

4. This involves cross-agency review and consultation process on the results of the GAM. There are many situations in which sector teams developing the raw scores for individual proposals or projects are not aware of other factors that might influence the scoring of a proposal. The review process enables fine-tuning of the results. The consultation process is very important in sorting out projects funded by multiple agencies and projects that may have a high dependency factor on a lead project being completed.

The GAM is a useful decision-making tool. The outcomes of a GAM reflect the values and judgments of public policy makers and provide a framework for setting priorities for the development of communities and societies. It is a useful technique, but it needs to be treated with care. Sometimes, the results may seem odd. For this reason, the final outcomes of the analysis need to be examined very carefully. There are often compelling reasons why some projects with low scores should be selected ahead of others.

Auxiliary Steps (if any):

It is useful before undertaking a GAM to become familiar with MCA as explained in the previous tool.

\section{Expected Results:}

1. Prioritized list of projects for an action plan on a sector-by-sector basis

2. Bundling or clustering of projects that can be implemented in a collaborative or programmatic manner

\section{Resources:}

The resources needed to prepare a GAM are mainly those to run the expert reference groups. However, the process can be very political as different agencies compete for projects. The process, therefore, can become prolonged, especially in developing the goal criteria and in finalizing the list and ranking of projects.

\section{Pointers for Implementation:}

It is very important to include senior decision makers and politicians in defining and weighting the "goals and achievements criteria" used to conduct the analysis. The analysis is best done on a thematic or sector-by-sector basis.

\section{References:}

Cities Development Initiative for Asia (CDIA). 2010. City Infrastructure Investment Programming \& Prioritisation Toolkit (CIIPP). http://cdia.asia/wp-content/uploads/User-Manual-Generic-version-2010.pdf (accessed 31 October 2011).

M. Hill. 1973. The Goals Achievement Matrix (GAM) Method of Evaluation. Chapel Hill, NC: University of North Carolina.

\section{Examples: Case Study}

The following example demonstrates the four-step process to prepare a GAM. The case study shows how GAM was applied to determine a priority list of projects to prepare an annual action plan for a district or local government in Viet Nam for a United Nations Development Programme urban management project. It was used to conduct an assessment for over 600 projects involving six sector agencies. Only a small amount of information for three sectors is shown.

While GAM may look confusing, it is a relatively simple and widely used technique. The technique has been further developed by the Cities Development Initiative for Asia (CDIA 2010) as the City Infrastructure Investment Programming and Project Prioritisation Toolkit and applied successfully for evaluation and prioritization of urban infrastructure projects in cities. 
Tool 19: Inclusive Urban Development Project/Program Preparation

\section{Objectives:}

- To understand and apply commercially viable project development principles to inclusive urban development capital investments.

- To promote project design based on the affordability of the targeted populations and support cost recovery.

- To finance projects through a basket of resources as dedicated funds for debt servicing.

\section{Approach:}

Based on key issues and problems identified in the city poverty and vulnerability profile, and the priorities and options established in Phase 2, the project/program component phase will define the nature of program or the type of project most suited to address the needs of the identified beneficiaries.

- To establish commercially viable projects through key financial indicators that include the following:

(i) Operating ratios: recurring revenue cover at least recurring expenses

(ii) Interest payments: operating surplus covers annual interest payment

(iii) Project returns: project returns > capital expenditure

- Debt repayment: Comfort level of the project is enhanced by ring-fenced dedicated revenues for debt servicing.

- To initiate new shelter and home improvement loans in community-based financial entities, credit unions, solidarity groups, dedicated finance companies, and/or public finance entities at market rates with products based on affordability and capacity to pay for the user.

- To prepare projects that can raise financing on the domestic capital market or through loans.

- To determine user fees on a system-wide basis rather than relying on cost recovery being project specific.

\section{Steps:}

1. Define the key sectoral issues and needs of the poor based on the city poverty and vulnerability profile.

2. Outline the prioritized spatial areas and target group/community for targeted inclusive investments.

3. Define the prioritized sector (water, solid waste, transport, shelter, etc.) and the sector focus (access, coverage, affordability, expansion of infrastructure/new infrastructure, climate proofing, etc.)

4. Decide on the basis of needs and priorities identified for the target area(s) and communities if the needs can be best addressed through a project or program. Ascertain if it fits into an existing program component.

5. Define the project objectives and expected targets, and establish indicators and measures for monitoring and evaluation.

6. Design the project keeping in mind social, cultural, economic, and environmental criteria. Take into account the capacity of the community to arrive at potential and realistic solutions. Integrate adaptable solutions within the existing physical environment to ensure least disruption.

7. To prepare commercially viable projects,

(i) estimate capital costs,

(ii) estimate recurring costs,

(iii) estimate recurring revenues,

(iv) determine level of debt, and

(v) recover costs.

6. Keep in mind the affordability assessment while setting fees and tariffs.

7. Incorporate potential public resources. Tap private resources and integrate corporate social responsibility components where available.

8. Determine the finance mechanism for the project as a loan or bond or any other such option. Identify the most feasible financial option that is affordable to the poor.

\section{Expected Results:}

- $\quad$ Projects developed as commercially viable can access the domestic capital market.

- Commercially viable projects can be serviced through a basket of resources, including user fees, general revenue, taxes, and special funds. 


\section{Pointers for Implementation:}

- $\quad$ Cities Development Initiative for Asia (CDIA) promotes a pre-feasibility study approach for cities. The pre-feasibility study process can provide the opportunity for the city to consider a range of issues during the project development stage, enabling it to design projects that have a greater and broader development impact. As such, it is ideal that city governments apply the pre-feasibility study process within their own planning frameworks to proactively develop and institutionalize changes that will support demand-driven urban development. (See the PFS User Manual (CDIA and UN-Habitat 2012) for detailed guidance on the development of bankable infrastructure projects).

- Community-based financial entities, credit unions, solidarity groups, and dedicated branch finance companies have the local knowledge that facilitates cost recovery, especially for shelter lending.

- Project design can be composed of different technical solutions based on affordability as part of the same service delivery system.

- For bond issues from the domestic capital market, "ring-fenced" resources raise the "comfort level" of investors, making the project a more attractive investment.

- Bulk lending modalities may be considered from formal sector finance entities to community-based organizations for small loans whose administrative costs would seem too high for larger firms.

\section{Resources:}

- The Asian Development Bank staff and developing member country project developers should consider the domestic capital market and insurance market as an important source of multiyear program finance.

- Bonds from infrastructure finance can lead to a secondary market to support resource flows.

- Pooled financing can join smaller projects that are commercially viable to pool together to venture into the domestic capital market.

\section{Sustainability:}

- Commercially viable projects are by definition sustainable if implemented as planned with identified initiatives for debt servicing and user fees.

- Local government requires the authority to enter into contractual relations with technical and finance entities to prepare, finance, and implement projects.

\section{References:}

International Finance Corporation. 2010. International Accountability Project. Key Issues for Upholding Housing, Land and Property Rights in the International Finance Corporation's Review of the Environmental and Social Policy and Standards. Washington, DC.

United States Agency for International Development (USAID). 2007. Municipal Finance: A Guide for USAID Staff and Partners. Washington, DC.

USAID/India. 2011. Developing Sustainable and Inclusive Urban Infrastructure Services. Washington, DC: The Communities Group International.

\section{Example:}

An example for undertaking urban renewal through a national program is shown in Box 3.

Cities Development Initiative for Asia (CDIA) and United Nations Human Settlements Programme (UN-Habitat). 2012. Pre-Feasibility Studies (PFS) User Manual. Manila: CDIA. 


\section{Box 3: Urban Renewal in India}

An Indian program, the Jawaharlal Nehru National Urban Renewal Mission (JnNURM), was initiated by the Government of India in 2001. JnNURM wants to draw up a coherent urbanization policy and strategy to implement projects in select cities. These projects are meant to implement urban sector reforms. They are fast-tracked and represent planned development with a focus on efficiency in urban infrastructure delivery. Community participation and accountability of urban local bodies toward its citizens is a value addition.

The JnNURM strategy takes a long-term view over a 20-25-year period, with 5-year updates. Each city in the mission program is to develop policies for funding that include national, state, local, and external sources, followed by future growth plans for each 5-year plan that integrate land use with services, urban transport, and environmental management. This is to be followed by specific city development plans, required for a city to access program funds. The plans are implemented through detailed project reports in identified cities with a clear role for the private sector in the development, management, and financing of urban infrastructure.

Among the objectives of this national program for urban development is the integrated development of slums in designated cities. The program, conceived as an enabling framework, provides improved shelter, basic services, and other civic amenities to the urban poor, as well as security of tenure, at affordable prices. Where possible, housing is located near people's workplace, reducing the environmental impact.

Source: ADB. 2011. Inclusive Cities. Manila. 
Tool 20: Basic Urban Infrastructure Program

Flowchart Reference-Phase 3: Project/Program Component

\section{Objectives:}

- To understand the urgency and issues of improving inclusive urban infrastructure project development in existing communities for national and especially local governments.

- To expand urban infrastructure to unserved and underserviced communities.

- To address site protection and mitigation infrastructure as part of inclusive urban infrastructure development.

\section{Approach:}

Based on key issues and problems identified in the city poverty and vulnerability profile, and the priorities and options established in Phase 2, the project/program component phase will define the nature of programs most suited to address the needs of the identified beneficiaries:

- To include informal and slum areas in the overall city system for power, water supply, sanitation, and solid waste management service systems.

- $\quad$ To identify safe sites for future growth and its proximity to existing infrastructure.

- To calculate user fees on a system-wide basis to cover expansion.

- To build resilience into the technical designs of the services to be provided.

- To consider areas upgraded in existing communities as part of the inclusive service system.

- To develop incremental options as part of the technical solutions proposed that respond to affordability.

- To include access to credit as needed for household connections and other improvements as part of the project.

- To engage with the private sector in project development and management.

- To support development at higher densities for their efficiencies.

Steps:

1. Define the key sectoral issues and needs of the poor based on the city poverty and vulnerability profile.

2. Outline the prioritized spatial areas and target group/community for targeted inclusive investments.

3. Define the prioritized sector (water, solid waste, transport, shelter, etc.) and the sector focus (access, coverage, affordability, expansion of infrastructure/new infrastructure, climate proofing, etc.).

4. Decide on the basis of the needs and priorities identified for the target area(s) and communities, if the needs can be best addressed through a project or program. Ascertain if it fits into an existing program component.

5. Build on the existing information base and the priorities identified for urban services for the existing built environment and future growth.

6. Identify formal and informal settlements that are not yet served and/or are yet part of the city's system.

7. Define the project objectives and expected targets, and establish indicators and measures for monitoring and evaluation.

8. Design the project keeping in mind social, cultural, economic, and environmental criteria. Take into account the capacity of the community to arrive at potential and realistic solutions. Integrate adaptable solutions within the existing physical environment to ensure least disruption.

9. Identify specific sites for future growth that consider climate change and disaster risk management.

10. Establish, through consultation and outreach with priority communities, their affordability, capacity to pay, and their willingness to pay for a service to be provided.

11. Prepare several technical and financial options for identified projects to be discussed with community members.

12. To prepare commercially viable projects,

(i) estimate capital costs,

(ii) estimate recurring costs,

(iii) estimate recurring revenues,

(iv) determine level of debt, and

(v) recover costs.

13. Keep in mind the affordability assessment while setting fees and tariffs.

14. Incorporate potential public resources. Tap private resources and integrate corporate social responsibility components where available.

15. Determine the commercial viability of the proposed project.

16. Determine the finance mechanism for the project as a loan or bond or any other such option. Identify the most feasible financial option that is affordable to the poor.

17. Carry out training identified to improve urban service operations, maintenance, and expansion. 


\section{Expected Results:}

- $\quad$ Projects developed as commercially viable can access the domestic capital market.

- Commercially viable projects can be served through a basket of resources, including user fees, general revenue, taxes, and special funds.

\section{Pointers for Implementation:}

- Establish the feasibility of service provision to communities on marginal land.

- Consider prepaid cards for use of public water supply under community management.

- Consider community toilets as a first phase of a sanitation system under community management.

- Water companies should be either a local government office or a state or regional entity responsible for reporting to the local government.

- Consider expanding service networks to infill underserved areas and develop extensions for close-in sites for new growth.

- Avoid selecting project sites far removed from the existing city; should a site be remote, consider value-added taxes to the properties that front on the new trunk lines, roads, and grids.

- Supporting access to consistent supplies of urban infrastructure is a stimulus to local economic development and needs to be dimensioned to accommodate that potential.

Resources:

- Urban infrastructure finance becomes a local government prerogative.

- User fees are set as part of a basket of resources required to operate, maintain, and expand a particular service.

- Metering and other technologies such as prepaid cards are employed to encourage responsible use and recover costs.

\section{Sustainability:}

- Urban infrastructure sustainability includes not only the financial aspects of service delivery but also the management capacity of the provider to operate, maintain, and expand the service system.

- Users pay for services provided.

- Building disaster risk management into technical designs, including the incremental development of a service system.

\section{References:}

ADB. 2003. Proposed Loan to Indonesia for the Neighborhood Upgrading and Shelter Sector Project. Manila.

Cities Alliance. 2007. Liveable Cities: The Benefits of Urban Environmental Planning. Washington, DC.

Cities Alliance. 2009. Land, Services and Citizenship for the Urban Poor. Washington, DC.

M. Kitay. 1985. Land Acquisition in Developing Countries: Policies and Procedures of the Public Sector. Cambridge, MA: Lincoln Institute of Land Policy.

United Nations Human Settlements Programme (UN-Habitat). 1996. An Urbanizing World: Global Report on Human Settlements. Oxford: Oxford University Press.

USAID/India. 2011. Developing Sustainable and Inclusive Urban Infrastructure Services. Washington, DC: The Communities Group International.

\section{Example:}

Cities Development Initiative for Asia (CDIA) and United Nations Human Settlements Programme (UN-Habitat). 2012. Pre-Feasibility Studies (PFS) User Manual. Manila: CDIA. 
Tool 21: Shelter/Upgrading Program

Flowchart Reference-Phase 3: Project/Program Component

Objectives:

- To identify priority slum areas, center city tenements, and informal settlements that can be improved, all of which share tenure, access to urban services and community facilities, and resilience issues and opportunities.

- To implement qualitative and quantitative improvements in housing units and sites to improve construction material durability, to initiate small commercial activities, and to avoid overcrowding.

- To improve urban services in priority communities, especially water supply, solid waste management, power and sanitation systems, and to increase coverage and service levels.

- To provide space for community facilities and their programs, including schools, clinics, and other community functions.

Approach:

- To build on the information consolidated in the prior phases of understanding the urban context and establishing priorities that identify needs and rank communities for upgrading.

- To validate and update the city poverty and vulnerability profile with specific data on priority communities.

- To provide technical and financial support through dedicated finance institutions and community-based financial organizations to families for upgrading their structures in size and durability, and for site protection.

- To provide technical and financial support to local governments to provide affordable urban services to improve the health of the community, and support local economic activity.

- To identify families for resettlement located in highly vulnerable areas that climate change and disasters will affect

- To train local community residents in improved construction skills and local economic development building material products for the local market.

- To document the programs and products developed for other communities to replicate.

Steps:

1. Establish a team in the local government to manage the slum upgrading program.

2. Enter into partnerships with national agencies, local nongovernment organizations (NGOs), and private sector entities engaged in construction, community outreach, and finance to support the implementation of community upgrading program s. Tools such as the Participatory Approach for Safe Shelter Awareness (PASSA), which is a participatory method of disaster risk reduction (DRR) related to shelter safety, developed by the International Federation of Red Cross and Red Crescent Societies, can be used for broader community engagement. The aim of PASSA is to develop local capacity to reduce shelter related risk by raising awareness and developing skills in joint analysis, learning and decision-making at community level (International Federation of Red Cross and Red Crescent Societies, 2011) ref: International Federation of Red Cross and Red Crescent Societies, 2011. PASSA Participatory Approach for Safe Shelter Awareness. Geneva. http://www.ifrc.org/PageFiles/95526/publications/305400-PASSA\%20manual-EN-LR.pdf

3. The team carries out, or contracts for, a survey of the needs of the slum communities in indicated priority slum communities, center city tenements, and informal settlements of the city.

4. The team prepares simple retrofit guidance sheets for families to take away for guidance on retrofitting strategic components of the home that could be potentially affected by high winds, sea-level rise, flooding, landslides, and earthquakes, among others.

5. The team carries out assessments of the resilience of community facilities, especially schools, clinics, and hospitals, among others.

6. Establish and publicize retrofitting programs through community consultations, household visits by retrofitting volunteers, and the local media.

7. Monitor the demand for and issues that arise in upgrading and document the improvements made and the technologies employed for the benefit of other families.

\section{Expected Results:}

- Assessments of slum communities, center city tenements, and informal settlements—their structures, services, and facilities - that prioritize upgrading investments.

- A typology of improvements detailed through upgrading guidance sheets that provide families with technical and cost information for improvements that reflect the settlement context, especially the incremental upgrading of services, structures, and the environment.

- $\quad$ Detailed upgrading programs that focus on priority locations and the shelter, site, and facilities to be upgraded.

- $\quad$ Program partnerships of national and local government offices with NGOs, private sector entities, and communitybased organizations to design, finance, and implement upgrading programs.

- Upgrading programs that are multiyear initiatives organized by local governments with national agencies, communitybased organizations, NGOs, and private sector companies offering support to slum improvements programs. 
- Capacity-building and training support for teams to carry out slum needs assessments and the recommended improvements in housing units and plots, community facilities, and urban services infrastructure

\section{Pointers for Implementation:}

- The team prepares guidance for an array of improvements that address the context of each location to be validated and vetted with identified communities.

- Upgrading surveys are carried out on the city information base that has prepared initial assessments of priority locations.

- Upgrading improvements can be a viable product in the lending portfolio, which the community lending organizations can support.

- Increasing the quality and coverage of urban service systems in slums, tenements, and informal settlements requires dedicated technical and financial support.

- Demonstration of upgrading programs can be a useful means to focus investment on the issue. The experience can be incorporated into larger slum upgrading, inner-city tenements, historic urban area, and informal settlement upgrading programs.

- Creating a demand for upgrading, and the proactive improvements it represents, is facilitated through community consultations to present the comparative costs of home and infrastructure improvements.

- The role of the community is critical in advocating change and improvements.

- Upgrading sheets would focus on the roof, wall materials, foundations, windows and doors, urban gardens, and plot improvements for water catchment, erosion control, and passive shelter protection of overhangs and windbreaks.

Resources:

- $\quad$ Finance for slum upgrading programs can be initiated through dedicated developing member country programs of the Asian Development Bank that serve to define the parameters, products, and process for upgrading initiatives.

- National urban upgrading programs can offer funds through incentives, with matching contributions from local governments, to spread available resources over a larger number of slum communities.

- Local technical and finance partners continue ongoing upgrading initiatives on the reflows of improvement loans.

- $\quad$ Bundling upgrading loans for a secondary market can bring fresh resources for onlending.

\section{Sustainability:}

- Local government can bring in important support through its political will to implement improvement programs by including slums, center city tenements, and informal areas on the official city map and through awareness campaigns.

- Local finance and development entities, NGOs, and private sector companies view lending for upgrading as an addition to the loan products they offer.

- The national government supports local government multiyear community upgrading initiatives through incentives and budget support.

\section{References:}

ADB. 2003. INO: Report and Recommendation of the President to the Board of Directors: Proposed Loan to Indonesia for the Neighborhood Upgrading and Shelter Sector Project. Manila.

ADB. 2003. Proposed Loan to Indonesia for the Neighborhood Upgrading and Shelter Sector Project. Manila.

International Federation of Red Cross and Red Crescent Societies, 2011. PASSA Participatory Approach for Safe Shelter Awareness. Geneva. http://www.ifrc.org/PageFiles/95526/publications/305400-PASSA\%20manual-EN-LR.pdf

L. Baker and K. McClain. 2009. Private Sector Initiatives in Slum Upgrading. Washington, DC: The World Bank Group.

F. Steinberg. 2009. Urban Renewal and Slum Rehabilitation: A Sectoral Agenda within ADB's Strategy 2020. Urban Community of Practice presentation. Manila: ADB.

United Nations Human Settlements Programme (UN-Habitat). 2003. The Challenge of Slums: Global Report on Human Settlements. London: Earthscan.

UN-Habitat Shelter Branch. 2003. Concept Paper on Pro Poor Land and Housing. Nairobi: UN-Habitat and Institute for Housing and Urban Development Studies.

\section{Example:}

F. Steinberg. 2008. Revitalization of Historic Inner-City Areas in Asia: The Potential for Urban Renewal in Ha Noi, Jakarta, and Manila. Urban Development Series. Manila: ADB. 
Tool 22: Shelter Program-Retrofitting Existing Structures and Urban Infrastructure
Flowchart Reference-Phase 3: Project/Program Component

\section{Objectives:}

- To address the vulnerabilities in existing communities by retrofitting existing structures, especially homes, schools, and community facilities.

- To determine the vulnerabilities and provide investments to upgrade a city's urban services, especially water supply, solid waste management, power and sanitation systems, and retrofit their networks, sites, and equipment.

\section{Approach:}

- To build on the information consolidated in the prior phases of understanding the urban context and establishing priorities that identify and rank vulnerable infrastructure and structures.

- To provide technical and financial support through dedicated finance institutions and community-based financial organizations to families for retrofitting their structures and for site protection.

- To provide technical and financial support to local governments to retrofit the city's urban services to improve the resilience of the city's urban infrastructure systems.

- To identify and focus retrofit initiatives on local hazards identified in the city information base and in disaster risk management assessments.

- To generate local economic activity in improving the resilience of homes and plots in vulnerable communities.

\section{Steps:}

1. Establish a team in the local government to manage a multiyear retrofit initiatives.

2. Enter into partnerships with local nongovernment organizations (NGOs) and private sector entities engaged in construction, community outreach, and finance to support retrofit program implementation.

3. The team carries out, or contracts for, a survey of vulnerable structures and services in priority communities and vulnerable areas of the city indicated in the city information base.

4. The team prepares simple retrofit guidance sheets for families to take away for retrofitting strategic components of the home that could be potentially affected by climate change impacts, including high winds, sea-level rise, flooding, landslides, and earthquakes, among others.

5. The team carries out assessments of the resilience of community facilities, especially schools, clinics, and hospitals, among others.

6. Establish and publicize retrofitting programs through community consultations, household visits by retrofitting volunteers, and the local media.

7. Monitor the demand and issues that arise from retrofitting programs and document the improvements made and the technologies employed for outreach to other families.

\section{Expected Results:}

- Assessments of vulnerable communities and structures that prioritize retrofit investments and home improvements.

- $\quad$ Simple retrofit guidance sheets to provide to families technical and cost information for improvements.

- $\quad$ Retrofit programs for community facilities, especially schools, health facilities, hospitals, and community structures.

- Program partnerships of national and local government offices with NGOs, private sector companies, and community-based organizations to design, finance, and implement retrofit initiatives.

- Retrofit programs that are multiyear initiatives organized by local governments.

- Capacity-building and training support for teams to carry out vulnerability assessments and the recommended improvements in house structures and plots, community facilities, and infrastructure. 


\section{Pointers for Implementation:}

- The team prepares guidance parameters to be vetted and validated with communities to demonstrate improvements to be made to tackle potential impacts of specific hazards.

- The vulnerability surveys to be carried out can build on the city information base that has prepared initial assessments.

- Retrofitting is to be considered a home improvement, which small community lending organizations can support.

- Retrofitting city urban service systems requires dedicated technical support and technical analysis as part of the maintenance programs for a city.

- Retrofitting finance programs can protect existing capital investments and can be a useful means to focus investment on the issue.

- The pilot experiences can be incorporated into larger slum upgrading, inner-city tenements, historic urban area, and informal settlement upgrading programs.

- Creating a demand for retrofitting, and the proactive improvement it represents, is best explained through presentations on hazard vulnerabilities and the comparative costs of small improvements and larger replacement costs for damages incurred.

- $\quad$ Retrofit guidance sheets would focus on the roof, wall materials, foundations, windows and doors, and plot improvements to control erosion flooding and contamination of water supplies, and the upkeep of sanitation facilities, among others.

Resources:

- $\quad$ Finance for retrofitting programs can be initiated through dedicated Asian Development Bank developing member country partner programs that serve to define the parameters, products, and process for retrofit initiatives.

- Local technical and finance partners continue ongoing initiatives on the reflows of improvement loans.

- Bundling retrofit loans for a secondary market can bring fresh resources for onlending.

\section{Sustainability:}

- Local government can bring important support through its political will to implement a retrofit program through awareness campaigns.

- Local finance and development entities, NGOs, and private sector companies view lending for retrofitting as an addition to the loan products they offer.

- Local government offers incentives and support to retrofitting programs to lending companies.

\section{References:}

Asian Disaster Preparedness Center. 2005. A Primer: Disaster Risk Management in Asia. Bangkok.

Asian Disaster Preparedness Center. 2005. A Primer: Integrated Flood Risk Management in Asia. Safe Cities Series. Bangkok.

World Bank. 2009. Climate Resilient Cities: A Primer on Reducing Vulnerabilities to Disasters. Washington, DC.

World Bank. 2010. Safer Homes, Stronger Communities: A Handbook for Reconstructing after Natural Disasters. Washington, DC.

\section{Example:}

F. Steinberg. 2008. Revitalization of Historic Inner-City Areas in Asia: The Potential for Urban Renewal in Ha Noi, Jakarta, and Manila. Urban Development Series. Manila: ADB. 
Tool 23: Shelter Program-Revitalization of Historic Areas

Flowchart Reference-Phase 3: Project/Program Component

\section{Objectives:}

- To incorporate historic urban areas as a resource into inclusive urban development programs.

- To establish the components of a historic urban area revitalization plan to formulate improvement and upgrade investments through a participatory process.

\section{Approach:}

- To build on the information consolidated in the prior phases of understanding the urban context and establish priorities that identify historic urban areas as a resource with their needs and opportunities.

- To prepare walking tours of selected historic areas to inform residents and visitors of the history and uniqueness of the area, construction, planning, and dwellings.

- To prepare a typology of historic urban areas and properties and the improvements that are needed to revitalize the area, structures, and the local economy.

- To provide technical and financial support through dedicated financial institutions and community-based financial organizations to families for conserving their structures' architectural details, construction methods, and site protection requirements.

- To prepare a management plan for revitalization issues, including tenure, rental development, regulatory interventions, public-private sector participation, and investment in services and support for local economic activity.

- To train local builders in conservation and improved construction technologies.

- To document programs and products developed for historic urban areas for outreach purposes.

\section{Steps:}

1. Establish an entity in the local government to manage the revitalization program.

2. Enter into partnerships with national agencies, local nongovernment organizations (NGOs), and private sector entities engaged in construction, community outreach, and finance to support historic urban area revitalization.

3. Carry out, or contract for, a survey of priority historic urban areas, including their histories and their particular architectural and planning importance, and details.

4. Prepare conservation and revitalization guidance sheets for families and builders for conservation, reuse, and resilience.

5. Provide technical support in formulating revitalization plans of a family or group of families to improve tenure, security, and livability for tenants, and guidance on architectural improvements, reuse, and site protection.

6. Establish and publicize historic urban area programs through community consultations, household and homeowner visits by conservation volunteers, the preparation of walking tours to encourage tourism, and the local media.

7. Monitor the demand and issues that arise and document the improvements made and the technologies employed for other historic areas and families.

\section{Expected Results:}

- Assessments of priority historic urban areas and their communities - their histories, structures, services, and facilities that prioritize revitalization investments.

- A typology of historic structures and their improvements detailed through conservation guidance sheets that provide builders, the private sector, and families with technical and cost information for improvements that reflect the area's context, especially architectural details, building plans, and the incremental upgrading of services and the environment.

- $\quad$ Detailed revitalization program profiles that focus on priority locations and the shelter, sites, and facilities to be upgraded.

- $\quad$ Program partnerships of national and local government offices with NGOs, private sector companies, and community-based organizations to design, finance, and implement revitalization programs.

- $\quad$ Revitalization programs that are multiyear initiatives organized by local governments and tenant associations with national agencies, community-based organizations, NGOs, and private sector companies offering support to historic urban area conservation.

- Capacity-building and training support for teams to carry out conservation needs assessments and the recommended improvements in building technologies, dwelling units and plots, community facilities, and urban infrastructure. 


\section{Pointers for Implementation:}

- The local government entity prepares guidance to be validated and vetted with identified owners and tenants, the array of improvements possible, and the context of each location that includes construction and/or rehabilitation of relevant basic infrastructure; upgrading existing buildings following conservation guidance; removing additions that were done as "modernization improvements"; and recycling and adaptive reuse of existing structures.

- Historic urban area revitalization builds on the city information base that has prepared initial assessments of priority locations.

- $\quad$ Upgrading improvements can be a viable product in the lending portfolio, which the community lending organizations can support.

- Demonstration of conservation programs can be a useful means to focus investment on the issue. The experience can be incorporated into larger historic urban area upgrading programs.

- Creating a demand for historic urban area revitalization, and the proactive improvement it represents, is facilitated through stakeholder consultations to present the value of the historic areas and the comparative costs of home and infrastructure improvements.

- The role of the local government with stakeholders is key in advocating change and improvements, enforcing regulations and providing incentives.

- Public-private partnerships represent a productive approach to revitalization.

\section{Resources:}

- $\quad$ Finance for historic urban area programs can be initiated through dedicated Asian Development Bank developing member country programs that serve to define the parameters, products, and the process for historic urban area conservation and revitalization initiatives.

- National conservation improvement programs can offer funds, with local governments matching contributions from that of private sector companies and owners, to include historic urban area upgrading in home improvement lending.

- Local technical and finance partners continue ongoing upgrading initiatives on the reflows of improvement loans.

- Bundling revitalization loans for a secondary market can bring fresh resources for on-lending.

\section{Sustainability:}

- Local government can bring in important support through its political will to implement historic urban area improvement programs by including them on the official city map and through awareness campaigns.

- Local finance and development entities, NGOs, and private sector companies view lending for revitalization and retrofitting as an addition to the loan products they offer.

- The national government supports local government multiyear revitalization initiatives through tourism development and incentives, budget support, and public-private partnerships.

\section{References:}

ADB. 2003. INO: Report and Recommendation of the President to the Board of Directors: Proposed Loan to Indonesia for the Neighborhood Upgrading and Shelter Sector Project. Manila.

E. Rojas. 1999. Old Cities, New Assets: Preserving Latin America's Urban Heritage. Washington, DC: Inter-American Development Bank.

F. Steinberg. 2008. Revitalization of Historic Inner-City Areas in Asia: The Potential for Urban Renewal in Ha Noi, Jakarta, and Manila. Urban Development Series. Manila: ADB.

A. Tyabji. 2006. Bhuj. India: Mapin PublishingMumbai.

E. Vines. 2005. Streetwise Asia. A Practical Guide for the Conservation and Revitalization of Historic Cities and Towns in Asia. Bangkok: UNESCO.

\section{Example:}

F. Steinberg. 2008. Revitalization of Historic InnerCity Areas in Asia: The Potential for Urban Renewal in Ha Noi, Jakarta, and Manila. Urban Development Series. Manila: ADB.

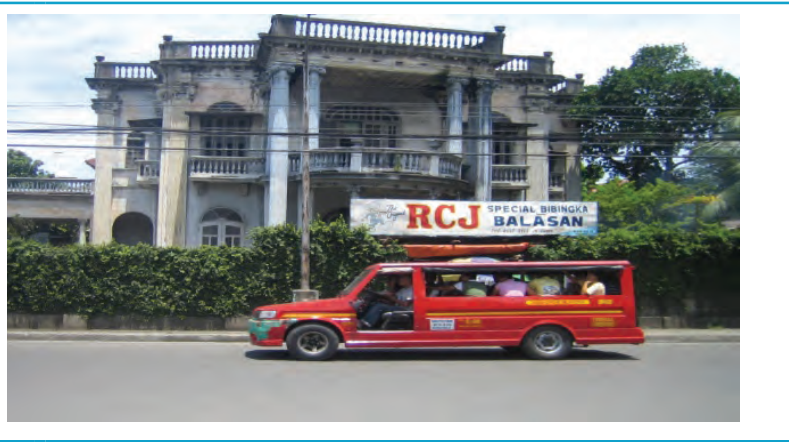


Tool 24: Shelter Program/Resettlement

\section{Objectives:}

- $\quad$ To place resettlement in the context of proactive disaster risk management (DRM) and inclusive urban development policy and practice as complementary components of retrofitting and new shelter development initiatives and/or stand-alone programs.

- To prepare programs for resettlement that feature acceptable location choices that offer opportunities for economic activity, social structure, and access to service.

Approach:

- $\quad$ To build on the information consolidated in the city poverty and vulnerability profile and prior phases of Understanding the Urban Context and Establishing Priorities that identify vulnerabilities, available land, improved building material resources and technologies, and infrastructure and shelter options for resettlement.

- To establish a participatory process to engage the local government with vulnerable families, especially low-income families, in the design and development of resettlement sites.

- To identify and map existing communities and locations vulnerable to natural hazards and climate change impacts and to assess the social and economic reasons for the choice of location.

- To prepare a typology of sites for resettlement that range from infill sites close to existing settlements and/or acceptable alternative locations that offer access and opportunities to relocated families.

- To provide technical and financial support to vulnerable families through nongovernment organizations (NGOs), dedicated finance institutions, and community-based financial organizations for inclusive resettlement initiatives.

- To support technical innovations and incremental implementation strategies in infrastructure delivery and shelter construction and development.

- To document the programs and products developed for outreach purposes.

Steps:

1. Establish a dedicated entity to manage resettlement policy that addresses land resources, development incentives, regulatory interventions, private sector participation, and support for local economic activity.

2. Prepare and implement a participatory process in partnership with national agencies, local NGOs, and private sector entities engaged in construction, community outreach, and finance to support resettlement.

3. Carry out, or contract for, a survey of communities vulnerable to natural hazards and climate change impacts based on the city information base.

4. Assess cost-benefit between remedial action and resettlement that limits damage and loss to life, property, and the local economy.

5. Provide support to local institutions, planning entities, and universities to formulate approaches and technical innovations for resettlement.

6. Establish public-private partnerships for resettlement as a component of guided land development.

7. Monitor resettlement implementation issues and document improvements made and the technologies employed.

\section{Expected Results:}

- $\quad$ Reduced loss of life and property in vulnerable locations and families

- Identification and assessment of priority vulnerable communities and alternative locations for resettlement

- Environmentally sensitive and natural protection areas not apt for development restored

- An inventory of available land resources, including landowners interested in guided land development

- Detailed resettlement program profiles that focus on priority infill and new settlement locations; access to transport, employment, and shelter; and urban services and facilities to be developed on resettlement sites

- A directory of program partners of national and local government offices, including NGOs, private sector companies, and community-based organizations to design, finance, and implement resettlement programs

- Capacity-building and training support for alternative planning and use of vacated settlement sites and vulnerable locations 


\section{Pointers for Implementation:}

- $\quad$ Prepare annotated vulnerability maps to identify communities subject to hazard and climate change impacts.

- Prepare maps that identify available land and owners of land resources that include infill sites and new settlement areas.

- $\quad$ Resettlement policy and programs build on the city information base that has prepared initial assessments of priority vulnerable locations and resettlement sites.

- Resettlement programs need to be voluntary, unless risk is extreme and the decision to relocate is based on the community history of cyclical disaster impacts.

- NGOs and community-based organizations are useful partners to facilitate consultations to inform communities on their risks and the alternatives available.

- Proactive planning and inclusive resettlement development are facilitated through stakeholder consultations to determine priorities, capacity to pay, and affordability guidance.

- The role of the local government with stakeholders is key in advocating change and improvements, enforcing regulations, and providing incentives for inclusive shelter and infrastructure development.

- Public-private partnerships and guided land development represent a productive approach to resettlement.

- $\quad$ Public-private partnerships represent a productive approach to revitalization.

\section{Resources:}

- Resettlement initiatives can initially be financed through dedicated Asian Development Bank developing member country programs that define parameters, products, and the process for resettlement.

- National inclusive urban infrastructure and shelter programs can offer funds through incentives, with local governments to include resettlement as stand-alone programs and/or components of urban upgrading initiatives.

- Resettlement can be a feature of locally financed infrastructure and shelter development and programs.

\section{Sustainability:}

- Local government provides the political will to engage in resettlement as part of its DRM programs.

- Local finance and development entities, NGOs, and private sector companies view lending for resettlement initiatives as an addition to the loan products they offer.

- National government DRM programs support local government resettlement initiatives as components of multiyear inclusive shelter and urban service delivery systems.

- Pooled financing can provide financial support to resettlement initiatives for smaller urban infrastructure development projects.

\section{References:}

ADB. 2003. Report and Recommendation of the President to the Board of Directors: Proposed Loan to Indonesia for the Neighborhood Upgrading and Shelter Sector Project. Manila.

H. Caminos and R. Goethert. 1983. Urbanization Primer. Cambridge, MA: MIT Press.

E. Correa. 2011. Resettlement as a Tool for Disaster Risk Reduction. In Populations at Risk of Disaster: A Resettlement Guide with F. Ramírez and H. Sanahuja. Washington, DC: World Bank.

International Federation of Red Cross and Red Crescent Societies, 2011. PASSA Participatory Approach for Safe Shelter Awareness. Geneva. http://www.ifrc.org/PageFiles/95526/publications/305400-PASSA\%20manual-EN-LR.pdf

J. Shaw and I. Ahmed. 2008. Design and Delivery of Post-Disaster Housing Resettlement Programs: Case Studies from Sri Lanka and India. Melbourne: Monash Asia Institute.

United Nations Human Settlements Programme (UN-Habitat). 2009. Post Tsunami Aceh-Nias Settlement and Housing Recovery Review. Jakarta.

United States Agency for International Development (USAID). 2005. LAC Housing and Urban Upgrading Assistance Retrospective, Honduras and Ecuador, 1980-2005. Research Triangle Institute. RTI International http://pdf.usaid.gov/ pdf_docs/pdacj073.pdf

World Bank. 2009. Climate Resilient Cities: A Primer on Reducing Vulnerabilities to Disasters. Washington, DC. 
Step 1: Define raw scores.

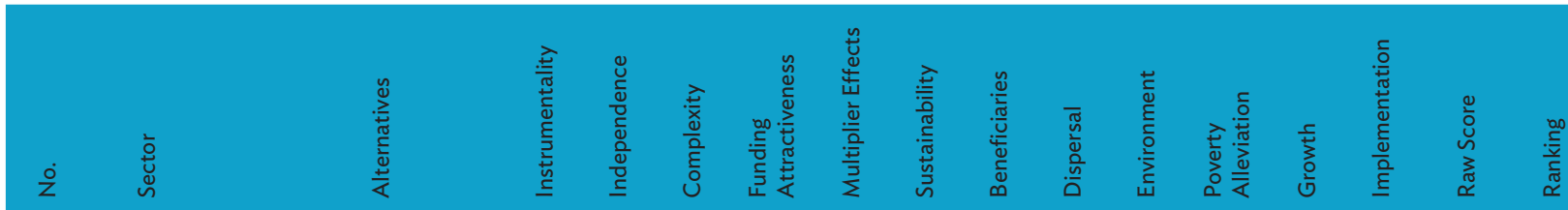

$\begin{array}{llllllllllllllllll} & & \begin{array}{l}\text { Complete inner } \\ \text { T1 }\end{array} & \text { Transport } & \text { ring road } & 2 & 3 & 3 & 4 & 5 & 3 & 2 & 3 & 3 & 5 & 2 & 4 & 3.3\end{array}$

\begin{tabular}{|c|c|c|c|c|c|c|c|c|c|c|c|c|c|c|c|}
\hline $\mathrm{T} 2$ & Transport & $\begin{array}{l}\text { Inner ring road } \\
\text { bridge }\end{array}$ & 2 & 4 & 4 & 2 & 3 & 1 & 5 & 4 & 4 & 5 & 3 & 2 & 3.3 \\
\hline T3 & Transport & $\begin{array}{l}\text { Urban buses and } \\
\text { other (pls specify) }\end{array}$ & 3 & 4 & 3 & 2 & 1 & 3 & 3 & 3 & 5 & 4 & 1 & 3 & 2.9 \\
\hline T4 & Transport & Inland waterways & 3 & 4 & 3 & 2 & 2 & 3 & 5 & 2 & 3 & 1 & 3 & 5 & 3.0 \\
\hline T5 & Transport & Outer ring road & 3 & 4 & 5 & 3 & 4 & 3 & 4 & 2 & 4 & 4 & 3 & 1 & 3.3 \\
\hline
\end{tabular}

$\begin{array}{lllllllllllllll}\text { T5 } & \text { Transport } & \text { Outer ring road } & 3 & 4 & 5 & 3 & 4 & 3 & 4 & 2 & 4 & 4 & 3 & 1\end{array}$

Improve road

intersections and/or

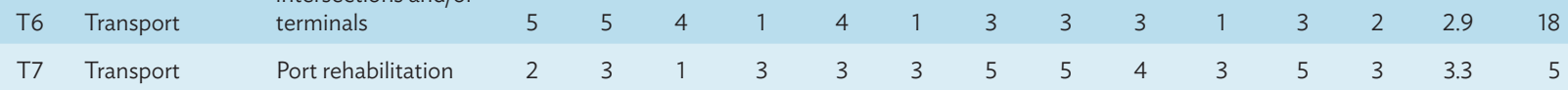

$\begin{array}{lllllllllllllllllll}\text { T8 } & \text { Mansport } & \begin{array}{l}\text { Main street } \\ \text { pedestrian mall }\end{array} & 4 & 2 & 3 & 5 & 1 & 2 & 3 & 2 & 3 & 3 & 4 & 5 & 3.0\end{array}$

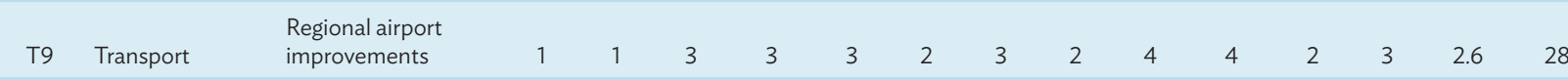

$\begin{array}{llllllllllllllllllllll} & \text { Pedestrian } & \text { Transport } & \text { overpasses } & 4 & 3 & 4 & 2 & 4 & 4 & 2 & 3 & 4 & 3 & 2 & 1 & 3.0 & 14\end{array}$

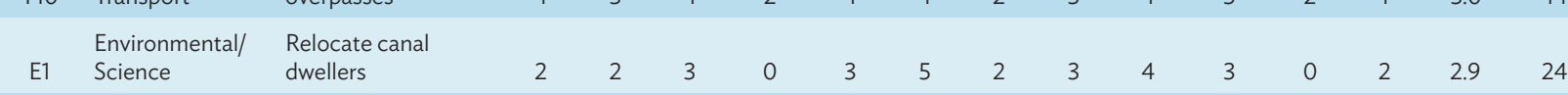

$\begin{array}{llllllllllllllllll}\text { E2 } & \begin{array}{l}\text { Environmental/ } \\ \text { Science }\end{array} & \begin{array}{l}\text { Coastal protection } \\ \text { works }\end{array} & 3 & 4 & 4 & 4 & 4 & 5 & 3 & 3 & 4 & 2 & 3 & 4 & 3.6 \\ \text { Environmental/ } & \text { Mangrove } & & & & & \end{array}$

$\begin{array}{llllllllllllllllll}\text { E3 } & \text { Science } & \text { rehabilitation } & 3 & 4 & 3 & 3 & 2 & 4 & 1 & 5 & 5 & 4 & 1 & 4 & 3.3 & 7\end{array}$

\begin{tabular}{|c|c|c|c|c|c|c|c|c|c|c|c|c|c|c|c|c|}
\hline E4 & $\begin{array}{l}\text { Environmental/ } \\
\text { Science }\end{array}$ & $\begin{array}{l}\text { Flood retention } \\
\text { basins }\end{array}$ & 4 & 2 & 2 & 2 & 3 & 1 & 3 & 2 & 3 & 1 & 3 & 3 & 2.4 & 29 \\
\hline
\end{tabular}

$\begin{array}{lllllllllllllllllllll}\text { E5 Science } & \text { areas } & 5 & 3 & 1 & 2 & 4 & 4 & 3 & 4 & 2 & 1 & 2 & 2 & 2.8 & 27\end{array}$

$\begin{array}{llllllllllllllllll}\text { Environmental/ } & \text { Science } & \text { Coastal land studies } & 3 & 1 & 5 & 2 & 3 & 1 & 3 & 2 & 5 & 3 & 3 & 4 & 2.9 & 18\end{array}$

\begin{tabular}{|c|c|c|c|c|c|c|c|c|c|c|c|c|c|c|c|c|}
\hline E7 & $\begin{array}{l}\text { Environmental/ } \\
\text { Science }\end{array}$ & Pollution modeling & 2 & 3 & 3 & 5 & 3 & 4 & 3 & 3 & 5 & 4 & 0 & 3 & 3.5 & 3 \\
\hline E8 & $\begin{array}{l}\text { Environmental/ } \\
\text { Science }\end{array}$ & $\begin{array}{l}\text { Acid soils } \\
\text { investigations }\end{array}$ & 4 & 2 & 3 & 5 & 2 & 5 & 3 & 5 & 3 & 3 & 0 & 2 & 3.4 & 4 \\
\hline E9 & $\begin{array}{l}\text { Environmental/ } \\
\text { Science }\end{array}$ & $\begin{array}{l}\text { Sewage effluent } \\
\text { plant no. } 2\end{array}$ & 2 & 5 & 4 & 3 & 3 & 2 & 2 & 2 & 3 & 3 & 5 & 3 & 3.0 & 10 \\
\hline E10 & $\begin{array}{l}\text { Environmental/ } \\
\text { Science }\end{array}$ & $\begin{array}{l}\text { Relocate industries } \\
\text { and treat pollution }\end{array}$ & 1 & 3 & 4 & 3 & 3 & 2 & 2 & 3 & 2 & 2 & 3 & 1 & 2.4 & 29 \\
\hline SI1 & $\begin{array}{l}\text { Social } \\
\text { Infrastructure/ } \\
\text { Services }\end{array}$ & $\begin{array}{l}\text { Reduce infant } \\
\text { mortality and } \\
\text { malnourishment }\end{array}$ & 2 & 3 & 3 & 4 & 5 & 3 & 2 & 3 & 2 & 2 & 2 & 3 & 2.8 & 25 \\
\hline $\mathrm{S} 12$ & $\begin{array}{l}\text { Social } \\
\text { Infrastructure/ } \\
\text { Services }\end{array}$ & $\begin{array}{l}\text { Move infectious } \\
\text { hospitals to outskirts }\end{array}$ & 2 & 4 & 4 & 2 & 3 & 1 & 3 & 4 & 3 & 4 & 3 & 2 & 2.9 & 18 \\
\hline $\mathrm{SI3}$ & $\begin{array}{l}\text { Social } \\
\text { Infrastructure/ } \\
\text { Services }\end{array}$ & $\begin{array}{l}\text { Promote press, } \\
\text { publication, and } \\
\text { printing }\end{array}$ & 3 & 4 & 3 & 2 & 1 & 5 & 3 & 2 & 3 & 4 & 3 & 2 & 2.9 & 18 \\
\hline
\end{tabular}


Step 1 continued

\begin{tabular}{|c|c|c|c|c|c|c|c|c|c|c|c|c|c|c|c|c|}
\hline$\dot{z}$ & 㐔 & 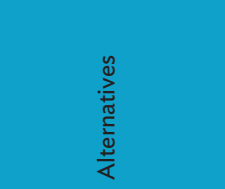 & 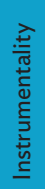 & 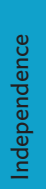 & 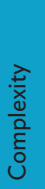 & 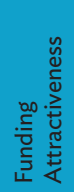 & 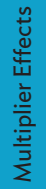 & 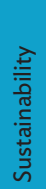 & 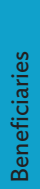 & $\begin{array}{l}\overline{\widetilde{n}} \\
\frac{0}{0} \\
\frac{0}{0} \\
\overline{0}\end{array}$ & 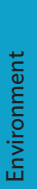 & 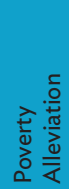 & $\begin{array}{l}\text { 弯 } \\
\text { o } \\
\text { iv }\end{array}$ & 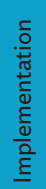 & 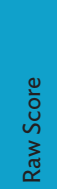 & 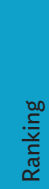 \\
\hline $\mathrm{SI} 4$ & $\begin{array}{l}\text { Social } \\
\text { Infrastructure/ } \\
\text { Services }\end{array}$ & $\begin{array}{l}\text { Secure land and } \\
\text { funding for new area } \\
\text { schools }\end{array}$ & 3 & 4 & 3 & 2 & 2 & 2 & 5 & 4 & 3 & 4 & 2 & 3 & 3.1 & 10 \\
\hline $\mathrm{SI} 5$ & $\begin{array}{l}\text { Social } \\
\text { Infrastructure/ } \\
\text { Services }\end{array}$ & $\begin{array}{l}\text { Increase } \\
\text { enrollments of } \\
\text { school-age children }\end{array}$ & 3 & 4 & 2 & 3 & 4 & 3 & 4 & 4 & 5 & 5 & 4 & 1 & 3.5 & 2 \\
\hline S16 & $\begin{array}{l}\text { Social } \\
\text { Infrastructure/ } \\
\text { Services }\end{array}$ & $\begin{array}{l}\text { Develop sports } \\
\text { recreation and } \\
\text { tourism facilities }\end{array}$ & 5 & 5 & 4 & 1 & 4 & 1 & 3 & 2 & 2 & 3 & 1 & 3 & 2.8 & 25 \\
\hline SI7 & $\begin{array}{l}\text { Social } \\
\text { Infrastructure/ } \\
\text { Services }\end{array}$ & $\begin{array}{l}\text { Promote film } \\
\text { industry and } \\
\text { cinemas }\end{array}$ & 2 & 3 & 1 & 3 & 3 & 3 & 5 & 3 & 3 & 3 & 5 & 2 & 3.0 & 14 \\
\hline $\mathrm{SI} 8$ & $\begin{array}{l}\text { Social } \\
\text { Infrastructure/ } \\
\text { Services }\end{array}$ & $\begin{array}{l}\text { Renovate and/or } \\
\text { expand museums } \\
\text { and libraries }\end{array}$ & 1 & 1 & 3 & 3 & 3 & 2 & 3 & 4 & 4 & 4 & 5 & 3 & 3.0 & 14 \\
\hline SI9 & $\begin{array}{l}\text { Social } \\
\text { Infrastructure/ } \\
\text { Services }\end{array}$ & $\begin{array}{l}\text { Complete national } \\
\text { university }\end{array}$ & 4 & 3 & 4 & 2 & 4 & 4 & 2 & 1 & 2 & 4 & 4 & 3 & 3.1 & 10 \\
\hline SI10 & $\begin{array}{l}\text { Social } \\
\text { Infrastructure/ } \\
\text { Services }\end{array}$ & $\begin{array}{l}\text { Modernize and/or } \\
\text { expand existing } \\
\text { hospitals }\end{array}$ & 5 & 3 & 1 & 2 & 4 & 4 & 3 & 3 & 1 & 3 & 4 & 2 & 2.9 & 18 \\
\hline
\end{tabular}

Step 2: Define weighted planning goals.

\begin{tabular}{ll}
\hline Instrumentality & 0.06 \\
\hline Independence & 0.07 \\
\hline Complexity & 0.09 \\
\hline Funding Attractiveness & 0.06 \\
\hline Multiplier Effects & 0.09 \\
\hline Sustainability & 0.10 \\
\hline Beneficiaries & 0.11 \\
\hline Dispersal & 0.09 \\
\hline Environment & 0.07 \\
\hline Poverty Alleviation & 0.09 \\
\hline Growth & 0.10 \\
\hline Implementation & 0.07 \\
\hline TOTAL & 1.00
\end{tabular}


Step 3: Calculate weighted scores.

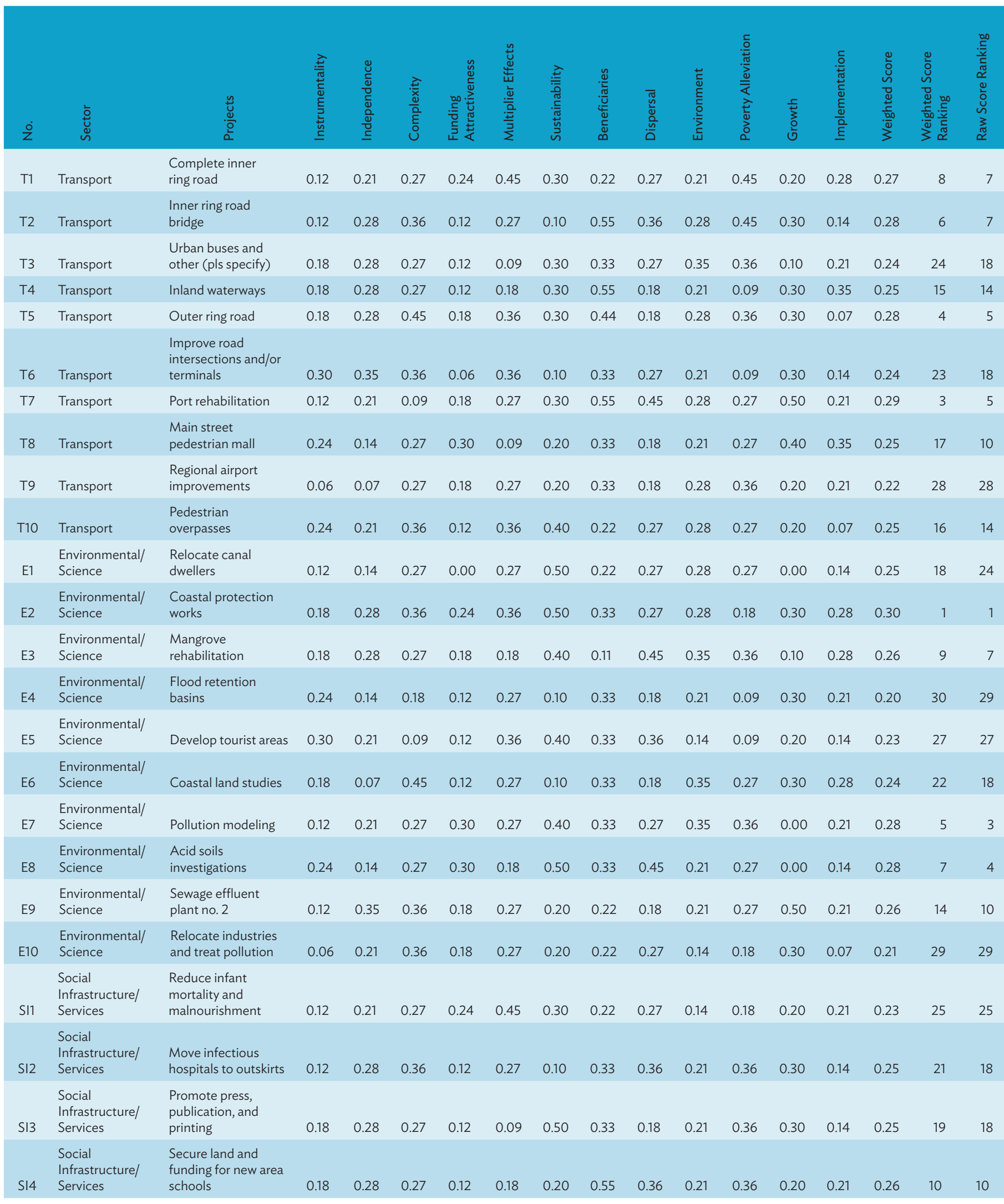


Step 3 continued

\begin{tabular}{|c|c|c|c|c|c|c|c|c|c|c|c|c|c|c|c|c|c|}
\hline$\stackrel{\dot{0}}{z}$ & 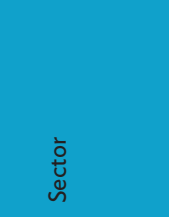 & $\begin{array}{l}\frac{\tilde{u}}{\mathscr{0}} \\
\frac{0}{2} \\
\frac{0}{2}\end{array}$ & 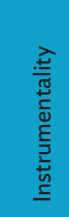 & 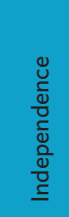 & 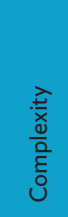 & 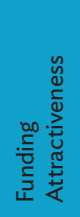 & 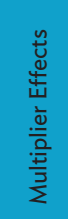 & 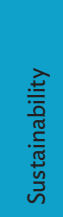 & 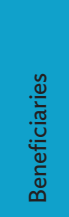 & $\begin{array}{l}\overline{\widetilde{n}} \\
\overline{\frac{\omega}{0}} \\
\overline{0} \\
\overline{0}\end{array}$ & 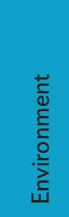 & 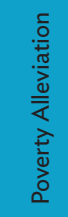 & 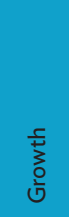 & 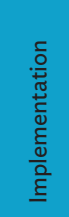 & 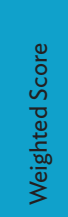 & 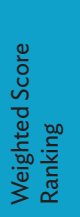 & 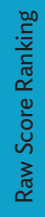 \\
\hline SI5 & $\begin{array}{l}\text { Social } \\
\text { Infrastructure/ } \\
\text { Services }\end{array}$ & $\begin{array}{l}\text { Increase enrollments } \\
\text { of school-age } \\
\text { children }\end{array}$ & 0.18 & 0.28 & 0.18 & 0.18 & 0.36 & 0.30 & 0.44 & 0.36 & 0.35 & 0.45 & 0.40 & 0.07 & 0.30 & 2 & 2 \\
\hline SI6 & $\begin{array}{l}\text { Social } \\
\text { Infrastructure/ } \\
\text { Services }\end{array}$ & $\begin{array}{l}\text { Develop, sports } \\
\text { recreation, and } \\
\text { tourism facilities }\end{array}$ & 0.30 & 0.35 & 0.36 & 0.06 & 0.36 & 0.10 & 0.33 & 0.18 & 0.14 & 0.27 & 0.10 & 0.21 & 0.23 & 26 & 25 \\
\hline SI7 & $\begin{array}{l}\text { Social } \\
\text { Infrastructure/ } \\
\text { Services }\end{array}$ & $\begin{array}{l}\text { Promote film } \\
\text { industry and cinemas }\end{array}$ & 0.12 & 0.21 & 0.09 & 0.18 & 0.27 & 0.30 & 0.55 & 0.27 & 0.21 & 0.27 & 0.50 & 0.14 & 0.26 & 11 & 14 \\
\hline SI10 & $\begin{array}{l}\text { Social } \\
\text { Infrastructure/ } \\
\text { Services }\end{array}$ & $\begin{array}{l}\text { Modernize and/or } \\
\text { expand existing } \\
\text { hospitals }\end{array}$ & 0.30 & 0.21 & 0.09 & 0.12 & 0.36 & 0.40 & 0.33 & 0.27 & 0.07 & 0.27 & 0.40 & 0.14 & 0.25 & 20 & 18 \\
\hline
\end{tabular}

Step 4: Determine proposal and project rankings.

\begin{tabular}{|c|c|c|c|c|c|c|}
\hline$\dot{z}$ & 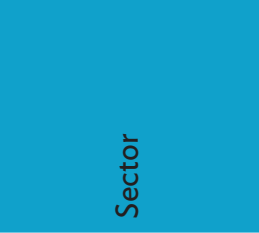 & $\frac{n}{\stackrel{U}{0}}$ & 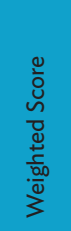 & 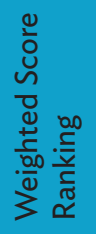 & 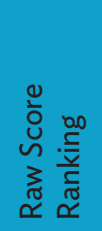 & 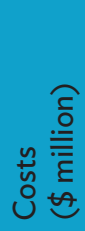 \\
\hline E2 & Environmental/Science & Coastal protection works & 0.30 & 1 & 1 & 12.5 \\
\hline SI5 & $\begin{array}{l}\text { Social Infrastructure/ } \\
\text { Services }\end{array}$ & Increase enrollments of school-age children & 0.30 & 2 & 2 & 41.0 \\
\hline $\mathrm{T7}$ & Transport & Port rehabilitation & 0.29 & 3 & 5 & 1.0 \\
\hline T5 & Transport & Outer ring road & 0.28 & 4 & 5 & 10.0 \\
\hline E7 & Environmental/Science & Pollution modeling & 0.28 & 5 & 3 & 17.0 \\
\hline $\mathrm{T} 2$ & Transport & Inner ring road bridge & 0.28 & 6 & 7 & 15.0 \\
\hline E8 & Environmental/Science & Acid soils investigations & 0.28 & 7 & 4 & 1.0 \\
\hline $\mathrm{T} 1$ & Transport & Complete inner ring road & 0.27 & 8 & 7 & 40.0 \\
\hline E3 & Environmental/Science & Mangrove rehabilitation & 0.26 & 9 & 7 & 1.5 \\
\hline SI4 & $\begin{array}{l}\text { Social Infrastructure/ } \\
\text { Services }\end{array}$ & Secure land and funding for new area schools & 0.26 & 10 & 10 & 2.0 \\
\hline SI7 & $\begin{array}{l}\text { Social Infrastructure/ } \\
\text { Services }\end{array}$ & Promote film industry and cinemas & 0.26 & 11 & 14 & 10.0 \\
\hline SI9 & $\begin{array}{l}\text { Social Infrastructure/ } \\
\text { Services }\end{array}$ & Complete national university & 0.26 & 12 & 10 & 16.5 \\
\hline $\mathrm{SI} 8$ & $\begin{array}{l}\text { Social Infrastructure/ } \\
\text { Services }\end{array}$ & Renovate and/or expand museums and libraries & 0.26 & 13 & 14 & 41.0 \\
\hline E9 & Environmental/Science & Sewage effluent plant no. 2 & 0.26 & 14 & 10 & 14.0 \\
\hline T4 & Transport & Inland waterways & 0.25 & 15 & 14 & 24.0 \\
\hline $\mathrm{T} 10$ & Transport & Pedestrian overpasses & 0.25 & 16 & 14 & 26.0 \\
\hline
\end{tabular}


Step 4 continued

\begin{tabular}{|c|c|c|c|c|c|c|}
\hline ㅇ & 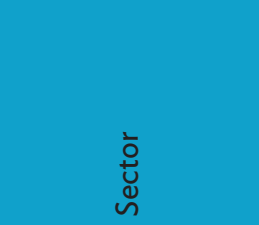 & 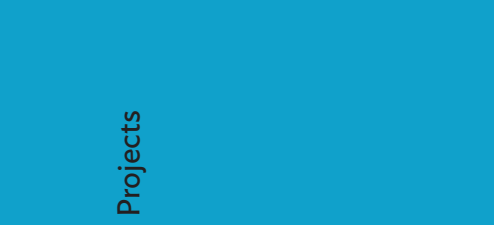 & 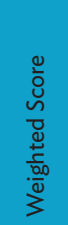 & 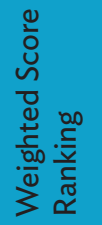 & 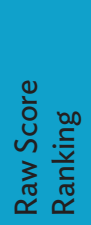 & 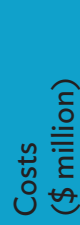 \\
\hline T8 & Transport & Main street pedestrian mall & 0.25 & 17 & 10 & 6.0 \\
\hline E1 & Environmental/Science & Relocate canal dwellers & 0.25 & 18 & 24 & 5.0 \\
\hline $\mathrm{SI} 3$ & $\begin{array}{l}\text { Social Infrastructure/ } \\
\text { Services }\end{array}$ & Promote press, publication, and printing & 0.25 & 19 & 18 & 59.0 \\
\hline SI10 & $\begin{array}{l}\text { Social Infrastructure/ } \\
\text { Services }\end{array}$ & Modernize and/or expand existing hospitals & 0.25 & 20 & 18 & 12.0 \\
\hline $\mathrm{SI} 2$ & $\begin{array}{l}\text { Social Infrastructure/ } \\
\text { Services }\end{array}$ & Move infectious hospitals to outskirts & 0.25 & 21 & 18 & 1.5 \\
\hline E6 & Environmental/Science & Coastal land studies & 0.24 & 22 & 18 & 26.0 \\
\hline T6 & Transport & Improve road intersections and/or terminals & 0.24 & 23 & 18 & 37.0 \\
\hline T3 & Transport & Urban buses and others (pls specify) & 0.24 & 24 & 18 & 26.0 \\
\hline S11 & $\begin{array}{l}\text { Social Infrastructure/ } \\
\text { Services }\end{array}$ & Reduce infant mortality and malnourishment & 0.23 & 25 & 25 & 20.0 \\
\hline SI6 & $\begin{array}{l}\text { Social Infrastructure/ } \\
\text { Services }\end{array}$ & Develop sports recreation and tourism facilities & 0.23 & 26 & 25 & 41.0 \\
\hline E5 & Environmental/Science & Develop tourist areas & 0.23 & 27 & 27 & 36.0 \\
\hline T9 & Transport & Regional airport improvements & 0.22 & 28 & 28 & 27.0 \\
\hline E10 & Environmental/Science & Relocate industries and treat pollution & 0.21 & 29 & 29 & 51.0 \\
\hline E4 & Environmental/Science & Flood retention basins & 0.20 & 30 & 29 & 29.0 \\
\hline
\end{tabular}

CAUTION: The Goals Achievement Matrix method of evaluation is a tool to aid in decision making, but it is not the decision-making process itself. It is useful primarily as a guide for decision making. Users cannot be sure that they have identified all the pertinent objectives or that they have considered all the important variables. 
Tool 25: Shelter Program/New Shelter Options/Sites and Services
Flowchart Reference-Phase 3: Project/Program Component

\section{Objective:}

- To understand the issues and opportunities for future growth in inclusive shelter project development for national and especially local governments.

\section{Approach:}

- To prepare a typology of affordable shelter,incremental housing, high density and low rise construction. To prepare sites and services for low-income families.

- To identify safe sites for future growth and its proximity to existing infrastructure.

- To initiate a shelter delivery system that operates on a multiyear program basis to establish a consistent flow of affordable housing on to the market.

- To create a demand for, and a consistent supply of, energy-efficient building materials that support self-help and self-managed construction.

- To establish a building materials training center to train skilled and unskilled construction workers in new resilient building technologies.

\section{Steps:}

1. Build on the existing information base and the priorities identified for new shelter options to address the existing demand and for future growth.

2. Identify specific sites for future growth that consider climate change and disaster risk management.

3. Establish, through consultation and outreach with priority communities, their affordability, capacity to pay, and willingness to pay for a new shelter solution.

4. Prepare several technical and financial options for identified projects to be discussed with stakeholders that may include incremental housing; higher-density, low-rise incremental multistory structures; and site and services schemes, among others.

5. Determine the commercial viability of the proposed project, access to credit, and technical backstopping requirements.

6. Carry out training identified to improve urban service operations, maintenance, and expansion.

\section{Expected Results:}

- Inclusive shelter programs that offer an array of shelter options in a project that responds to the preferences and the capacity to pay of low-income families

- A shelter strategy by a developing member country entity at the national, state, or local level to provide a consistent supply of new shelter options to the market

- $\quad$ Partnerships with private sector entities and civil society organizations to participate in the new shelter delivery system

- Local governments in possession of a typology of shelter solutions that reflect the local context of location, climate, affordability, and technologies

- Training initiatives in improved, more resilient construction technologies

\section{Pointers for Implementation:}

- Develop a typology of shelter solutions that respond to the affordability of the 50 th income percentile and downward.

- Consider climate-sensitive design in the typology, especially multifamily walk-up apartments.

- Look for land-sharing opportunities as a strategy for new shelter development.

- Modify standards codes to include renewable resources for construction to expand the building materials market toward production of more energy-efficient materials.

- Build resilience into the technology for its represents a small increase of 5\%-7\% in the budget, far less than total replacement costs that disasters bring along.

- Consider new shelter options as part of local resettlement initiatives for communities located on marginal land or in hazardous locations.

- $\quad$ Climate change makes the case for higher-density strategies for shelter and mixed-use development. 


\section{Resources:}

- Shelter finance comes from dedicated finance institutions, including housing finance companies, credit unions, community-based finance entities, and public sector housing companies.

- Secondary mortgage markets support the financia flows to lending agencies and the stream of affordable solutions.

\section{Sustainability:}

- Offering affordable solutions supports cost recovery.

- A shelter typology that builds on self-help brings costs down and progress is family driven.

- $\quad$ Limiting debt to self-employed families through starter solutions they may acquire supports sustainability.

- The demonstrated success of affordable housing will build the comfort level of finance institutions to continue supply of credit to low-income families.

\section{References:}

ADB. 2003. Proposed Loan to Indonesia for the Neighborhood Upgrading and Shelter Sector Project. Manila.

H. Caminos and R. Goethert. 1983. Urbanization Primer. Cambridge, MA: MIT Press.

United States Agency for International Development (USAID). 2005. LAC Housing and Urban Upgrading Assistance Retrospective, Honduras and Ecuador, 1980-2005. Research Triangle Institute.

B. Yuen. 2005. Squatters No More: Singapore Social Housing. Third Urban Research Symposium: Land Development, Urban Policy and Poverty Reduction. Washington, DC: World Bank. 
Tool 26: Addressing Future Growth: Inclusive New Infrastructure and Guided Land Development

Flowchart Reference-Phase 3: Project/Program Component

\section{Objectives:}

- To coordinate and guide future growth with new infrastructure trunk line and design and development of distribution networks.

- To plan and implement mixed-use growth that features affordable housing, commercial space, city and community facilities, and open spaces at higher densities for a green future.

\section{Approach:}

- To build on the information consolidated in the prior phases to avoid vulnerable areas and identify safe, available land apt for infill distribution networks and additional trunk line development and shelter requirements, and for future growth sites.

- To prepare a typology of urban service options based on efficiency, affordability, and incremental development.

- To provide technical and financial support through dedicated finance institutions and community-based financial organizations for inclusive infrastructure, including connection costs for low-income families.

- To prepare a participatory management plan for guided land development that partners local government with private sector developers and landowners.

- To train local builders and developers in improved and resilient infrastructure construction technologies.

- To document the programs and products developed for inclusive infrastructure development for outreach purposes.

Steps:

1. Establish an entity in the local government to manage inclusive infrastructure and guided land development programs.

2. Enter into partnerships with national agencies, local nongovernment organizations (NGOs), and private sector entities engaged in construction, community outreach, and finance for inclusive infrastructure and guided land development.

3. Carry out, or contract for, an inclusive infrastructure development action plan that identifies priority trunk line and distribution network projects, guided land development opportunities, standards for incremental growth, and development of priority infrastructure systems and comparative system costs.

4. Prepare inclusive infrastructure and guided land development guidance sheets, highlighting comparative technical and development options and their costs.

5. Provide technical support in formulating inclusive infrastructure and guided land development programs.

6. Monitor the demand for and project development of inclusive infrastructure and guided land development supply issues that arise and document the improvements made and the technologies employed.

\section{Expected Results:}

- Identification of priority underserved and unserved urban areas and their communities, resilient locations for future growth supported by infrastructure investment, and ownership of priority landholdings

- A typology of incremental, inclusive infrastructure technologies and their costs detailed through inclusive infrastructure guidance sheets that provide builders, the private sector, and families with technical and cost information for improvements that reflect the area's environmental context and the incremental provision of urban services

- $\quad$ Program partnerships of national and local government offices with NGOs, private sector companies, and community-based organizations to design, finance, and implement inclusive infrastructure programs

- Inclusive infrastructure program profiles that are multiyear initiatives organized by local governments with national agencies, community-based organizations, NGOs, and private sector companies for new areas of future growth and for unserved and underserved communities

- Cost recovery systems based on reflective system-wide recovery parameters

- Capacity-building and training support for teams to carry out inclusive infrastructure needs assessments and the recommended improvements in urban infrastructure technologies and delivery systems 


\section{Pointers for Implementation:}

- Guided land development is a tool of inclusive infrastructure that builds on the city information base that has identified infill infrastructure requirements, unserved areas, and available land and prepared initial assessments of priority locations for trunk line and distribution network growth.

- Local government and its partners can validate and vet with identified landowners potential guided land development opportunities.

- Household connections and distribution networks can be a viable product in the lending portfolio, which the community lending organizations can support.

- Increasing the quality and coverage of urban service systems for future growth requires dedicated technical and financial support from the public and private sectors.

- Inclusive infrastructure is a multiyear investment opportunity for infrastructure investment companies through the domestic capital market.

- Creating a demand for incremental urban service delivery is facilitated through stakeholder consultations to present the incremental service delivery approach and the comparative costs of infrastructure improvements.

- The role of the local government with stakeholders is key in advocating change and improvements, enforcing regulations, and providing incentives.

- $\quad$ Public-private partnerships represent a productive approach to inclusive infrastructure development.

\section{Resources:}

- Finance for inclusive infrastructure initiatives, including guided land development programs, can be initiated through dedicated Asian Development Bank developing member country programs that serve to define the parameters, products, and the process for inclusive infrastructure investment initiatives.

- National infrastructure development programs can offer funds through incentives, with local governments matching contributions from that of private sector companies and owners, for guided land development and inclusive infrastructure.

- Local technical and finance partners continue ongoing infrastructure initiatives on the reflows of user fees.

- Bundling inclusive infrastructure loans for a secondary market can bring fresh resources for on-lending.

\section{Sustainability:}

- Local government can bring in important support through its political will to implement inclusive infrastructure through its updated city information base of transparent information and mapping of trunk lines, distribution networks, and available land.

- Local finance and development entities, NGOs, and private sector companies view lending for inclusive infrastructure as an addition to the loan products they offer.

- National and local governments support multiyear infrastructure development through incentives and budget line item support and public-private partnerships.

\section{References:}

ADB. 2003. Proposed to Indonesia for the Neighborhood Upgrading and Shelter Sector Project. Manila.

Cities Alliance. 2007. Liveable Cities: The Benefits of Urban Environmental Planning. Washington, DC.

Government of India. 2005. Jawaharlal Nehru National Urban Renewal Mission: Towards Better Cities: Guidelines for Basic Services for the Urban Poor (BSUP). New Delhi.

United States Agency for International Development (USAID)/India. 2011. Developing Sustainable and Inclusive Urban Infrastructure Services. Washington, DC: The Communities Group International. 


\section{BIBLIOGRAPHY}

ADB. 1999. Guidelines for the Economic Analysis of Water Supply Projects. Economics and development resource Center. Manila. http://www.adb.org/sites/default/files/ institutional-document/32759/files/economic-analysis-water-projects.pdf

- - -2004. City Development Strategy. http://www.adb.org/Documents/Books/City_ Devt_Strategies/citydevt.pdf

- - 2006. Special Evaluation Study on Urban Sector Strategy and Operations. Manila.

- - - 2007. Improving Local Governance and Pro-Poor Service Delivery: Citizen Report Card Learning Toolkit. Manila: ADB and ADB Institute.

2008. Managing Asian Cities. Manila.

-_- 2011a. Asia 2050: Realizing the Asian Century. Manila.

-_- 2011b. Tool Kit for Public-Private Partnerships in Urban Bus Transport for the State of Maharashtra, India. Manila.

- - - 2011c. Walkability and Pedestrian Facilities in Asian Cities State and Issues. Sustainable Development Working Papers. Manila.

- - . 2012. Urban Operational Plan 2012-2020. Strategy. Manila.

Baharoglu, D., and C. Kessides. 2002. Urban Poverty. In J. Klugman, ed. A Sourcebook for Poverty Reduction Strategies. Washington, DC: World Bank.

Baker, J., and N. Schuler. 2004. Analyzing Urban Poverty: A Summary of Methods and Approaches. Policy Research Working Paper Series. WPS No. 3399. Washington, DC: World Bank.

Baker, J.L. 2008. Urban Poverty: A Global View. Urban Papers. Washington, DC: World Bank. Camagni, R. 1998. Sustainable Urban Development: Definition and Reasons for a Research Programme. International Journal of Environment and Pollution. 10 (1). pp. 6-27.

Choe, K., and A. Laquian. 2008. City Cluster Development: Toward an Urban-Led Development Strategy for Asia. Manila: ADB.

Cities Alliance. 2011. City Development Strategy. http://www.citiesalliance.org/ca/about-cds (accessed 1 September 2011).

Cities Development Initiative for Asia (CDIA). 2010. City Infrastructure Investment Programming \& Prioritisation Toolkit (CIIPP). 2010. http://cdia.asia/wp-content/ uploads/User-Manual-Generic-version-2010.pdf (accessed 31 October 2011).

CDIA and United Nations Human Settlements Programme (UN-Habitat). 2012. Pre-Feasibility Studies (PFS) User Manual. Manila.

- - . 1996. Territorial Competition and the Predictability of Collective (In)Action. International Journal of Urban and Regional Research. 23 (3). pp. 383-399.

Fitzgerald, J., and P. Meyer. 1986. Recognizing Constraints to Local Economic Development. Journal of the Community Development Society. 17. pp. 115-126. Columbus: Community Development Society

Lindfield, M., and F. Steinberg. 2011. Inclusive Cities. Manila: ADB. International Federation of Red Cross and Red Crescent Societies, 2011. PASSA Participatory Approach for Safe Shelter Awareness. Geneva. http://www.ifrc.org/PageFiles/95526/ publications/305400-PASSA\%20manual-EN-LR.pdf 
McKeown, R. 2002. The Education for Sustainable Development Toolkit. http://www. esdtoolkit.org/esd_toolkit_v2.pdf (accessed 20 October 2011).

McHarg, I. 1969. Design With Nature. American Museum of Natural History. Garden City, New York: Doubleday. McKinsey Global Institute. 2009. Preparing for China's Urban Billion-Impacts of Urbanization: Implications for Urban Infrastructure. McKinsey \& Company.

_- - 2010. India's Urban Awakening. Building Inclusive Cities, Sustaining Economic Growth. Mumbai: McKinsey \& Company.

Mercado, S. et al. 2007. Responding to the Health Vulnerabilities of the Urban Poor. Urban Summit, Rockefeller Foundation. WHO Centre for Health Development; Alliance for Healthy Cities, and Southeast Asian Press Alliance.

Moser, C., M. Gatehouse, and H. Garcia. 1996. Urban Poverty Research Sourcebook Module II: Indicators of Urban Poverty. Urban Management Program Working Paper Series. No. 5. Washington, DC: UNDP, UNCHS(Habitat), and World Bank.

Naik Singru, R. 2008. Democracy, Competitive Governance \& Spatial Transformation in "Globalising" Mumbai. Barcelona: ISA World Forum of Sociology.

Naik Singru, R., and M. Lindfield. 2016 (forthcoming). Manual for Undertaking National Urban Assessments. Manila: ADB.

Narotam Sekhsaria Foundation (NSF). 2010. Civil Society Initiatives. http://www. nsfoundation.co.in/civilsintivatives.html (accessed 10 June 2012).

Nicholls, R., S. Hanson, C. Herweijer, N. Patmore, S. Hallegatte, J. Corfee-Morlot, J. Chateau, and R. Muir-Wood. 2007. Ranking Port Cities with High Exposure and Vulnerability to Climate Extremes Exposure Estimates. Paris: Organisation for Economic Co-operation and Development. http://www.oecd.org/ dataoecd/16/58/39720578.pdf

Roberts, B. 2015. Toolkit Guide for Rapid Economic Assessment, Planning and Development of Cities in Asia (CCED). Manila: ADB.

Saunders, D. 2010. Arrival City: How the Last Great Migration Is Reshaping Our World. Sydney: Allen \& Unwin.

Singh, K., F. Steinberg, and N. von Einsiedel, eds. 1996. Integrated Urban Infrastructure Development in Asia. Oxford Publishing.

U. Tuli. 2003. Amar Jyoti Inspires Confidence. UN Special. No. 617.

UN-Habitat. 1986. UN-Habitat Urban Management Programme. http://www.unhabitat.org/ content. asp?typeid=19\&catid=374\&cid=188 (accessed 1 September 2011).

- - . 2001a. Inclusive Cities Initiative - The Way Forward. www.unhabitat.org/.../ docs/2115_1346_way_forward_29.May.doc (accessed 10 June 2012).

- - - 2001b. Tools to Support Participatory Urban Decision Making. Nairobi.

- - . 2011. Cities and Climate Change-Global Report on Human Settlements. Nairobi.

- - - 2012. Pro-Poor Partnerships for Participatory Settlement Upgrading. http://www. fukuoka.unhabitat.org/projects/sri_lanka/detail08_en.html (accessed 10 June 2012).

United States Agency for International Development (USAID). 2011. Guidebook: Developing Sustainable and Inclusive Infrastructure Services in India. http://www. urbaninfrastructureindia.org/guidebook.html 
URBACT. 2011. http://urbact.eu/en/header-main/integrated-urban-development/ understanding-integrated-urban-development/

Wilson, D. and L. Beaton. 2003. Promoting Institutional and Organisational Appraisaland Development: A Source Book of Tools and Techniques. London: Department forInternational Development of the United Kingdom. http://webarchive.nationalarchives.gov.uk/+/http://www.dfid.gov.uk/pubs/files/ prominstdevsourcebook.pdf

World Bank. 2007. Tools for Institutional, Political and Social Analysis of Policy Reform. Washington, DC: International Bank for Reconstruction and Development/ World Bank.

-_- 2009. Approaches to Urban Slums: Adaptive and Proactive Strategies. http://info. worldbank.org/etools/urbanslums/index.html (accessed 18 June 2012).

- - . 2011. Data Urban Development. http://data.worldbank.org/topic/urban-development (accessed 31 October 2011).

-_- 2012. Accessibility. http://web.worldbank.org/WBSITE/EXTERNAL/TOPICS/ EXTSOCIALPROTECTION/EXTDISABILITY/0,,contentMDK:20192134 menuP K:414202 pagePK:148956 piPK:216618 theSitePK:282699,00.html (accessed 18 June 2012). 


\section{Annex 1: Urban Indicators and Data}

\begin{tabular}{|c|c|c|}
\hline Urban Indicators & $\begin{array}{l}\text { Data and Reporting } \\
\text { Mechanisms }\end{array}$ & Indicative Data Sources \\
\hline \multicolumn{3}{|l|}{ WATER AND SANITATION } \\
\hline \multicolumn{3}{|c|}{ Water } \\
\hline Total length of pipe network (baseline year) & $\mathrm{km}$ & Water utilities \\
\hline Length of new pipe network (baseline year) & $\mathrm{km}$ & Water utilities \\
\hline Physical loss/nonrevenue water (baseline year) & $\%$ & Water utilities \\
\hline \multicolumn{3}{|c|}{ Access } \\
\hline $\begin{array}{l}\text { Urban } \mathrm{HH} \text { served with new or improved water supply } \\
\text { (baseline year) }\end{array}$ & $\begin{array}{l}\mathrm{HH}: \% ; \mathrm{FHH}: \% \text {; low- } \\
\text { income } \mathrm{HH}: \% \text {; urban } \\
\text { poor } \mathrm{HH} \%\end{array}$ & Water utilities \\
\hline Urban $\mathrm{HH}$ served with piped water by utilities (baseline year) & $\begin{array}{l}\mathrm{HH} \text { : no.; } \mathrm{FHH} \text { : no.; low- } \\
\text { income HH: no.; urban } \\
\text { poor } \mathrm{HH} \text { : no. }\end{array}$ & Water utilities \\
\hline $\begin{array}{l}\text { Urban average hours to fetch water per day per } \mathrm{HH} \text { (baseline } \\
\text { year) }\end{array}$ & $\begin{array}{l}\mathrm{HH} \text { : hours; } \mathrm{FHH}: 00 \\
\text { hours; low-income } \mathrm{HH} \text { : } \\
\text { OO hours }\end{array}$ & Annual consumer survey \\
\hline Average hours of supply in urban areas (baseline year) & $\begin{array}{l}\text { Hours per day in } \\
\text { baseline year }\end{array}$ & Annual consumer survey \\
\hline $\begin{array}{l}\text { Urban HH served with continuous 24-hour water supply } \\
\text { (baseline year) }\end{array}$ & $\%$ of total $\mathrm{HH}$ & Water utilities \\
\hline $\begin{array}{l}\text { Urban HH served with continuous 24-hour water supply } \\
\text { (baseline year) }\end{array}$ & $\begin{array}{l}\mathrm{HH} \text { : no.; } \mathrm{FHH} \text { : no.; low- } \\
\text { income } \mathrm{HH} \text { : no.; urban } \\
\text { poor } \mathrm{HH} \text { : no. }\end{array}$ & Water utilities \\
\hline Urban $\mathrm{HH}$ served with improved sanitation & $\begin{array}{l}\mathrm{HH}: \% \text {; } \mathrm{FHH}: \% \text {; low- } \\
\text { income } \mathrm{HH}: \% \text {; urban } \\
\text { poor } \mathrm{HH}: \%\end{array}$ & Annual consumer survey \\
\hline \multicolumn{3}{|c|}{ Water Quality and Standards } \\
\hline Average availability of water in service area (baseline year) & Ipcd & Annual consumer survey \\
\hline $\begin{array}{l}\text { Average pressure of water supply at consumer end (baseline } \\
\text { year) }\end{array}$ & $\mathrm{m}$ & Annual consumer survey \\
\hline $\begin{array}{l}\text { Compliance of water samples with national drinking water } \\
\text { quality standards (baseline year) }\end{array}$ & $\%$ & Water Regulatory Board \\
\hline \multicolumn{3}{|c|}{ Efficiency } \\
\hline Reduction in average nonrevenue water & $\%$ & Water utilities \\
\hline Households potentially benefiting from saved urban water & No. per year & Water utilities \\
\hline Energy saved by utilities & $\begin{array}{l}\text { Kilowatt-hour per } \\
\text { milliliter of water } \\
\text { produced by water } \\
\text { supply systems }\end{array}$ & Water utilities \\
\hline
\end{tabular}


Annex 1 continued

\begin{tabular}{|c|c|c|}
\hline Urban Indicators & $\begin{array}{l}\text { Data and Reporting } \\
\text { Mechanisms }\end{array}$ & Indicative Data Sources \\
\hline Energy saved by utilities & $\begin{array}{l}\text { Kilowatt-hour per } \\
\text { milliliter of wastewater } \\
\text { treated }\end{array}$ & Water utilities \\
\hline \multicolumn{3}{|c|}{ Water Security } \\
\hline Water endowment per person & kl per year & Department of Environment \\
\hline Watershed protection & ha & Department of Environment \\
\hline Changes in groundwater resources & $\%$ & Department of Environment \\
\hline Persons protected by flood mitigation initiatives & No. & Department of Environment \\
\hline Water storage (dams) capacity added & Megaliters & Department of Environment \\
\hline Changes in withdrawals by households, industry, farming & $\%$ & Department of Environment \\
\hline \multicolumn{3}{|c|}{ Water Management } \\
\hline Number of water user groups & No. of groups in 2011 & Water Regulatory Board \\
\hline $\begin{array}{l}\text { Average response time to customers' complaints (baseline } \\
\text { year) }\end{array}$ & $\begin{array}{l}\text { Minutes/no standards } \\
\text { currently in place }\end{array}$ & Annual consumer survey \\
\hline Revenue collected according to the financial plan & $\%$ of target & Water utilities \\
\hline \multicolumn{3}{|c|}{ Street Drainage } \\
\hline Incidence of street flooding & $\begin{array}{l}\text { No. of flooding } \\
\text { incidents in } 2011\end{array}$ & Department of Transport \\
\hline Flood management along urban corridors & $\begin{array}{l}\text { No. of flood-free days } \\
\text { on main traffic routes }\end{array}$ & Department of Transport \\
\hline \multicolumn{3}{|c|}{ Quality } \\
\hline Utilities implementing a water safety plan & No. & Water utilities \\
\hline Wastewater treatment added & $\mathrm{cm}^{3}$ per day & Water utilities \\
\hline Wastewater treated as a percentage of wastewater generated & $\%$ & Water utilities \\
\hline River quality improvement & $\begin{array}{l}\text { None or km meeting set } \\
\text { national standard }\end{array}$ & $\begin{array}{l}\text { Department of Environment/ } \\
\text { Natural Resources }\end{array}$ \\
\hline Waterways (lakes) improved & $\begin{array}{l}\text { Measurement is square } \\
\text { kms of waterways } \\
\text { improved. Standard is - } \\
\text { reaching a set national } \\
\text { standard }\end{array}$ & $\begin{array}{l}\text { Department of Environment/ } \\
\text { Natural Resources }\end{array}$ \\
\hline \multicolumn{3}{|c|}{ Solid Waste Management } \\
\hline HH connected to treatment facilities (septic and/or other) & $\begin{array}{l}\text { Total HH: no.; FHH: no.; } \\
\text { low-income HH: no.; } \\
\text { urban poor HH: no. }\end{array}$ & City government \\
\hline HH connected to treatment facilities (septic and/or other) & $\begin{array}{l}\% \text { of total urban } \\
\text { population }\end{array}$ & City government \\
\hline $\mathrm{HH}$ covered by septage treatment facilities & $\begin{array}{l}\text { Total HH: no.; FHH: no.; } \\
\text { low-income HH: no.; } \\
\text { urban poor HH: no. }\end{array}$ & City government \\
\hline
\end{tabular}


Annex 1 continued

\begin{tabular}{|c|c|c|}
\hline Urban Indicators & $\begin{array}{l}\text { Data and Reporting } \\
\text { Mechanisms }\end{array}$ & Indicative Data Sources \\
\hline $\mathrm{HH}$ covered by septage treatment facilities & $\begin{array}{l}\% \text { of total urban } \\
\text { population }\end{array}$ & City government \\
\hline Service area coverage with piped sewerage system & $\%$ of total urban area & City government \\
\hline Solid waste collected & $\begin{array}{l}\% \text { in service area; } \% \text { in } \\
\text { low-income } \mathrm{HH} \text {; and } \% \\
\text { from } \mathrm{FHHs}\end{array}$ & City government \\
\hline \multicolumn{3}{|c|}{ Water Governance } \\
\hline Introduction of integrated water resources management & $\begin{array}{l}\text { No. of river basins } \\
\text { and/or scorecard status }\end{array}$ & $\begin{array}{l}\text { Dept. of Environment/Natural } \\
\text { Resources }\end{array}$ \\
\hline $\begin{array}{l}\text { Urban utilities implementing corporatized principles and } \\
\text { practices }\end{array}$ & No. & \\
\hline
\end{tabular}

$\mathrm{cm}^{3}$ = cubic centimeter, $\mathrm{FHH}=$ female-headed household, $\mathrm{HH}=$ household, $\mathrm{kl}=$ kiloliter, $\mathrm{km}=$ kilometer, lpcd = liter per capita per day, $\mathrm{m}=$ meter.

Source: Asian Development Bank, Water Sector Group. 


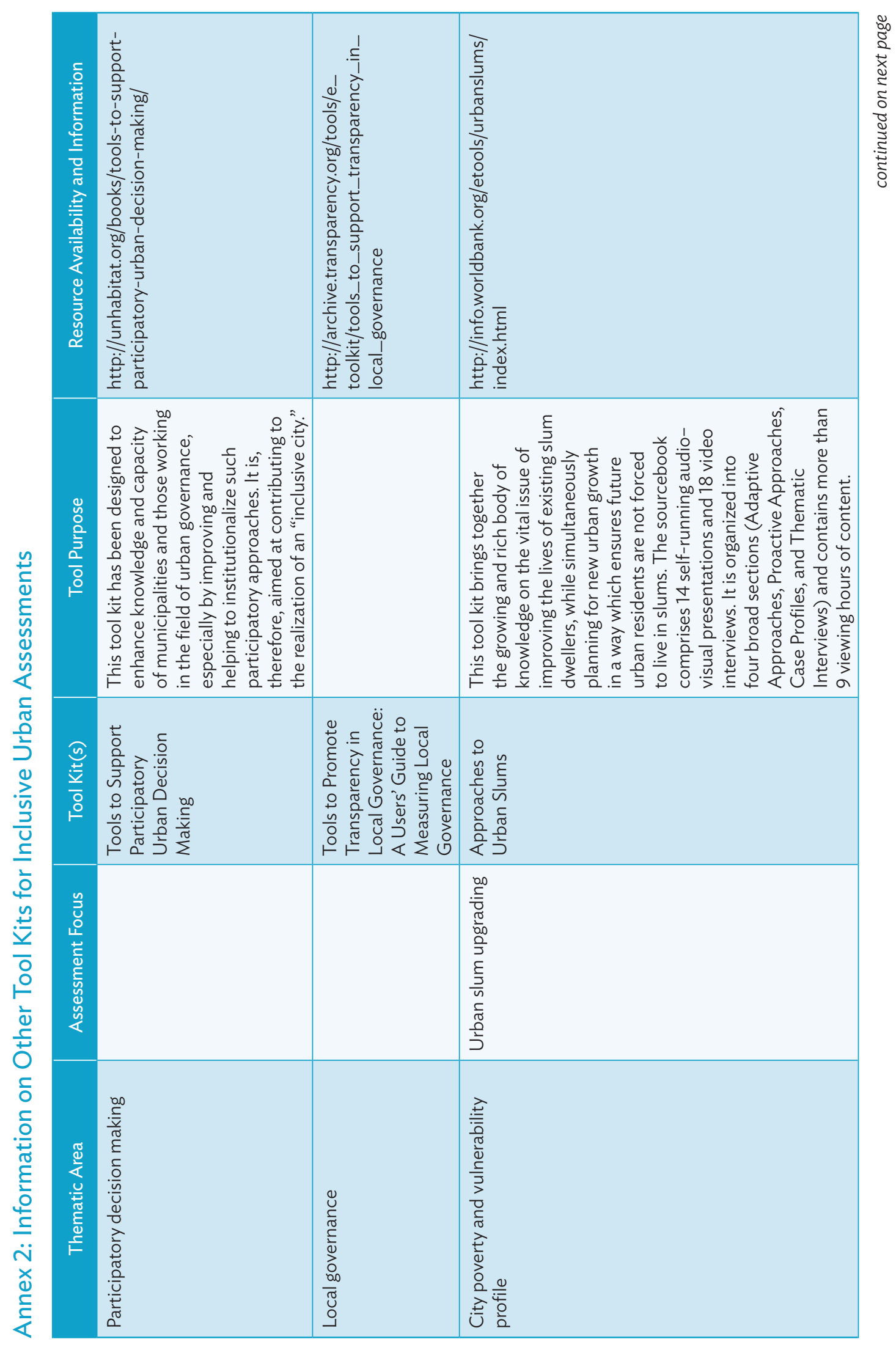




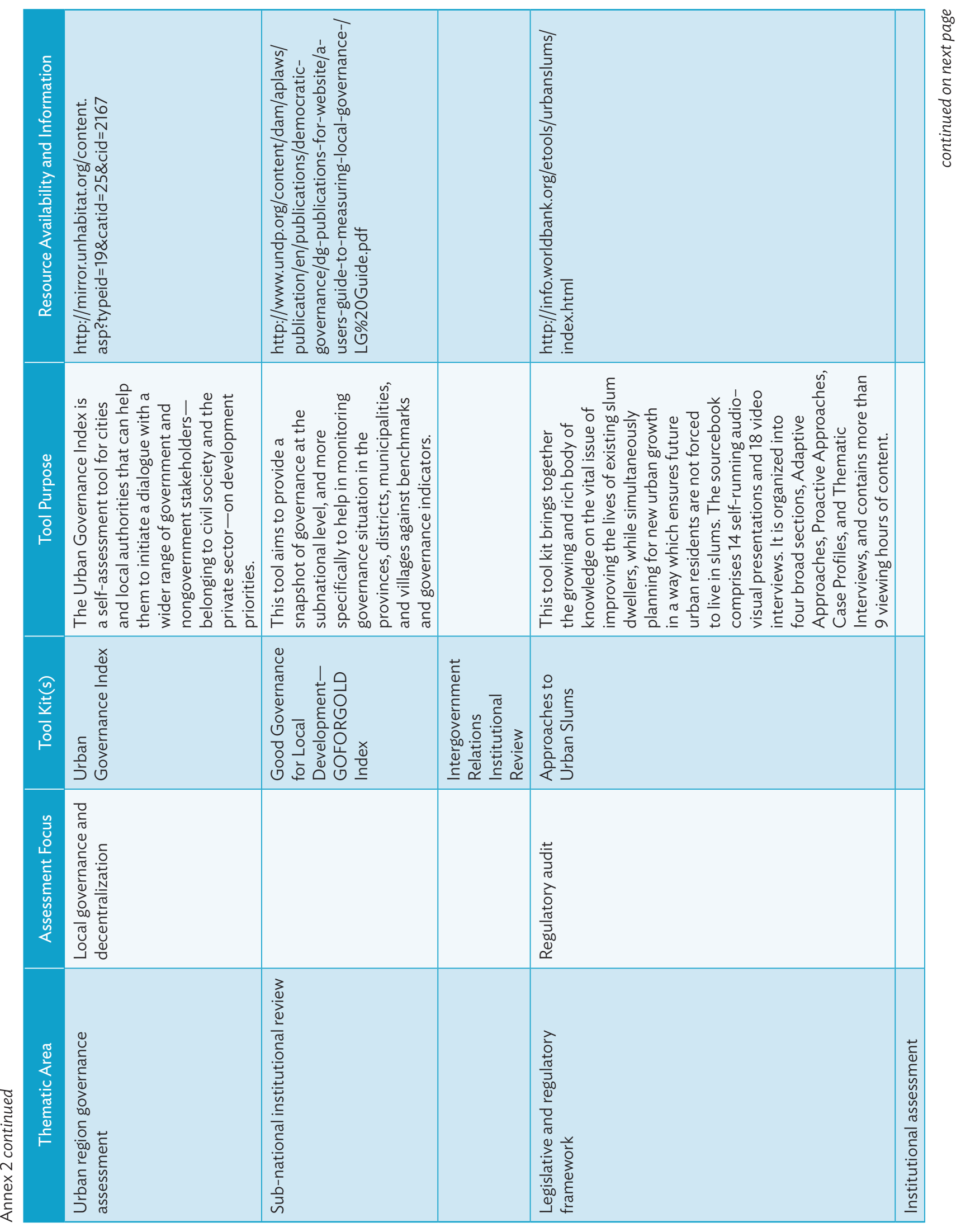




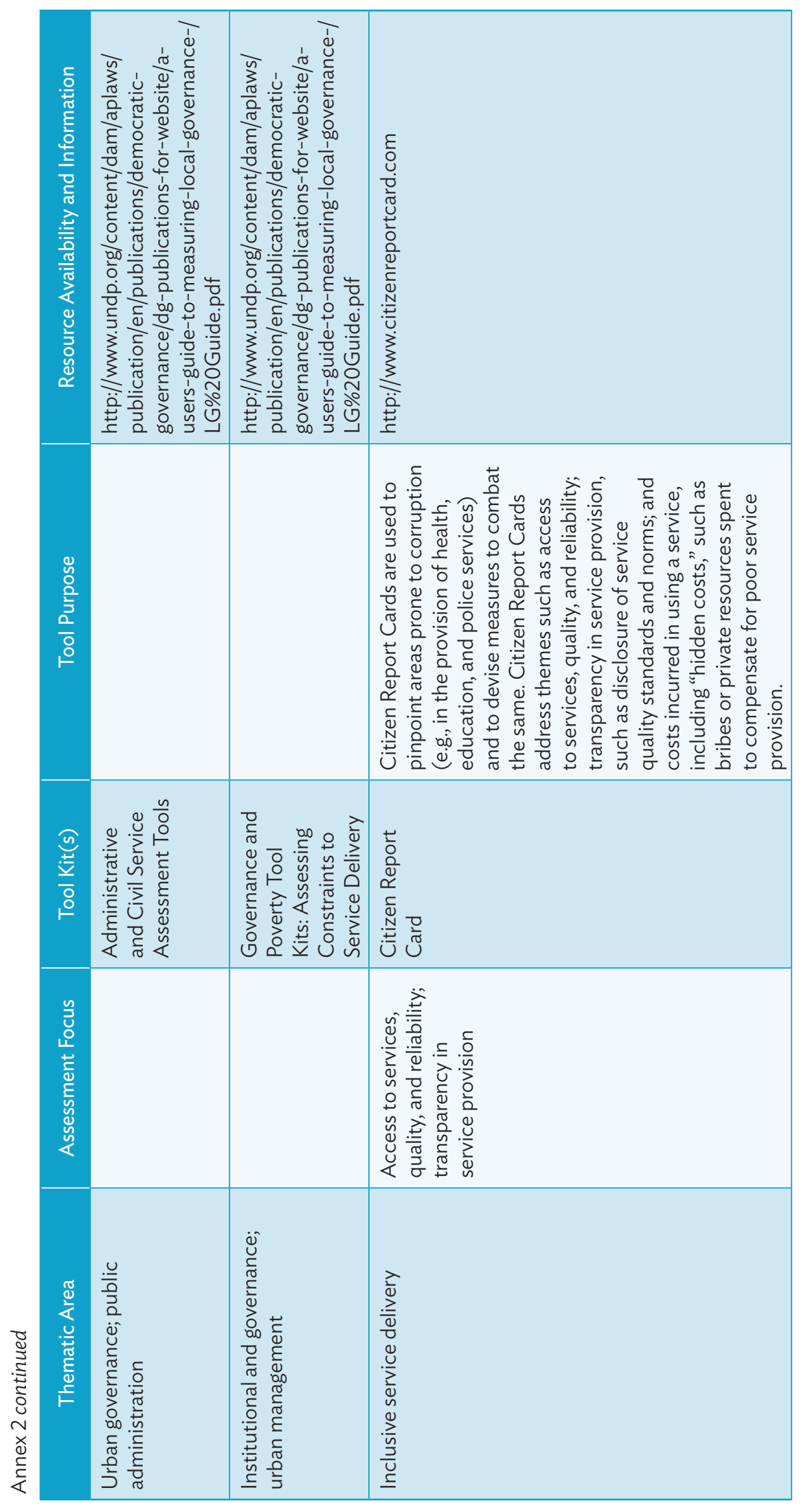

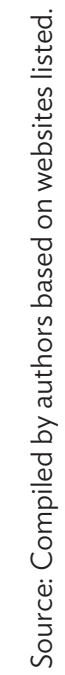



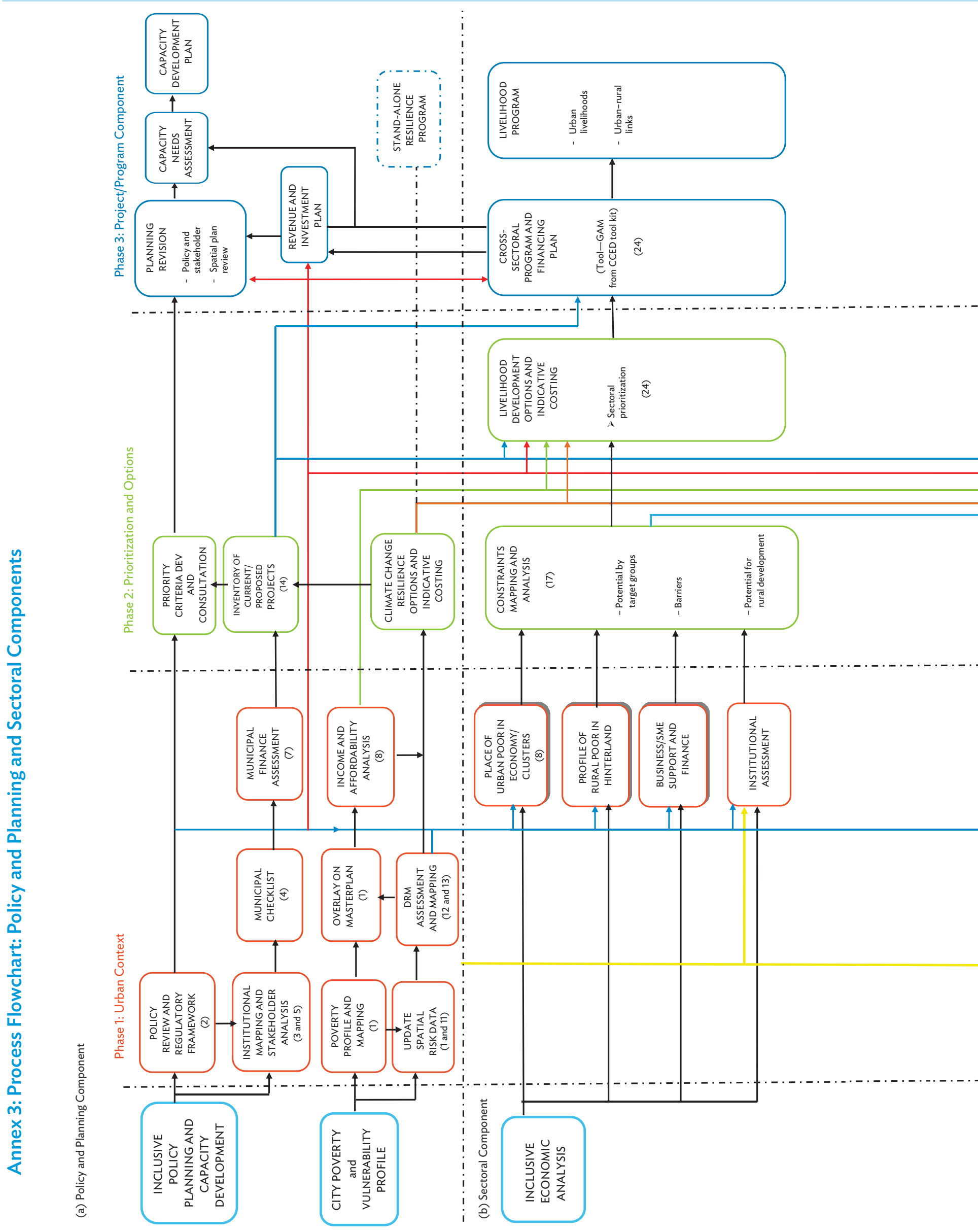

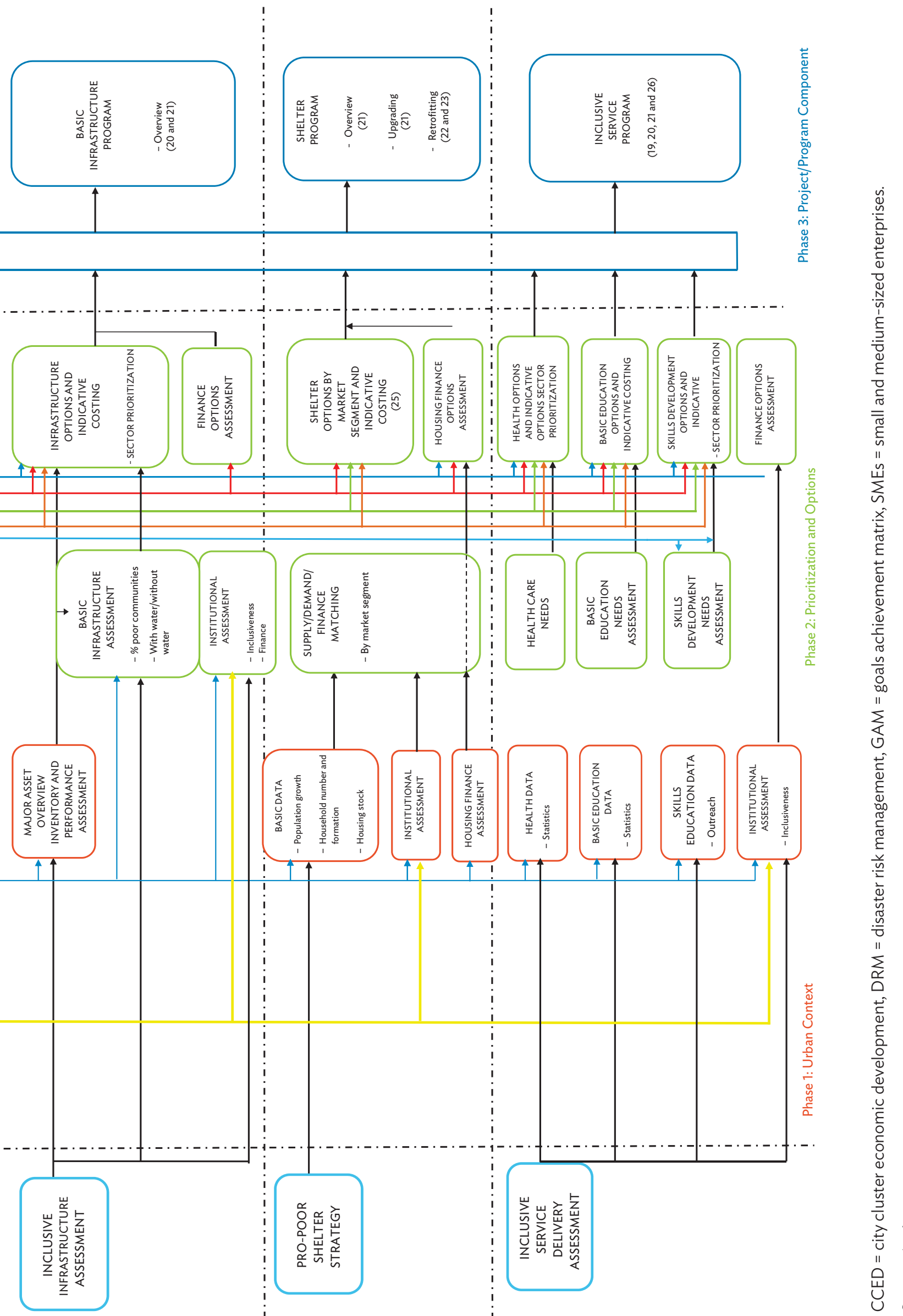


\section{Enabling Inclusive Cities \\ Tool Kit for Inclusive Urban Development}

This tool kit presents an integrated approach to inclusive urban development and was prepared for ADB staff and their partners to engage in inclusive urban development programming and implementation as an integral component of ADB's lending programs. It presents methods to gather required information on a particular context and location for inclusive urban development; to decide priorities; and to plan, design, and implement inclusive urban projects. The operational focus is provided by practical guidelines and criteria for inclusive urban development projects and is designed to stimulate innovation in the solution and approaches that define inclusive urban development projects.

\section{About the Asian Development Bank}

ADB's vision is an Asia and Pacific region free of poverty. Its mission is to help its developing member countries reduce poverty and improve the quality of life of their people. Despite the region's many successes, it remains home to a large share of the world's poor. ADB is committed to reducing poverty through inclusive economic growth, environmentally sustainable growth, and regional integration.

Based in Manila, ADB is owned by 67 members, including 48 from the region. Its main instruments for helping its developing member countries are policy dialogue, loans, equity investments, guarantees, grants, and technical assistance. 